\title{
Personal Comfort Systems: A review on comfort, energy, and economics
}

Rawal, Rajan; Schweiker, Marcel; Kazanci, Ongun Berk; Vardhan, Vishnu; Jin, Quan; Duanmu, Lin

Published in:

Energy and Buildings

Link to article, DOI:

10.1016/j.enbuild.2020.109858

Publication date:

2020

Document Version

Peer reviewed version

Link back to DTU Orbit

Citation (APA):

Rawal, R., Schweiker, M., Kazanci, O. B., Vardhan, V., Jin, Q., \& Duanmu, L. (2020). Personal Comfort Systems: A review on comfort, energy, and economics. Energy and Buildings, 214, [109858].

https://doi.org/10.1016/j.enbuild.2020.109858

\section{General rights}

Copyright and moral rights for the publications made accessible in the public portal are retained by the authors and/or other copyright owners and it is a condition of accessing publications that users recognise and abide by the legal requirements associated with these rights.

- Users may download and print one copy of any publication from the public portal for the purpose of private study or research.

- You may not further distribute the material or use it for any profit-making activity or commercial gain

- You may freely distribute the URL identifying the publication in the public portal 


\section{Journal Pre-proof}

Personal Comfort Systems: A review on comfort, energy, and economics

Rajan Rawal, Marcel Schweiker, Ongun Berk Kazanci, Vishnu Vardhan, Quan Jin , Lin Duanmu

PII:

DOI:

Reference:

To appear in:

Received date:

Revised date:

Accepted date:
S0378-7788(19)31611-1

https://doi.org/10.1016/j.enbuild.2020.109858

ENB 109858

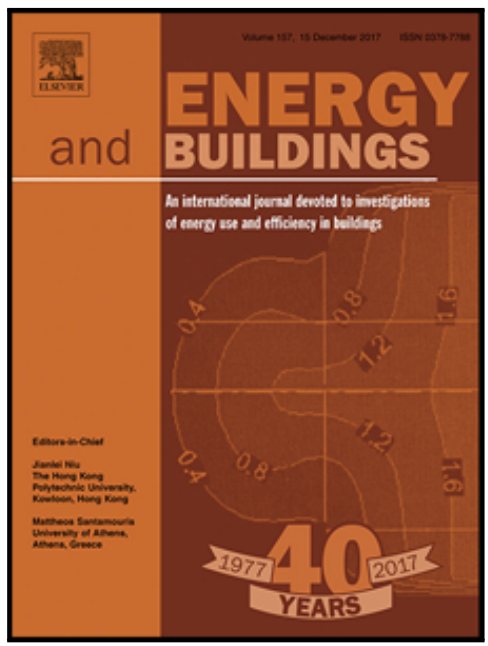

Please cite this article as: Rajan Rawal, Marcel Schweiker, Ongun Berk Kazanci, Vishnu Vardhan, Quan Jin, Lin Duanmu, Personal Comfort Systems: A review on comfort, energy, and economics, Energy \& Buildings (2020), doi: https://doi.org/10.1016/j.enbuild.2020.109858

This is a PDF file of an article that has undergone enhancements after acceptance, such as the addition of a cover page and metadata, and formatting for readability, but it is not yet the definitive version of record. This version will undergo additional copyediting, typesetting and review before it is published in its final form, but we are providing this version to give early visibility of the article. Please note that, during the production process, errors may be discovered which could affect the content, and all legal disclaimers that apply to the journal pertain.

(C) 2020 Published by Elsevier B.V. 


\section{HIGHLIGHTS}

- $\quad$ Personal Comfort Systems (PCS) provide thermal comfort at an individual level.

- PCS operate on heating, cooling, ventilation and combination modes.

- Conventionally, PCS need less than half the energy required for HVAC operation.

- This review discusses the results of over 150 published studies on PCS. 


\title{
Personal Comfort Systems: A review on comfort, energy, and economics
}

\section{Rajan Rawal ${ }^{1,}$, Marcel Schweiker ${ }^{2}$, Ongun Berk Kazanci ${ }^{3}$, Vishnu Vardhan ${ }^{1}$, Quan Jin ${ }^{4}$, Lin Duanmu}

1. Centre for Advanced Research in Building Science and Energy, CEPT University, Ahmedabad 380009 India.rajanrawal@cept.ac.in

2. Karlsruhe Institute of Technology, Karlsruhe, Germany

3. International Centre for Indoor Environment and Energy, Department of Civil Engineering, Technical University of Denmark, 2800 Kgs. Lyngby, Denmark

4. Dept. of Architecture and Civil Engineering, Chalmers University of Technology, Sweden

5. Dalian University of Technology, Dalian, China

\begin{abstract}
Conventional heating, ventilation, and air-conditioning (HVAC) systems are designed to condition the entire building volume. In contrast, Personal Comfort Systems (PCS) target conditioning only the occupied zones of the space, while maintaining the remaining volume at a relatively under-conditioned state. PCS offer the occupants the choice of modulating their immediate thermal ambience with local controls. The individual-level control helps in improving the subjective thermal and air quality acceptability with the desired thermal sensation. This review paper details on the various types of heating, cooling, ventilation, heating with ventilation, and cooling with ventilation PCS devices. It summarises the thermal ambience created by the respective PCS devices and the resultant subjective responses of the occupants. This review also identifies the energy saving potential of various kinds of PCS devices, the power use of PCS devices, and discusses their economic viability.
\end{abstract}

Keywords: Personal Comfort Systems; Thermal Comfort; Air Quality; Energy Efficiency; Economics.

Abbreviations
\begin{tabular}{|l|l|}
\hline ACE & Air Change Effectiveness \\
\hline ATD & Air Terminal Device \\
\hline CC & Chilled Ceiling \\
\hline COMP & Computer Mounted Panel \\
\hline CLO & Clothing Insulation (clo) \\
\hline CIR & Cross Infection Risk \\
\hline CSA & Cross-Sectional Area \\
\hline CMP & Cylindrical Movable Panel \\
\hline D & Diameter \\
\hline DV & Displacement Ventilation \\
\hline EHT & Equivalent Homogeneous Temperature $\left({ }^{\circ}\right.$ C) \\
\hline HDG & Horizontal Desk Grill \\
\hline IF & Intake Fraction \\
\hline LCG & Liquid Cooled Garment \\
\hline MV & Mixed Ventilation \\
\hline MP & Movable Panel \\
\hline PAQ & Perceived Air Quality \\
\hline PAUE & Personalised Air Utilisation Efficiency \\
\hline PCS & Personal Comfort Systems \\
\hline PEM & Personal Environment Module \\
\hline PEE & Personal Exposure Effectiveness \\
\hline PCG & Phase Change Garment \\
\hline PERI & Pollution Exposure Reduction Index \\
\hline PMV & Predicted Mean Vote \\
\hline RP & Radiant Panel \\
\hline REI & Re-inhaled Exposure Index \\
\hline RH & Relative Humidity (\%) \\
\hline
\end{tabular}




\begin{tabular}{|l|l|}
\hline RNG & Re-Normalisation Group \\
\hline RMP & Round Movable Panel \\
\hline $\mathrm{T}_{\text {core }}$ & Body Core/Rectal Temperature \\
\hline $\mathrm{T}_{\text {eqv }}$ & Equivalent Temperature $\left({ }^{\circ} \mathrm{C}\right)$ \\
\hline $\mathrm{T}_{\mathrm{PCS}}$ & PCS supply air temperature $\left({ }^{\circ} \mathrm{C}\right)$ \\
\hline $\mathrm{T}_{\text {room }}$ & Room ambient air temperature $\left({ }^{\circ} \mathrm{C}\right)$ \\
\hline $\mathrm{T}_{\text {skin }}$ & Skin Temperature $\left({ }^{\circ} \mathrm{C}\right)$ \\
\hline $\mathrm{T}_{\text {surface }}$ & Surface Temperature $\left({ }^{\circ} \mathrm{C}\right)$ \\
\hline TVV & Total Volume Ventilation \\
\hline UFAD & Under-Floor Air Distribution \\
\hline VDG & Vertical Desk Grill \\
\hline VE & Ventilation Effectiveness \\
\hline
\end{tabular}

\section{Introduction}

The wellbeing of the occupants in an indoor environment has been associated among others with thermal comfort, health, and availability of control [1]. On one hand, thermal comfort is affected by the air temperature, mean radiant temperature, relative humidity, and air velocity of the ambience in addition to the clothing insulation and metabolic rate of the occupants, while on the other hand, thermal adaptation and individual control play a major role as well [2]. As a reaction to the variety of indoor thermal conditions, occupants' thermoregulation system reacts with skin temperature adjustments and other physiological responses to keep the body core within the pre-set limits of temperature [3], [4]. In addition, occupants interact with their immediate thermal vicinity to attain an acceptable state of comfort. In contrast to conventional heating, ventilation, and air conditioning (HVAC) systems, Personal Comfort Systems (PCS) target conditioning this "personal space" instead of the entire built volume.

The PCS approach brings along several benefits and challenges in terms of controlling the indoor environment, energy performance, in addition to moderating the occupants' interaction with the ambient environmental control systems. There has been a growing interest in studies concerning PCS since as early as 1979, when a personalized heating system was created by Lund Madsen and Saxhof [5]. PCS are claimed to have several benefits over the traditional HVAC systems that are used to condition spaces in buildings, such as improved health and productivity, potential energy savings [6]-[8], as well as higher satisfaction with the indoor environment due to the improvements in the immediate indoor environment experienced by the occupants and due to the possibility of personalized control [9]-[11].

\subsection{How do PCS work?}

The application of PCS enables relaxing the temperature requirements for the ambient zones (zones outside of the zone conditioned by PCS) in buildings [12]. This builds upon the assumption that the occupants will be spending most of their time at the individually conditioned workstations and will spend only a limited amount of time in other zones in a building [13]. Similar temperature ranges are specified by different studies; however, the same studies also point out the lack of data on the more extreme temperatures, i.e. lower than $14^{\circ} \mathrm{C}$ and higher than $32^{\circ} \mathrm{C}$ [14]-[16]. It is possible to achieve comfort with PCS up to $30^{\circ} \mathrm{C}$ and $70 \%$ RH with the cooling mode and down to $15^{\circ} \mathrm{C}$ with the heating mode [17]. Based on different studies, it is likely that a dissatisfaction lower than $20 \%$ will be obtained in a temperature range between 18 to $32^{\circ} \mathrm{C}$ with the availability of PCS [18], [19].

Almost all studies available in the literature indicate increased user satisfaction with the indoor environment in the presence of a PCS device. An early study suggested that it is technically possible to satisfy all occupants (0\% dissatisfied) with PCS, based on field measurements [20]. In another large-scale field study, Kroner and Stark-Martin suggested that it is possible to increase productivity by at least $2 \%$ with the application of PCS (in their study, they called it "Environmentally Responsive Workstations") [21]. Based on a summary of 13 human subject experiment studies by different researchers, Zhang et al. showed that the satisfaction rate of the occupants is always higher with PCS than without PCS [22]. These studies, however limited in number, support the claimed advantages of PCS.

In addition to optimizing the instrumentally quantifiable parameters, PCS provide the occupants with a psychological relief of 'having control' over the ambience through occupant-controlled personalised settings, 
which leads to enhanced thermal delight [23], [24]. These 'personalised' settings help fine tune the cooling, heating, and ventilation as per the occupant's needs, which depends on factors such as the age, gender, clothing levels, metabolic rates, personal preference, etc. [25]-[28]. For instance, there is a difference in the preferred thermal sensation of occupants in general - some perceive a 'slightly cool' sensation as the most comfortable setting, while for some, a 'slightly warm' sensation proves to be the best [29].

\subsection{Review Objective}

PCS have actively been researched upon in the recent while - there have been three major review studies on the topic in the past 5 years. Godithi et al. reviewed multiple Personal Environmental Control (PEC) Systems used for Thermal, Visual, and Acoustic Comfort, along with the controllable plug load-based systems [7]. Warthmann et al. studied the past researches on Personal Thermal Comfort Systems, categorized them on the basis of devices and detailed upon the human-centred closed loop control (HCCLC) platform for PCS control [18]. Zhang et al. provided one of the most substantial contribution to the topic by defining the term 'Corrective Power' for PCS devices, it is the "difference between two ambient temperatures at which equal thermal sensation is achieved - one with no PCS (the reference condition), and one with PCS in use.” [30]

Figure 1 shows the Venn-diagram of the references of the three aforementioned review studies (Godithi et al. [7], Warthmann et al. [18], Zhang et al. [30]) and the present study. The three studies included 124, 179, and 99 references respectively, as indicated in the parentheses. There are three references common across all the four studies, while the present study holds the highest commonality with Zhang et al., with 40 common citations. The Venn diagram was created using a freely available online tool developed by Heberle et al. [31]. The objective of this study is to summarize the findings of a multiple PCS devices, referring the most prominent, published, peerreviewed research. It addresses the thermal comfort results of multiple PCS devices, along with a review of their energy savings and economics through the review of 184 referred papers, out of which 116 have never been included in a review paper before. This study, along with the three aforementioned review papers, can offer a reader substantial understanding of the various facets of PCS and help devise the way forward towards the future of personal comfort.

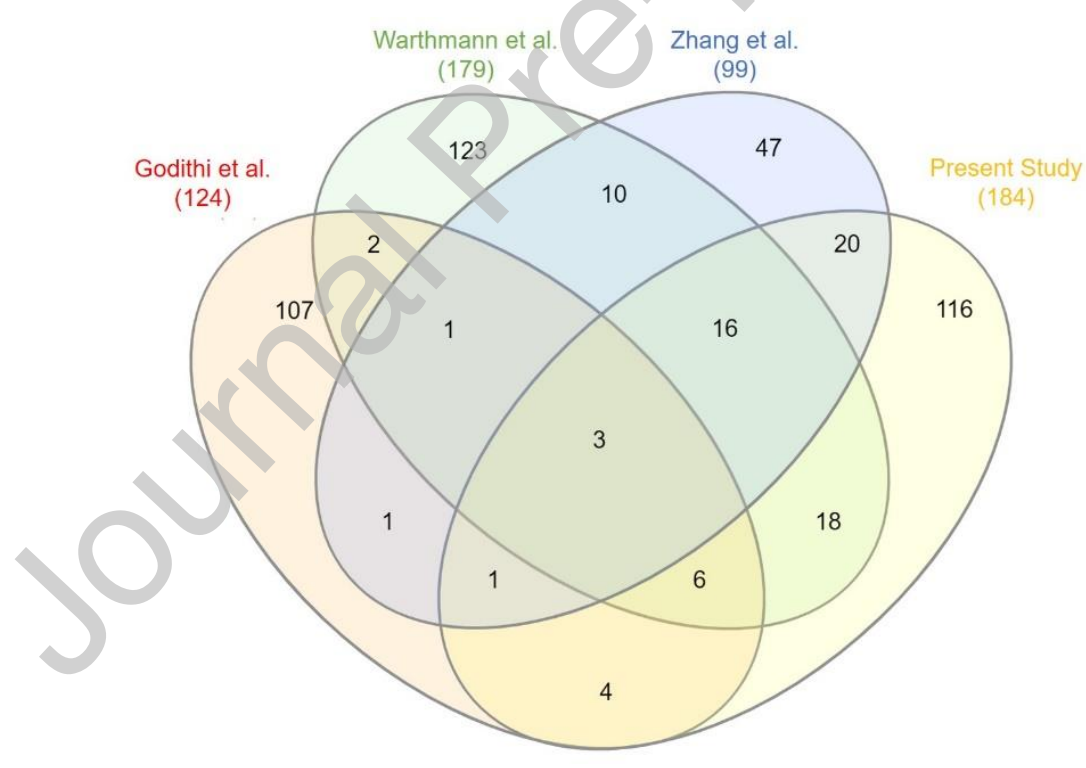

Figure 1. Venn diagram [31] showing the number of common citations by Godithi et al., Warthmann et al., Zhang et al., and the present study.

Figure 2 shows the frequency of words throughout the reviewed literature for the present study. A high frequency is indicated by the vicinity to the centre of the figure and the font size. For instance, since 'air' is the most mentioned word throughout the body text of the cited literature, followed by 'thermal', 'temperature', etc., one can infer that 'thermal conditioning of air' is one of the dominant phenomenon visible throughout the referred studies involving PCS - the later sections validate the same. 


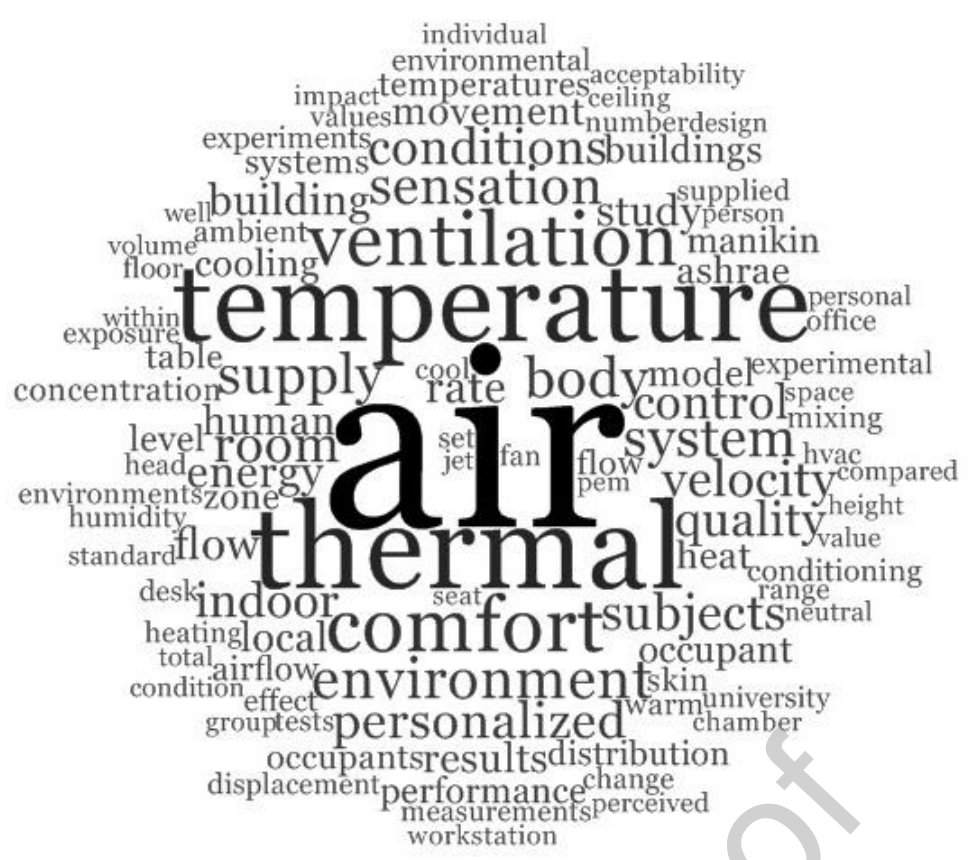

Figure 2. Word frequency chart for the references used in the present study.

Figure 3 shows the co-occurrence map of the most frequently used terms in the abstracts of the reviewed publications. It was made using a freely available software, VOS-viewer [32]. As the title says, it shows the extent of terms occurring simultaneously in the reviewed volume of words. The connection between the two simultaneous terms is represented by the network, while the frequency of a particular term is represented by its bubble size. As can be seen here, the term 'comfort' is used most frequently and is correlated with nearly every other term. It is noticeable that all the mentioned terms are strongly interconnected with one another, as can be seen from the dense network, except from the ones located further away from the dense network cluster, for example, 'non uniform', 'age', 'male', etc.

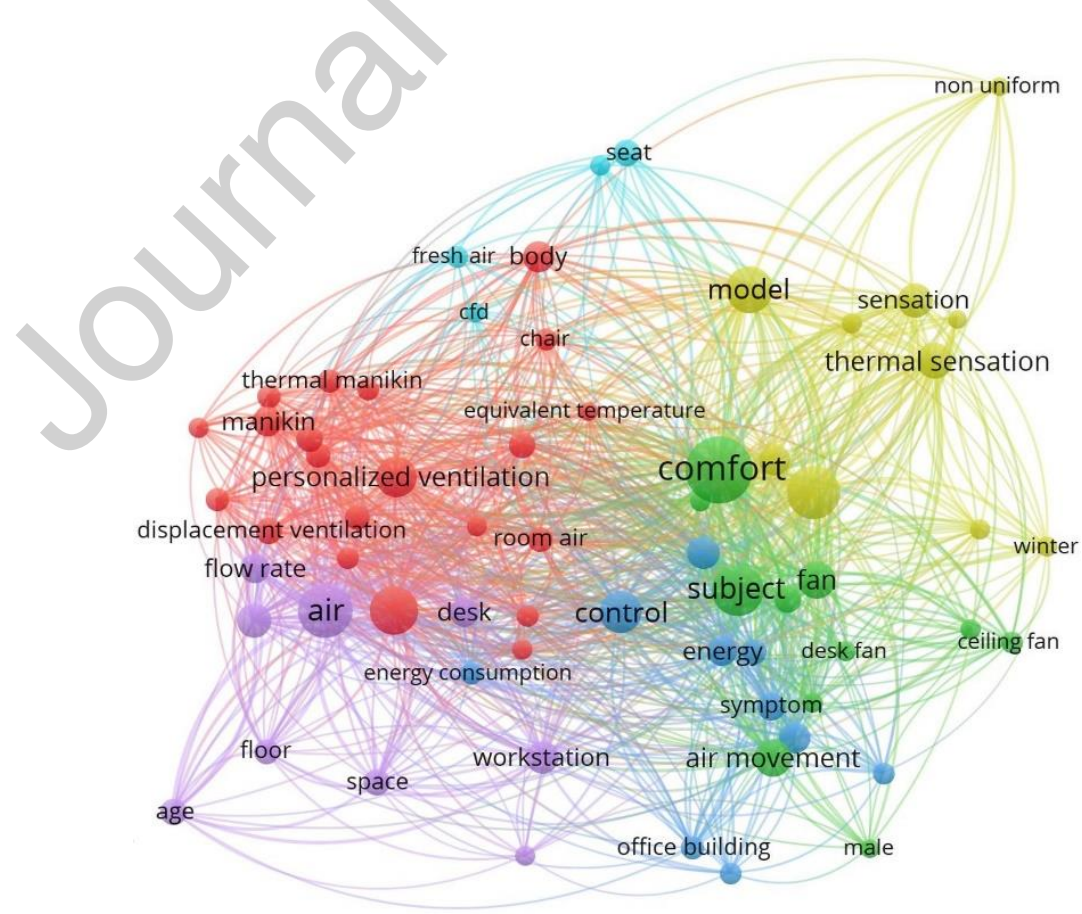

Figure 3. Co-occurrence map of keywords from the abstract the referred journal papers. 


\subsection{PCS Categories}

In the past, PCS have been studied using the physical lab environment, the digital simulation environment, and the field conditions. The physical environment incorporates device-based measurements, measurements with the help of human subjects, and measurements with the help of thermal mannequins. The digital environment allows for the measurement using computer simulations with the combined use of dynamic thermal modelling, computational fluid dynamics, and numerical thermoregulation models. The field studies aim at gathering subjective responses from occupants in their surroundings, and monitoring the ambient thermal variables without controlling them. Since this study is aimed towards understanding the impact of PCS in their ability to provide comfort, save energy, and be economical in the process, the authors have chosen to section the available literature into the following categories:
a) Heating
b) Heating and Ventilation
c) Cooling
d) Cooling and Ventilation
e) Ventilation

There were multiple ways to categorise the PCS, such as - on the basis of mode of heat transfer, on the basis of subject's response, etc. However, the final categorisation was made on the basis of the nature of conditioning the PCS device provides.

Heating PCS provide warmth to the subjects using local heating devices without air movement, primarily through the heat transfer principles of radiation and conduction, and are used in heating dominated indoor ambiences, conventionally below the indoor air temperature of $20^{\circ} \mathrm{C}$. Heating and Ventilation PCS couple the heat transfer mechanism of convection along with the aforementioned to facilitate conditioning in heating dominated indoors. The indoor air temperature for their operation should be the same as the Heating PCS, but is actually found to be higher in the reviewed studies.

Cooling PCS offer coolth to the subjects without any noticeable air motion, using mainly radiation and conduction. The indoor air temperature for Cooling PCS operation should be above $24^{\circ} \mathrm{C}$. Cooling and Ventilation PCS supply air to the subjects which has been sensibly cooled through compressive cooling or another means of active cooling. Some of these devices also include a 'Cooling PCS' device along with an isothermal ventilation device, thereby together qualifying as a Cooling and Ventilation PCS device. These devices should be operated above $20^{\circ} \mathrm{C}$ as per the reviewed literature. The Ventilation PCS devices are the most commonly used ones since they simply involve increasing the velocity of indoor (or outdoor) air and resupplying to the subject. Ventilation PCS devices do not perform any sensible cooling of the air and can be found operational above $18^{\circ} \mathrm{C}$ of indoor air temperature.

\subsection{Review Sectioning}

The following sections detail upon the Heating, Heating and Ventilation, Cooling, Cooling and Ventilation, and Ventilation PCS devices in the respective order. Each of the PCS sections include the following devices in respective order:

a) Heating PCS: Air Sleeves, Heated Seats, Foot Heater, and Palm Warmer.

b) Heating and Ventilation PCS: Desktop-mounted Devices, Seat with Radiant Panel, and Nozzle with Movable Panel.

c) Cooling PCS: Air Sleeve, Seat, Garment, and Radiant Panel

d) Cooling and Ventilation PCS: Desktop-based Devices, Round Movable Panel, Nozzle-based Devices, Radiant Panels with Fan, and Seat.

e) Ventilation PCS: Desktop-based Devices, Movable Panel-based Devices, Fixed Panel or Nozzlebased Devices, Mechanical Fans, Seats, and Garment.

As mentioned before, studies involving research on PCS do so in four primary modes: Field Studies, LabHuman Studies, Lab-Mannequin Studies, and Simulation Studies. The studies mentioning the respective devices under the sections "Cooling and Ventilation PCS" and "Ventilation PCS" have been further sub-categorized on the basis of the research mode - this has been done to ensure readability. Rest of the sections have not been subcategorised this way since their readability was considered adequate and further subcategorization would not have yielded enough studies in each sub-category. 
The details within each device include the room air temperature, and the PCS supply temperature, where available. The volume of studies referred in this paper limits us from reviewing the methodology with the aforementioned granularity. The scope of this paper is limited to documenting the effect of various categories of PCS devices through the parameters of Thermal Comfort (7-point scale), Sensation (7-point scale), Acceptability (3-point scale), and Preference (3-point scale). The experimentally measured, calculated, or simulated parameters included the skin temperature $\left(\mathrm{T}_{\text {skin }}\right)$, equivalent homogeneous temperature (EHT), rectal/core temperature $\left(\mathrm{T}_{\text {core }}\right)$, and the Predicted Mean Vote (PMV). It must be noted that throughout the paper, the 'local' parameters stand for an individual body part, while the 'overall' parameters stand for the entire body. The effect of air movement was studied by subjective measurement of air movement preference, air flow acceptability, and air quality acceptability. Further air quality parameters were measured by studying the air change effectiveness (ACE), ventilation effectiveness (VE), personal air utilisation efficiency (PAUE), intake fraction (IF), pollutant concentration, personal exposure effectiveness (PEE), re-inhaled exposure risk (REI), cross infection risk (CIR), and pollution exposure reduction index (PERI). A few studies also assessed the impact of PCS on subjects' productivity, while monitoring any sick-building symptoms.

The next two sections detail upon the effectiveness of PCS in achieving energy savings and their economics, respectively. Section 7 mentions of the power requirement of various PCS devices and details upon the scope of energy savings through the device. Section 8 proposes a framework to assess the cost effectiveness of a PCS device. The last section discusses and summarises the entire reviewed literature. It emphasises on the future of PCS, recommends the appropriate parameters to be monitored for analysis of PCS, and touches upon the themes of health and thermal alliesthesia vis-à-vis PCS.

\section{Heating PCS}

Heating Personal Comfort Systems (PCS) incorporate devices such as air sleeves, seats, local radiant warming devices, etc. Their effectiveness is dependent on the extent of electrical or any other form of energy converted into sensible heat, the body parts exposed to the device and their surface areas [33]. Most of the research done on these devices involved human subject-based experiments in climate-controlled conditions. Table 1 includes a list of the referred studies on Heating PCS categorised as per the ambient air temperature $\left(\mathrm{T}_{\text {room }}\right)$ at which they are operated.

Table 1. Studies on Heating PCS.

\begin{tabular}{|c|c|c|}
\hline PCS Type & Ambient Air Temperature Range $\left({ }^{\circ} \mathbf{C}\right)$ & Studies \\
\hline \multirow{4}{*}{ Heating } & Below 8 & {$[34]$} \\
\cline { 2 - 3 } & $8-10$ & {$[34][35]$} \\
\cline { 2 - 3 } & $10-12$ & {$[34][35][36][37]$} \\
\cline { 2 - 3 } & $12-14$ & {$[34][36]$} \\
\cline { 2 - 3 } & $14-16$ & {$[34][35][38]$} \\
\cline { 2 - 3 } & $16-18$ & {$[34][35][38][39][40]$} \\
\cline { 2 - 3 } & $18-20$ & {$[38][37][38][40][41][42][43][44][8]$} \\
\cline { 2 - 3 } & $20-22$ & \\
\hline
\end{tabular}

\subsection{Air Sleeve}

Arens et al. and Zhang et al. utilised air sleeves to provide warmth to the human subjects in their respective experiments to measure the local and overall thermal sensation and comfort through questionnaires [39],[41]. Both studies mentioned that the wearables prevented the subjects from perceiving the air movement next to the skins due to a low turbulence airflow flow within the garment. The subjects were only impacted by the temperature of the supplied air. The custom-designed air sleeves were velcro-stuck on the respective body parts and were supplied with an approximate amount of warm air to maintain the desired thermal conditions. Arens et al., while studying the cases of 'back warming' and 'hand warming', found that 'local warming' across the 19 individual body parts influenced the overall thermal sensation less drastically than 'local cooling', later sections on cooling-type PCS detail on the same. Instantaneous measurements indicated that with the introduction of 'back warming' $\left(\mathrm{T}_{\text {room }}=18^{\circ} \mathrm{C}, \mathrm{T}_{\mathrm{PCS}}=35^{\circ} \mathrm{C}\right)$ and 'hand warming' $\left(\mathrm{T}_{\text {room }}=19^{\circ} \mathrm{C}, \mathrm{T}_{\mathrm{PCS}}=37^{\circ} \mathrm{C}\right)$, the thermal sensation of the back increased from the scale of 'slightly cool - very cold' to 'warm - neutral', whereas, for the hand, the sensation changed from 'very cold - cold' to 'neutral - very hot'. Similar trials on the feet, neck, and 
breathing zone (at $\mathrm{T}_{\text {room }}=20^{\circ} \mathrm{C}, \mathrm{T}_{\mathrm{PCS}}=35^{\circ} \mathrm{C}$ ) resulted in the increase of local thermal sensation by $\sim 2.5$ votes (for feet and breathing zone) and 1.5 votes (for neck). Results also indicated that when the overall thermal sensation was neutral, the sensation of feet was always cooler than the body. Zhang et al. thereafter developed on the same study to devise thermal sensation and comfort models for non-uniform, transient environments. They calculated coefficients for the 19 individual body parts and provided a validated model, which reproduced the interdependence of thermal comfort responses and thermal environments. The model accounted for "the relationship between local comfort to local sensation and the overall thermal state; effects of non-uniform environments; asymmetric local comfort maxima that are higher than found in neutral uniform conditions; and differences in individual body parts' preference for cooling and warming” [39].

\subsection{Seat}

He et al. conducted a field study in the local street markets of three Chinese towns during winters to quantify the working of a traditional personal heating seating device - Huotong (warm-barrel) [36]. The device had an open front with a brazier at the base to hold a thick layer of charcoal ash. The wooden-cased device required $\sim 0.1 \mathrm{~kg}$ of charcoal at a time as the source of heat. The warmth was transferred to the seated user through the direct radiative heat of the coal, the convective currents from the perforations at the seat-top, and the conductive heating through the contact surfaces. The study found out that $96.3 \%$ of the subjects were within the 'slightly warm' and 'slightly cool' sensation band, and 51.2\% of the subjects had a preference of 'no change' in their thermal ambience. In order to test the device in controlled conditions, He et al. conducted a series of experiments on a retrofitted version of the device [35]. The retrofit incorporated replacing the incandescent coal with a heat lamp and covering the internal surfaces with aluminium foil to facilitate radiative heat transfer. The results revealed that throughout all the $\mathrm{T}_{\text {room }}$ setpoints, the overall thermal sensation remained within a 0.5 vote margin from 'neutral' after 30 minutes of exposure; the overall thermal comfort was up to $\sim 1$ vote on the warmer side from 'neutral' after a 1 hour of exposure. The subjects found their thermal ambience acceptable within 30 minutes of exposure, while their preference remained in the range of 'neutral-slightly warmer'. The feet were found to be cold and uncomfortable at the colder ambient conditions, while the buttocks and thighs were found to be the warmest, being in direct contact with the device.

Brooks and Parsons conducted a study on an automobile seat with encapsulated carbonized fabric, heated as per subjects' preference [34]. The study analysed the subjects' overall thermal sensation, overall thermal comfort and local skin surface temperature through subjective questionnaires. They found that the thermal sensation for the case of 'heated seat' was $\sim 0.5-2$ votes higher than that of a 'control seat' with no heating. The highest variation in the thermal sensation of 'heated' and 'control' seats was observed at the ambient temperature of $10^{\circ} \mathrm{C}$, while the lowest at $20^{\circ} \mathrm{C}$. The local temperature measurements indicated thermal asymmetries in the subjects' bodies; however, they did not lead to any discomfort. Pasut et al. studied the effect of heated and cooled seats in an office-like controlled condition through subjective questionnaires [42]. The subjects could control the seat temperature through regulators that could change the seat and backrest temperatures. Similar to the conclusion drawn for the case of 'air sleeve' by Arens et al.[41], this study found the cooled seat to be more effective than the heated seat in providing overall thermal comfort and maintaining a neutral thermal sensation. In another study, Pasut et al. utilised the same experimental logistics with another set of subjects to test various variants of the heating seat and collect subjective responses [43]. They tested the cases of: seat with a fabric cover over the mesh surface - 'cover', seat with the subject having an additional layer of clothing - 'extra clo', and a seat with no cover - 'no cover'. At $\mathrm{T}_{\text {room }}=16^{\circ} \mathrm{C}$, the overall thermal sensation of the subjects was closest to 'neutral' for the case of 'extra clo', while it remained warmer (better) than the control seat. Whereas, at $18^{\circ} \mathrm{C}$, all the cases indicated a similar sensation and remained close to 'neutral'. The overall thermal comfort of the subjects for the 'no cover' case, at $\mathrm{T}_{\text {room }}=16^{\circ} \mathrm{C}$, was marginally better than the other cases; while at $\mathrm{T}_{\text {room }}=18^{\circ} \mathrm{C}$, the 'cover' case was found to be the most comfortable. Luo et al. found a combination of a heated seat, heated wristpad and heated insoles to extend the lower comfortable temperature limit by $6.5^{\circ} \mathrm{C}$ [44]. The average local thermal sensation of the hands was found to increase by $\sim 1.5$ sensation votes (on an 8-point scale).

Zhang et al. performed controlled chamber experiments with human subjects on a heated seat and collected subjective responses. The seat was embedded with pipes which were supplied with water at various temperatures to facilitate the heat exchange with the seated subjects' back and pelvic region to induce thermal comfort [38]. Correlating the heat exchange between the seat and the subjects' bodies, their thermal acceptability, and the comfort votes, they derived an 'optimal heat flow' control model. Operating the seat as per this control model provided an overall thermal satisfaction to $90 \%$ of the subjects (at $\mathrm{T}_{\text {room }}=15.6-28^{\circ} \mathrm{C}$ ). 
Carmichael et al. studied the effect of a subject-controlled heating seat which incorporated thermoelectric Peltier junctions in the seat and back cushions on human subjects through subjective questionnaires [40]. In contrast to the previous studies, this seat did not facilitate thermal comfort at low ambient temperatures. As per their findings (at $\mathrm{T}_{\text {room }}=16-22^{\circ} \mathrm{C}$ ), the PCS operation resulted in the subject's thermal sensations to remain between 'cool' and 'neutral', while the thermal comfort was between the bands of 'just uncomfortable' and 'comfortable'. Oi et al. studied the impact of a heated seat on the subjects' overall thermal sensation and comfort through subjective questionnaires [37]. At the ambient temperature of $10^{\circ} \mathrm{C}$, the operation of the heated seat was found to improve the thermal sensation and comfort by $\sim 0.7$ and $\sim 1$ votes. At $20^{\circ} \mathrm{C}$, the thermal sensation of the 'unheated seat' was maintained on the warmer side at $\sim 0.3$, which, upon heating rose on the warmer side to $\sim 1$ votes.

\subsection{Foot Heater}

In addition to the seat, Oi et al. also utilised a foot heater made up of five film-based radiant heating panels [37]. It was operated at a temperature $10^{\circ} \mathrm{C}$ and $20^{\circ} \mathrm{C}$ higher than the $\mathrm{T}_{\text {room. With the }} \mathrm{T}_{\text {room }}$ at $10^{\circ} \mathrm{C}$, operating the heater at $30^{\circ} \mathrm{C}$ resulted in a $\sim 0.5$ vote improvement in thermal sensation and a $\sim 1$ vote improvement in thermal comfort. At $\mathrm{T}_{\text {room }}=20^{\circ} \mathrm{C}$, operating the heater at $40^{\circ} \mathrm{C}$ resulted in the two thermal comfort and sensation changing by $\sim 0.5$ votes each; the $\sim 0.5$ vote increment in the thermal sensation was away from the 'neutral' indicating a warmer sensation, while it was towards the 'neutral' for the case of thermal comfort - indicating a more comfortable thermal state. Zhang et al. also used an "insulated box with a reflective foil lining" on the internal surfaces as a foot warmer [39]. The box utilized a reflector-type heating lamp (30 W) to warm the top of the feet. It was operated in tandem with additional heating and ventilating-type PCS, therefore its individual impact on the subjective responses could not be quantified. In another human subject-based study, Zhang et al. used foot heaters with the heat source as four incandescent reflector bulbs (160 W) [8]. The effect of the device was comparable to the effect of a general $750-1500 \mathrm{~W}$ electric heater as it confined the warm air close to the feet. The study found that $75 \%$ of the subjects chose to use the device, however, there was no significant statistical difference between the thermal acceptability of the subjects with and without the foot heater.

\subsection{Palm Warmer}

The devices tested by Zhang et al. included a 'palm warmer' [39]. It was a curved surface made out of highthermal conductivity aluminium, stuck with electrical heating tapes underneath. The device was placed in front of the keyboard, close to the natural position of the palms. The study did not delve into the subjective impact of the individual device, therefore the sensation or comfort cannot be commented upon. Vesely et al. studied the effect of radiant hand warmers and radiant heating panels on subjects' local skin temperature, sensation, and acceptability [45]. The usage of radiant hand warmers kept the local $\mathrm{T}_{\text {skin }}$ (fingertips) in the range of $\sim 29-32^{\circ} \mathrm{C}$ for the male subject and $\sim 23-32^{\circ} \mathrm{C}$ for the female. The variation of overall thermal sensation was identical to the variation of local thermal sensation (at hands) and remained within a \pm 1 vote band from neutral. They also studied the effect of a radiant heating panel (at $\mathrm{PMV}=0,-0.9$ ) to find out that the local skin temperature of the nose was lower than that of the forehead by $\sim 4^{\circ} \mathrm{C}$ after a 100 -minute exposure to the device at the cooler ambient condition (PMV $=-0.9)$. They also reported that the cooler ambient state led to a reduction of up to $12^{\circ} \mathrm{C}$ and $6^{\circ} \mathrm{C}$ at the fingertips and the hand in comparison to the temperatures at the neutral state. The thermal sensation trends revealed that prolonged exposure to the cooler ambient condition, even with the radiant panels in operation, caused the overall and local thermal sensation to be 'cool', which indicates the effectiveness of the device.

\section{$3 \quad$ Heating and Ventilation PCS}

Heating with Ventilation type Personal Comfort Systems (PCS) include conventional desk mounted devices supplying warm air, movable panel based devices (RMP - Round Movable Panel, and CMP - Cylindrical Movable Panel), and heating Radiant Panels (RP) used in tandem with isothermal air movement devices. Table 2 enlists the referred studies on Heating and Ventilation categorised as per the ambient air temperature $\left(\mathrm{T}_{\text {room }}\right)$ at which they are operated.

Table 2. Studies on Heating and Ventilation PCS.

\begin{tabular}{|c|c|c|}
\hline PCS Type & Ambient Air Temperature Range $\left({ }^{\circ} \mathbf{C}\right)$ & Studies \\
\hline Heating and & Below 18 & - \\
\cline { 2 - 3 } Ventilation & $18-20$ & {$[46][47]$} \\
\hline
\end{tabular}




\begin{tabular}{|c|c|c|}
\hline \multirow{4}{*}{} & $20-22$ & {$[48][49][50][51]$} \\
\cline { 2 - 3 } & $22-24$ & {$[48][49][52]$} \\
\cline { 2 - 3 } & $24-26$ & - \\
\cline { 2 - 3 } & $26-28$ & - \\
\cline { 2 - 3 } & Above 28 & {$[53]$} \\
\hline
\end{tabular}

\subsection{Desktop Mounted Device}

Alain et al. developed a mathematical model to study the working of DV in combination with personal ventilation [46]. They considered a desktop mounted nozzle-based ATD and represented the case with heat balance equations. They validated the model using controlled experiments and found that with the operation of DV and PCS, the air temperature close to the lower height levels $(1200-1400 \mathrm{~mm})$ was cooler by $\sim 2^{\circ} \mathrm{C}$ while it was found to remain unchanged at the heights ranging from 1800-2400 mm. Tsuzuki et al. compared two PCS devices named 'ClimaDesk' and 'Personal Environmental Module' (PEM) to measure the change in the Equivalent Homogeneous Temperature (EHT) of a thermal mannequin [51]. ClimaDesk supplied 3.5-7 L/s of air to two under-desk laminar flow vents. The heat was supplied through a $200 \mathrm{~W}$ electrically heated panel $(800 \times 600 \mathrm{~mm})$ placed at the underside of the desk surface, above the mannequin's thigh. The PEM mixed the indoor air with the outdoor supply air $(9.6-71 \mathrm{~L} / \mathrm{s})$ to attain the desired temperature. At $\mathrm{T}_{\text {room }}=20-21^{\circ} \mathrm{C}$, the PCS operation was able to increase the EHT in comparison to a control case (no PCS operation) by $1.8-2.2^{\circ} \mathrm{C}$. Upon the application of heating RP, the chest, back, thighs, and pelvis experienced the highest change in EHT for the case of ClimaDesk, while the legs and feet experienced the highest change in EHT for the case of PEM. Bauman et al. conducted a field study to understand the functioning of the PEM [54]. Their survey recorded various occupancy-related parameters including the indoor thermal environment satisfaction and air movement satisfaction. The study also recorded the occupants' thermal sensation in the presence of a PCS device (PEM) and compared it with a control group (no PCS). When the $T_{\text {room }}$ was below $23^{\circ} \mathrm{C}$, the mean thermal sensation of the control group was found to be on the colder side in comparison to the group with PCS. At $\mathrm{T}_{\text {room }}=21^{\circ} \mathrm{C}$, the group with PCS were found to have an improved thermal sensation by $\sim 0.8$ votes.

\subsection{Seat with Radiant Panel and Round Movable Panel}

Melikov et al. studied the combined heating effect of a seat with convectively heated backrest, an under-desk radiant heating panel, and a floor-heating panel on subjects in a climate controlled chamber [48]. Additionally, a round movable panel and an under-desk device supplied fresh air to ensure appropriate air quality. The subjects could control the temperature of the floor-heating panels, the seat's heated airflow, and the flow rate of the fresh air devices. After $45 \mathrm{~min}$ of exposure, the thermal acceptability and comfort showed significant improvement in comparison to the reference case. The percentage of dissatisfied subjects reduced from $\sim 50 \%$ (for the reference case) to $\sim 20 \%$. The results indicated that the satisfaction level of the subjects could be further improved by improving the quality of PCS supply air, decreasing foot-level air velocity, and providing manual control of the device to each subject. Watanabe et al. added on to the same study and performed similar experiments on a thermal mannequin with an identical setup [49]. They measured the equivalent skin temperature $\left(T_{\text {eqv }}\right)$ of 23 body parts and found the range of variation to be the highest for the 'back', 'pelvis', and 'back side', whereas the variation was marginal for the 'legs' and 'hands'. The calculated overall $\mathrm{T}_{\text {eqv }}$ for the ambient temperatures of 20,22 , and $26^{\circ} \mathrm{C}$ was $25.9,26.9$, and $29.7^{\circ} \mathrm{C}$ respectively. They found that at $\mathrm{T}_{\text {room }}=20^{\circ} \mathrm{C}$, the heating effect of the seat, floor-mounted radiant panel, and the under-desk radiant panel were equivalent to an increase in $\mathrm{T}_{\text {room }}$ by $5.2,2.1$, and $2.8^{\circ} \mathrm{C}$ respectively, while a combined effect of the three devices was equivalent to an increase in $\mathrm{T}_{\text {room }}$ by $5.9^{\circ} \mathrm{C}$. Amai et al. conducted extensive controlled experiments with human subjects at the ambient temperature of $28^{\circ} \mathrm{C}$ [53]. They used heating RP with various ventilation devices and in-built floor ventilation. Due to the naturally high $\mathrm{T}_{\text {room }}$, most of the subjects did not choose to operate the RP at all. Considering all the instances of the RP operation, it was almost always used by the females as they indicated a distinct preference to the warmer thermal sensation.

\subsection{Nozzle with Movable Panel}

Jin et al. studied the impact of local heating on the whole body and head of human subjects through surveys. The heating device comprised of two nozzles $(\mathrm{D}=50 \mathrm{~mm}$ ) aimed at the head from the two sides of a workstation [47]. The local heating is ensured by blocking extra air from reaching lower parts of the body through a fabric cover. The measured thermal sensation votes at $\mathrm{T}_{\text {room }}=19.5^{\circ} \mathrm{C}$ with $\mathrm{T}_{\mathrm{PCS}}=50^{\circ} \mathrm{C}$ indicated that the subjects who 
were acclimatised to a cool ambience $\left(19.5^{\circ} \mathrm{C}\right)$ for a longer time, had a more prominent warmer sensation to the applied heat in comparison to the subjects with a shorter acclimatisation period. After prolonged exposure, however, the subjects' overall thermal sensation votes remained in the range of 0-2 (on the warmer side). The overall thermal sensation was well-correlated with the head thermal sensation and no instances of eye dryness were reported. Kaczmarczyk et al. studied the subjects' response to locally supplied warm air through a Round Movable Panel (RMP) placed at a distance of $0.4 \mathrm{~m}$ from the seated subject in a climate controlled chamber [50]. They took surveys for thermal and air movement acceptability and sensation to find that the overall thermal sensation was always within the comfortable range of -0.5 to 0.5 votes. At $\mathrm{T}_{\text {room }}=20^{\circ} \mathrm{C}$, the absence of PCS resulted in a 'closer to neutral' overall and local thermal sensation in comparison to when the PCS was operated at the supply temperature of $21^{\circ} \mathrm{C}$. The preference of increased air movement was seen to increase with time of PCS operation and was comparable for the two supply temperatures, however, $15-25 \%$ of the subjects experienced eye-irritation over a prolonged period of PCS operation. The eye-irritation can be remediated by providing individual control of PCS supply velocity and direction. Lan et al. studied the impact of a bedmounted Cylindrical Movable Panel (CMP) which supplied air directly to the breathing zone of the sleeping subject [52]. The CMP was mounted on a movable arm-duct, which allowed the subjects to orient the device as per their preference. The study monitored the thermal comfort and sensation of the subjects while they were awake and further recorded sleep quality parameters for a deeper insight. The thermal sensation of the subjects, two minutes prior to sleeping, improved by $\sim 0.4$ votes in comparison to the case without a CMP. The thermal comfort improved marginally by $\sim 0.1$ votes. The mean $\mathrm{T}_{\text {skin }}$ for the case without CMP was consistently higher by $\sim 0.2^{\circ} \mathrm{C}$ even after prolonged exposure. However, the subjective sleep quality survey did not indicate a major statistical difference between the two cases.

\section{Cooling PCS}

Cooling Personal Comfort Systems incorporate the same or similar devices as the Heating PCS, only operating at a lower temperature. It must be noted that in this context, cooling devices' indicate the devices which facilitate heat transfer without a noticeable air motion; they include - air sleeves, seats, garments, and radiant panels. Table 3 includes a list of all the studies on Cooling PCS categorised as per the ambient air temperature $\left(\mathrm{T}_{\text {room }}\right)$ at which they are operated.

Table 3. Studies on Cooling PCS.

\begin{tabular}{|c|c|c|}
\hline PCS Type & Ambient Air Temperature Range $\left({ }^{\circ} \mathbf{C}\right)$ & Studies \\
\hline \multirow{4}{*}{ Cooling } & Below 24 & - \\
\cline { 2 - 3 } & $24-26$ & {$[38][40]$} \\
\cline { 2 - 3 } & $26-28$ & {$[38][40]$} \\
\cline { 2 - 3 } & $28-30$ & {$[19][38][39][40][41][42][43][55]$} \\
\cline { 2 - 3 } & $30-32$ & {$[19][38][56]$} \\
\cline { 2 - 3 } & $32-34$ & {$[19][38]$} \\
\cline { 2 - 3 } & Above 34 & {$[38][57]$} \\
\hline
\end{tabular}

\subsection{Air Sleeve}

As described in section 2.1, Arens et al. and Zhang et al. studied the effect of air sleeves on human subjects for local cooling and heating [41][39]. Arens et al. studied the cases of local cooling (at $\left.\mathrm{T}_{\mathrm{PCS}}=14^{\circ} \mathrm{C}\right)$ supplied to 'head', 'back', 'hand', and 'pelvis' (at $\mathrm{T}_{\text {room }}=28^{\circ} \mathrm{C}$ ) and found that the 'head', 'back', and 'pelvis' showed a reduction in $\mathrm{T}_{\text {skin }}$ by $\sim 5^{\circ} \mathrm{C}$ each, while the $\mathrm{T}_{\text {skin }}$ for 'hand' reduced by $\sim 12^{\circ} \mathrm{C}$. The device maintained the local thermal sensations in the range of -2 to -4 sensation votes (on a 9-point sensation scale) across body parts. The overall thermal sensation was most prominently impacted by the change in the $\mathrm{T}_{\text {skin }}$ of the 'back' and 'pelvis', and least by that of the 'hand'. When cooling the 'face' at $\mathrm{T}_{\mathrm{PCS}}=23^{\circ} \mathrm{C}$ and $\mathrm{T}_{\text {room }}=28^{\circ} \mathrm{C}$, the local thermal comfort and sensation of the face stabilized on the warmer side ( 1.5 votes), whereas cooling the back at the same conditions led to the overall comfort being within the -1 to 1 sensation vote band. Study of further cases indicated that a $2^{\circ} \mathrm{C}$ reduction in $\mathrm{T}_{\text {room }}\left(30^{\circ}\right)$ with the help of PCS, resulted in a $\sim 1.5^{\circ} \mathrm{C}$ decrease in the 'chest' and 'leg' temperatures, while the 'breathing zone' temperature was affected negligibly during the case of facecooling. The subjects did not report any instances of dry eyes or any other discomfort. 


\subsection{Seat}

Pasut et al. analysed the effect of subject-controlled cooled seats in an office-like climate controlled chamber at $29^{\circ} \mathrm{C}$ through a survey-based study [42]. The seats were equipped with a thermoelectric device, which could modulate the seat and backrest temperatures. The research found the heated seat to be more effective than the cooled seat in regard to the local and overall thermal sensation and comfort. The study also indicated an insignificant statistical difference between the 'cushion' and 'mesh' types of seats as per the measured subjective parameters. In another survey-based study, Pasut et al. utilised the same experimental setup with another set of subjects to test various variants of the cooled seat [43]. They tested the cases of a seat with a fabric cover over the mesh surface - 'cover', a seat with no cover - 'no cover', and a reference seat with no cooling. At $\mathrm{T}_{\text {room }}=29^{\circ} \mathrm{C}$, the overall thermal sensation was found to be the lowest for the seat with 'no cover' this was lower than the reference case by $\sim 2$ sensation votes. The 'cover' seat indicated a $\sim 0.4$ vote warmer thermal sensation than the 'no cover' seat. Thermal comfort also followed a similar trend, with the 'no cover' seat being the most comfortable. In regard to the local thermal sensation, the back and pelvis were closest to the neutral for the 'no cover' case, and the local thermal comfort was also the maximum. As mentioned in the previous section, Zhang et al. and Carmichael et al. also studied a seat-based cooling type PCS in controlled conditions [38], [40]. The functionality of the seats was akin to that of the heating type PCS, but with a difference in the $\mathrm{T}_{\text {room }}$ and $\mathrm{T}_{\mathrm{PCS}}$. The survey results of the two studies indicated that the change in subjects' thermal comfort and sensation votes was more significant when the $\mathrm{T}_{\text {room }}$ was greater than $22^{\circ} \mathrm{C}$.

\subsection{Garment}

Barwood et al. studied the impact of cooling garments on the $\mathrm{T}_{\text {skin }}$ and $\mathrm{T}_{\text {core }}$ of subjects after a workout session in a warm-humid setting [56]. The study analyses the impact of a $3 \mathrm{~kg}$, vest-styled phase-change garment (PCG) containing cooling packs inserted in the front and rear of the vest, closely stuck to the body through Velcro straps. The cooling packs contained long-chained organic compounds which extracted heat from their contact surfaces by melting (phase change) when the $\mathrm{T}_{\text {room }}$ was above $10^{\circ} \mathrm{C}$. The same study analysed another $(4.1 \mathrm{~kg})$ liquid cooled garment (LCG), which contained a wearable vest with a battery pack, an ice pack reservoir, and a circulation pump - all placed in a wearable rucksack. The pump circulated saline water cooled by the ice pack around a series of interconnected flat tubes embedded in the vest, adjacent to the subject's body. A thermostat regulated the flow of saline water to be maintained at most at $\mathrm{T}_{\mathrm{PCS}}=12.3^{\circ} \mathrm{C}$. The measured value of the rectal temperature $\left(\mathrm{T}_{\text {core }}\right)$ for the maintained by the PCG was marginally lower than that maintained by the LCG, and the calculated value for the $\mathrm{T}_{\text {skin }}$ as maintained by the PCG $\left(\sim 33.0^{\circ} \mathrm{C}\right)$ was significantly lower than that maintained by the LCG $\left(\sim 34.5^{\circ} \mathrm{C}\right)$ for a 15 -minute exposure. Gao et al. used a $(2.2 \mathrm{~kg}) \mathrm{PCG}$ which incorporated a mixture of sodium sulphate and additives as the phase change material and underwent phase change at $\mathrm{T}_{\text {room }}=21^{\circ} \mathrm{C}$ [57]. The $\mathrm{T}_{\text {skin }}$ of the torso, calculated as a mathematical average of the chest, scapula, abdomen and lower-back skin temperatures, was found to reduce by over $2.5^{\circ} \mathrm{C}$ within 15 minutes of exposure. The measured $\mathrm{T}_{\text {core }}$, however, did not undergo any significant change even after prolonged exposure. The surveyed thermal sensation and comfort votes remained in the range of $0-1$ after a 20 -minute exposure to the PCG - although, in the first 20 minutes, the thermal sensation of the torso was found to be cold.

\subsection{Radiant Panel}

Melikov et al. studied cooling Radiant Panels (RP) in a controlled environment on human subjects through questionnaires [55]. The RP was installed in front of the seated subject, above the computer monitor and maintained at a near-constant surface temperature of $17^{\circ} \mathrm{C}$ by circulating chilled water through the embedded pipes. The subjects were surveyed for overall and local (head) thermal sensation and acceptability to find that within 30 minutes of the device's operation, the overall sensation reduced by over 1 vote and remained constantly within $0-1$ votes for prolonged exposure periods. The overall acceptability remained within the range of 0-0.6 votes. The local thermal sensation and acceptability of the head also remained in the same margin. He et al. studied the impact of water-cooled RP on subjects through a survey study in controlled conditions [19]. At $\mathrm{T}_{\mathrm{PCS}}=28^{\circ} \mathrm{C}$, the RP operation improved the overall thermal acceptability, sensation, and comfort by over 0.5 votes each, while it also improved the thermal preference by $\sim 1$ vote. This improvement was most prominent for prolonged exposure at $\mathrm{T}_{\text {room }}=32^{\circ} \mathrm{C}$. Steady-state local thermal sensation and comfort results indicate that the upper body parts were cooler than the lower - this difference was also found to be higher at higher $\mathrm{T}_{\text {room }}$ levels. 


\section{Cooling and Ventilation PCS}

The cooling and ventilation based PCS devices typically incorporate air movement devices, which supply air at a temperature lower than the room temperature, primarily through compressor-based cooling. In a few cases, localised air movement devices operating at isothermal conditions spread the compressor-cooled air using additional cooling systems. These devices, similar to 'Ventilation' PCS, included desktop-based devices, round movable panels, nozzles, radiant panels, and seat-based devices. The reviewed studies dominantly monitored the thermal sensation, comfort, and air quality parameters similar to the former PCS category. Table 4 lists the studies referred for 'Cooling and Ventilation' PCS, categorised as per the ambient air temperature $\left(\mathrm{T}_{\text {room }}\right)$ at which they are operated.

Table 4. Studies on Cooling and Ventilation PCS.

\begin{tabular}{|c|c|c|}
\hline PCS Type & Ambient Air Temperature Range $\left({ }^{\circ} \mathbf{C}\right)$ & Studies \\
\cline { 2 - 3 } & Below 18 & - \\
\cline { 2 - 3 } & $18-20$ & {$[46][58]$} \\
\cline { 2 - 3 } Cooling and Ventilation & $20-22$ & {$[48][46][58][59]$} \\
\cline { 2 - 3 } & $22-24$ & {$[20][48][58][59][60][61][62]$} \\
\cline { 2 - 3 } & $24-26$ & {$[63][64][65][66][67][68][69][70][71]$} \\
\cline { 2 - 3 } & $26-28$ & {$[48][58][51][60][61]$} \\
& $28-30$ & {$[65][60][61][62][63][63][64][65]$} \\
\cline { 2 - 3 } & $30-32$ & {$[35][53][47][55][61][71][82][83]$} \\
\cline { 2 - 3 } & Above 32 & {$[35][47][83][84]$} \\
\cline { 2 - 3 } & & - \\
\hline
\end{tabular}

\section{$5.1 \quad$ Desktop-based devices}

\subsubsection{Field Studies}

Bauman et al. conducted multiple field studies to estimate the impact of PCS on the occupants [20], [54], [60]. They utilised a desktop-based PCS, known as the PEM (Personal Environment Module), which included two desktop based supply nozzles used for supplying cooled, conditioned air (at $\mathrm{T}_{\mathrm{PCS}}=16-20^{\circ} \mathrm{C}$ ) to the subjects. They could control the airflow rate, temperature, and direction with the help of a control panel. The results indicated that, in comparison to a group without PCS, the overall thermal quality and air quality satisfaction ratings increased. The operation of PCS also led to fewer instances of subjects experiencing sick building syndrome. Akimoto et al. also conducted a field study using the same setup as Bauman et al [78]. They found that at $\mathrm{T}_{\text {room }}=26-27.5^{\circ} \mathrm{C}$, the desktop-based personal ventilation system was able to keep the air temperatures in the workstation lower by $1-2^{\circ} \mathrm{C}$. Although $\sim 50 \%$ of the subjects perceived their sensations to be on the warmer side, $80 \%$ of them found themselves to be comfortable.

Bauman et al. and Arens et al. studied a desk mounted PCS in combination with a floor based ventilation system (UFAD) [68], [73]-[75]. Both air delivery methods provided the option of air speed and direction control and their performances were analysed on human subjects in controlled/field conditions. In field conditions, they found that the subjects operated less than $33 \%$ of the installed PCS setups due to complaints of uncomfortable draft [68]. Additionally, more than $80 \%$ of the subjects were found to adjust the supply velocity and direction setting less than once per week. They used the same setup to study the effect of change in PCS flow rate, location, direction and temperature [73], [74]. They found that the floor based UFAD assembly posed the risk of the uncomfortable draft, which could be remediated by personally optimising the direction of the supply. A low UFAD flow rate also led to enhanced thermal stratification in the room $\left(>3^{\circ} \mathrm{C}\right)$, which caused discomfort - an optimised flow rate was found to be the best suited. In another study, they conducted controlled experiments with the same setup on human subjects as well as thermal mannequin [75]. The study reiterated the findings of the aforementioned studies; in addition, it found out that the operation of UFAD system gave rise to thermal asymmetries in the body cooling and might lead to local discomfort.

Atthajariyakul and Lertsatittanakorn studied the impact of a fan-assisted air conditioner on human subjects in a field study through surveys in a warm-humid climate [72]. The fan ( $D=150 \mathrm{~mm}$ ) was placed in front of each subject and operated at multiple speeds. The marked subjective responses and thermal sensation calculations 
indicated that the subjects could remain close to a neutral thermal sensation when the fan is operated at the speed of $1-2 \mathrm{~m} / \mathrm{s}$ at $\mathrm{T}_{\text {room }}=28^{\circ} \mathrm{C}$.

\subsubsection{Laboratory Studies with Subjects}

Amai et al. studied the impact of a desktop mounted diffuser (PEM) on subjects in controlled conditions [53]. They measured the thermal comfort and sensation votes using surveys and found that the subjects were the most comfortable when their sensation was within a \pm 1 vote from the 'neutral'. However, some subjects also reported being comfortable when their sensation was 'cold'.

Dalewski et al. studied the performance of a desktop mounted ductless RMP $(\mathrm{D}=330 \mathrm{~mm})$ in combination with $\mathrm{DV}$ and MV [61]. The RMP supplied outdoor air, which was cooled by $3-5^{\circ} \mathrm{C}\left(\mathrm{T}_{\mathrm{PCS}}=20-26^{\circ} \mathrm{C}\right)$ and allowed the subjects to control its flow rate and direction. The subjects were studied for thermal comfort, sensation and air quality responses through survey questionnaires. The results indicated that the PCS was more effective in improving the PAQ and thermal comfort in comparison to DV and MV. 80\% of the subjects preferred to operate the PCS at an air velocity of $1.5-1.7 \mathrm{~m} / \mathrm{s}$ at $\mathrm{T}_{\mathrm{room}}=26-29^{\circ} \mathrm{C}$. Another interesting finding indicates that at $\mathrm{T}_{\text {room }}=26^{\circ} \mathrm{C}$, the improvement in subjects' thermal comfort was due to the increase in PCS supply velocity alone - the flow rate or the temperature of the air supplied using DV did not have any impact on the subjects. The subjects were also found to bring the RMP closer to their heads as the $\mathrm{T}_{\text {room }}$ increased, which although improved the comfort parameters, led to increased instances of eye dryness by $30 \%$.

Gong et al. studied the impact of a fixed round panel on human subjects through questionnaire based surveys [62]. The round panel $(\mathrm{D}=180 \mathrm{~mm})$ was oriented towards the subject's head and supplied conditioned outdoor air at various predefined velocities and $\mathrm{T}_{\mathrm{PCS}}=21-26^{\circ} \mathrm{C}$. The results revealed that at $\mathrm{T}_{\mathrm{room}}=23^{\circ} \mathrm{C}$, the preferred air velocity ranged between $0.3-0.45 \mathrm{~m} / \mathrm{s}$, while at $\mathrm{T}_{\text {room }}=26^{\circ} \mathrm{C}$, the preferred velocity range increased to $0.3-0.9$ $\mathrm{m} / \mathrm{s}$. The preferred thermal sensation was on the cooler side, and the personal air movement helped improve the overall/local thermal and air movement sensation. Jin et al. studied the response of human subjects to two headoriented nozzles $(\mathrm{D}=50 \mathrm{~mm})$ supplying cool air [47]. The study monitored the change in the subjects' thermal sensations in step changes in ventilation strategies (PCS-cooling and ambient cooling). They found that as the ventilation strategy was changed from 'PCS' to 'ambient', the subjects' thermal sensations changed towards the warmer side. The trend was the opposite when the strategy was changed from 'ambient' to 'PCS'. The local cooling of the head brought down the thermal sensation by 1-2 votes. The results also indicated that the subjects' thermal sensation was found to be cooler after they had experienced warmer ambient environments for $\sim 50$ minutes.

Kaczmarczyk et al. studied the cases of HDG $(15 \times 245 \mathrm{~mm}), \mathrm{RMP}(\mathrm{D}=185 \mathrm{~mm}), \mathrm{MP}(75 \times 240 \mathrm{~mm}), \mathrm{VDG}$ $(20 \times 220 \mathrm{~mm})$ and Headrest-based ATD $(8 \times 35 \mathrm{~mm})$ on human subjects under controlled conditions [63]. With $\mathrm{T}_{\mathrm{PCS}}=20^{\circ} \mathrm{C}$ for all the cases $\left(\mathrm{T}_{\mathrm{room}}=23,26^{\circ} \mathrm{C}\right)$, the study monitored the local thermal sensation across multiple body parts. The results indicated that all the ATD led to a more moderated overall thermal sensation in comparison to the ambient air alone. The combination of HDG and VDG led to the coolest sensation, while the headrest based ATD was the warmest. All the ATD kept the local thermal sensation at the face on the cooler side, while the legs were kept on the warmer sensation spectrum. The order of subjects' preference of the ATD was: $\mathrm{RMP}>\mathrm{MP}>\mathrm{RMP}+\mathrm{HDG}>\mathrm{HDG}+\mathrm{VDG}>\mathrm{Headrest}$. RMP was the most preferred choice among the subjects as it provided a uniform air distribution with low turbulence intensity, while the horizontal airflow due to HDG was found to be unpleasant by the subjects. Cho et al. studied a PEM and UFAD assembly through an experimental setup [84]. They measured the $\mathrm{T}_{\text {room }}$ to find that the PEM could provide a temperature reduction of $0.4-0.6^{\circ} \mathrm{C}$ in comparison to a $1.2^{\circ} \mathrm{C}$ reduction by the UFAD assembly, with $\mathrm{T}_{\mathrm{PCS}}=20^{\circ} \mathrm{C}$. However, above the desk level $(440 \mathrm{~mm})$ - the PEM maintains a good airflow and temperature distribution. The PMV measured at the heights of 600-2000 mm revealed that the PEM case had a better PMV distribution by a margin of 0.1-0.4 votes.

Faulkner et al. studied the indoor airflow patterns and pollutant removal efficiency of a desktop based PCS [58]. The desktop mounted nozzles supplied outdoor air and had the option of controlling the temperature $\left(\mathrm{T}_{\mathrm{PCS}}=15\right.$ $21^{\circ} \mathrm{C}$ ), flow rate and direction of the personal ventilation. The indoor airflow patterns were studied using a tracer gas setup. The results indicated that the PCS provided the best air quality when $100 \%$ of the outdoor conditioned air was used with no recirculation. The conclusions of the study also point that the use of the given PCS assembly led to "marginal improvements in the spatial patterns of air delivery to occupants, compared to an air delivery system that yields thoroughly mixed indoor air". Tsuzuki et al. studied three ventilation and cooling strategies - PEM, ClimaDesk, and TAM [51]. The PEM provided a supply airflow of 9.5-71 L/s through two 
$360^{\circ}$ movable vents above the desk surface. ClimaDesk supplied laminar flow in the range of 3.5-7 L/s through two movable vents located under the desk surface. The TAM unit $(600 \times 600 \mathrm{~mm})$ supplied conditioned air through four $(\mathrm{D}=127 \mathrm{~mm})$ nozzles at $23.5-85 \mathrm{~L} / \mathrm{s}$ - both the orientation and flow rate of the supply could be changed. The PEM, ClimaDesk, and TAM facilitated a whole-body heat loss equivalent to cooling of 7, 1, and $5^{\circ} \mathrm{C}$ respectively. The extent of control over the temperature of supply is reduced at lower flow rates.

\subsubsection{Laboratory Studies with Mannequins}

Yang et al. studied 'spot' and 'wide-cover' type ATD devices using thermal mannequin measurements [82]. 'Spot' ATD focussed a strong airflow over localised regions such as the head, jaw, and upper chest. With an effective diameter of supply opening as $70 \mathrm{~mm}$, air velocity of $1.7 \mathrm{~m} / \mathrm{s}$, and $\mathrm{T}_{\mathrm{PCS}}=20^{\circ} \mathrm{C}$, this strategy resulted in resultant target velocities of $0.3-0.6 \mathrm{~m} / \mathrm{s}$ towards the mentioned body parts. 'Wide-cover' ATD, on the contrary, produced downward flows and spread the coolth to a wider body surface area. The calculated percentage of dissatisfied subjects decreased from $40 \%$ (spot ATD) to $10 \%$ (wide-cover ATD). Tham and Pantelic studied the impact of desktop-mounted nozzle-based ATD ( $\mathrm{D}=8 \mathrm{~mm}, 30$ openings), supplying $\mathrm{T}_{\mathrm{PCS}}$ at $23^{\circ} \mathrm{C}$, and under-desk fans $(80 \times 80 \mathrm{~mm})$ through experiments on a breathing thermal mannequin and CFD simulations [79]. The results revealed that the combination of the two strategies reduced the local $\mathrm{T}_{\text {skin }}$ for the facial region and increased it for thighs and arms. The fans were found to improve the PEE and reduce the floor-level pollutants from entering the breathing zone when the mannequin was placed close to the PCS assembly. However, when placed at a distance of beyond $540 \mathrm{~mm}$ from the desk, the PEE was found to be reduced significantly. Therefore, the PCS assembly was deemed effective for a limited personal occupied zone.

\subsection{Round Movable Panel}

\subsubsection{Laboratory Studies with Subjects}

Chen et al. studied the impact of a round panel-based PCS $(D=100 \mathrm{~mm})$ in combination with ceiling mounted ambient air supply [64]. They measured the overall and local thermal sensation and airflow acceptability of human subjects through subjective questionnaires. They found that the subjects preferred a higher airflow rate in the beginning and the requirement reduces by 0-2 L/s after 15-30 minutes of exposure. Contrary to the findings of other similar studies, these results indicated that the acceptability of thermal environment and the ambient airflow was not found to vary with $\mathrm{T}_{\text {room }}\left(23,26^{\circ} \mathrm{C}\right)$ or $\mathrm{T}_{\mathrm{PCS}}\left(20,23,26^{\circ} \mathrm{C}\right)$ - the authors suggest that this might have been possible as the subjects were given individual control over the PCS flow rate. Jin and Duanmu studied the effect of a pair of head-oriented nozzles $(\mathrm{D}=50 \mathrm{~mm})$ supplying conditioned air $\left(\right.$ at $\mathrm{T}_{\mathrm{PCS}}=26.5-30^{\circ} \mathrm{C}$ ) to human subjects [83]. They recorded subjective responses and physical readings around the subjects. The results indicated that thermal sensation gradually became warmer after stepping into the ambient environment, while entering the workstation environment, the thermal sensation reduced to the coolest, then reached close to neutral. The results also indicated that the subjects' movement did not have a negative impact on the thermal ambience. The facial skin temperature change was the most dynamic and strongly correlated to the overall thermal sensation. It was found that as the subjects were exposed to a warm thermal environment, the $T_{\text {skin }}$ of the face increased quickly for the first 10 minutes and then slows down.

Li et al. studied the case of a round panel in combination with UFAD on human subjects [80]. The round panel $\left(\mathrm{D}=100 \mathrm{~mm}\right.$ ) supplied $4^{\circ} \mathrm{C}$ cooler air at the flowrates of $5-10 \mathrm{~L} / \mathrm{s}$, while the UFAD flow was cooler by $4-10^{\circ} \mathrm{C}$. The $\mathrm{T}_{\text {UFAD }}$ was found to have a strong impact on the local thermal sensation at the feet - the best scenario (with the highest air movement acceptability) indicated both the $\mathrm{T}_{\mathrm{PCS}}$ and $\mathrm{T}_{\mathrm{UFAD}}$ to remain $4^{\circ} \mathrm{C}$ lower than $\mathrm{T}_{\text {room}}$. However, when the setup is operated without PCS, the change in air movement acceptability was found to be negligible. The overall thermal comfort was also found to be the highest for the aforementioned case at an airflow rate of $10 \mathrm{~L} / \mathrm{s}$. Conclusively, the PCS was able to cool the front and upper body parts, while the UFAD ensured that the feet were not cooled excessively.

Melikov et al. studied the impact of RMP-based PCS $\left(\mathrm{T}_{\mathrm{PCS}}=24^{\circ} \mathrm{C}\right)$ on human subjects in warm and humid ambient conditions through questionnaires and physical measurement of SBS [85]. The direction and airflow rate of the RMP could be personally controlled by the subjects. The results indicated that the acceptability of air quality and freshness increased significantly with the use of the PCS across the two studied temperatures. The overall and local thermal sensations were found to reduce by $\sim 0.8-1$ vote across the studied cases. The study also surveyed for multiple sick building syndrome symptoms across the subjects and found that the PCS case performed better than the non-PCS case for all the instances except for the symptom of eye irritation. The subjects operating the PCS were also found to be more productive by 10-15\% and reported decreased levels of mental and physical fatigue. Sekhar et al. utilised a movable rectangular panel-based ATD $(100 \times 235 \mathrm{~mm}$, at 
$\mathrm{T}_{\mathrm{PCS}}=20-26^{\circ} \mathrm{C}$ ) to study subjects' response to a hot and humid climate through questionnaire based surveys, physical measurements and calculations [65]. The results indicated that the PCS was able to improve the acceptability of thermal comfort and air quality by $58 \%$ and $64 \%$, respectively. The PCS was also able to improve ventilation effectiveness and reduce the inhaled air temperature by $2-5^{\circ} \mathrm{C}$ in comparison to the control case. Similar to the other studies, the results indicated that the PCS supply temperature and flow rate were the most critical parameters affecting the subjects' responses.

Verhaart et al. studied the case of desktop mounted nozzle-based PCS on human subjects through questionnaires [81]. The $\mathrm{T}_{\text {room }}$ was maintained at $\sim 27.5^{\circ} \mathrm{C}$ for the entire duration of the experiment while the $\mathrm{T}_{\mathrm{PCS}}$ was kept between $23-26^{\circ} \mathrm{C}$. The subjects could control the PCS airflow rate. The results indicated an improvement in overall and local thermal comfort and sensation, in addition to the reduction of SBS. The subjects were found to use the lowest speed setting for the lowest $\mathrm{T}_{\mathrm{PCS}}$. The subjective difference in PCS usage was attributed to 'body composition'. The females chose lower airspeeds due to a naturally cooler thermal sensation, while the males chose the opposite. The authors also indicate the role of basal metabolic rate in the variation of PCS operation. Niu et al. studied a seat-based, flexible under-chin ATD on human subjects in controlled conditions through questionnaires and physical measurements [67]. The ATD $(\mathrm{D}=100 \mathrm{~mm})$ provided cool air at $\mathrm{T}_{\mathrm{PCS}}$ ranging between $15-20^{\circ} \mathrm{C}$, with the $\mathrm{T}_{\text {room }}=22^{\circ} \mathrm{C}$. The results revealed that the personalised flow was able to reduce the pollutant concentration in the inhaled air by up to $80 \%$. The quality of the inhaled air was found to improve as the airflow rate was increased, while the utilisation efficiency of the fresh air reduced at the same time. Flow rates beyond $1.6 \mathrm{~L} / \mathrm{s}$ were shown to induce symptoms of excessive head-cooling and deemed non-desirable by the subjects.

\subsubsection{Laboratory Studies with Mannequins}

Sun et al. studied the effect of an RMP to study the thermal sensation, skin temperature, and air movement around human subjects and a breathing thermal mannequin [66]. The experiments varied flow through the RMP $(\mathrm{D}=180 \mathrm{~mm})$ to change the turbulence intensity from $<15 \%$ to $>40 \%$. The results indicated that the air temperature $\left(\mathrm{T}_{\mathrm{PCS}}=21-26^{\circ} \mathrm{C}\right)$ for the low-turbulence airflow was lower than the high-turbulence flow by $1.5-2^{\circ} \mathrm{C}$ (at a distance of $200 \mathrm{~mm}$ from the nose). The difference in air temperatures led to a difference in the local skin temperature (at the face) by up to $4^{\circ} \mathrm{C}$. The mean thermal sensation at the face was on the colder side for the case with low turbulence intensity by $\sim 0.3$ votes. Pan et al. studied the effect of a bed-based PCS on a thermal mannequin through subjective surveys [59]. The two rectangular, vaned ATDs $(900 \times 100 \mathrm{~mm})$ were symmetrically placed on the two sides of the bed. Interestingly, as the high flow rates yielded a greater energy utilisation coefficient, the PMV was found to decrease. Positioning the vanes at $+45^{\circ}$ allowed the upper body parts and breathing zone to be directly be influenced by the PCS flow, thereby resulting in an improved PMV; however, when placed at $-45^{\circ}$, the PMV was found to decrease as the PCS flow did not impact the breathing zone.

Melikov et al. studied the impact of desktop mounted round panels $(\mathrm{D}=100 \mathrm{~mm})$ in combination with UFAD on human subjects through questionnaires [86]. A thermal mannequin was used to measure the equivalent $\mathrm{T}_{\text {skin }}$ across various cases. The results indicated that the thermal comfort and sensation was found to improve with the combined operation of PCS and UFAD in comparison to each of these setups alone. The PCS was operated at $\mathrm{T}_{\mathrm{PCS}}=22,26^{\circ} \mathrm{C}$, while the UFAD was operated at $\mathrm{T}_{\mathrm{PCS}}=16-22^{\circ} \mathrm{C}$. The findings also indicate that a cooler PCS supply towards the head will further increase the local (head) and overall thermal sensation and comfort, while a warmer UFAD supply temperature (than the current setting), will improve the local thermal sensation at the feet. The portion of clean outdoor personalised air inhaled was found to increase at low PCS supply temperatures, while the other air quality parameters were found to improve with an increase in the air speed at the face.

\section{$5.3 \quad$ Nozzle-based Devices}

Yang et al. studied the impact of a ceiling-mounted PCS on human subjects through surveys and physical measurements [69]. The nozzle-based ATD $(\mathrm{D}=95 \mathrm{~mm})$ offered cooled airflow $\left(\mathrm{T}_{\mathrm{PCS}}=21-26^{\circ} \mathrm{C}\right)$ with a low turbulence intensity and a longer spread of the air jet. The study also found that $\mathrm{T}_{\mathrm{PCS}}$ had a stronger impact on the subjects' thermal sensation (except on the lower body parts) in comparison to $T_{\text {room }}$. The subjects also perceived $\mathrm{T}_{\mathrm{PCS}}$ to be lower when the PCS flow rate was increased - this improved the PAQ. Interestingly, the rate of improvement of PAQ with respect to PCS flow rate was found to be independent of the $T_{\mathrm{PCS}}$ and $\mathrm{T}_{\text {room}}$.

Yang et al. also studied a ceiling mounted PCS in combination with a ceiling-supply mixing ventilation on a thermal mannequin in field-laboratory conditions [70]. The multiple ATD (D=95 mm) supplied airflow with a 
low turbulence ratio and was found to increase the neutral level from $800 \mathrm{~mm}$ to $1100 \mathrm{~mm}$ by increasing the airflow rate. The upper portions of the body, directly exposed to the cool air plume (at $\mathrm{T}_{\mathrm{PCS}}=21-26^{\circ} \mathrm{C}$ ) were found cooler than the rest of the body and led to thermal asymmetry. The best $\mathrm{T}_{\text {room }} / \mathrm{T}_{\mathrm{PCS}}$ combination was found as $23.5 / 21^{\circ} \mathrm{C}$ at an airflow rate of $16 \mathrm{~L} / \mathrm{s}$ - the effect of PCS was equivalent to a reduction in $\mathrm{T}_{\text {room }}$ by $6^{\circ} \mathrm{C}$. The study concluded that PCS flow rate was the most prominent factor influencing the local/overall cooling of the subject. Lo and Novoselac conducted a CFD study on ceiling mounted PCS placed in an open-office ambience [71]. The simulation results indicated that the PCS moderated the air temperature and air velocity in the targeted area, despite the open plan of the office. The temperature difference between the target zone and the ambient zone was $\sim 2^{\circ} \mathrm{C}$. The PCS was also able to improve the air quality in the target area by improving the ventilation effectiveness and reducing the concentration of pollutants emanating from the floor and walls.

\subsection{Radiant Panels with Fans}

He et al. studied the response of human subjects to a desk-based, water-cooled radiant panels (RP) $(1200 \times 600$ $\mathrm{mm})$ in combination with a desktop fan $(\mathrm{D}=180 \mathrm{~mm})$ [87]. The subjects were not allowed to change either the temperature of the RP or the airflow rate/direction of the fan. The subjective responses indicated that the PCS, in tandem, extended the acceptable $\mathrm{T}_{\text {room }}$ range to $32^{\circ} \mathrm{C}$. The best possible scenario across all the studied cases (at $\mathrm{T}_{\text {room }}=32^{\circ} \mathrm{C}$ ) was when the RP was in operation in combination with the fan (at $2.2 \mathrm{~m} / \mathrm{s}$ ). At lower $\mathrm{T}_{\text {room }}$ levels, the subjects preferred lower airflow rate or no air movement at all. Melikov et al. also studied the case of operating radiant cooling panels $(600 \times 700 \mathrm{~mm})$ with fans [55]. The surface of the RP was constantly maintained at $17^{\circ} \mathrm{C}$, with $\mathrm{T}_{\text {room }}=28^{\circ} \mathrm{C}$. The results of the questionnaires posed to the human subjects indicated that their overall thermal sensation improved by $\sim 1$ vote within 30 minutes of exposure to the "radiant panel with fan" combination. Results also showed that the local thermal sensation, air movement acceptability and overall thermal acceptability improved significantly with the introduction of "radiant panel with fan" combination. The PCS strategy proved to be even more effective as it did not lead to additional SBS (in comparison to the case with no PCS). Operation of fan was found to increase the frequency of SBS.

\subsection{Seat}

Zhang et al. performed controlled experiments on a group of male and female thermal mannequins subjected to cooling through a seat-based PCS in combination with under-aisle ventilation in an aircraft cabin [76]. The rectangular nozzle-based PCS terminals $\left(45 \times 85 \mathrm{~mm}\right.$ ) provided conditioned air $\left(\right.$ at $\left.\mathrm{T}_{\mathrm{PCS}}=19.5^{\circ} \mathrm{C}\right)$ directly to the faces of the thermal mannequins and helped improve the inhaled air quality by keeping the breathing zone free of pollutants. Given that the ATD was embedded in the seat armrests, the possibility of draft discomfort was also greatly reduced. As an extension to the study, Zhang et al. performed a CFD-based study by in-depth modelling of the previous experiment [77]. The results of this study reiterated the experimental findings of the former study. In addition, the simulation results revealed that the under-aisle ventilation provided a rising flow pattern, naturally shielding the subject from pollutants. The PCS device added on to the under-aisle ventilation, thereby providing enhanced protection from contaminants.

\section{Ventilation PCS}

Ventilation-based PCS are the most popularly researched mode of personal comfort. They include a wide spectrum of devices including desktop-based devices, movable panel-based devices, fixed panel/nozzle-based devices, with fans, seats, and garments. They function by reducing the subjects' skin temperatures by increasing the air movement around the subjects' bodies and facilitating increased evaporation of sweat, inducing a 'cool' sensation without using any compressor-based cooling. The thermal comfort and sensation related parameters have been monitored in the following studies using subjective surveys and physical measurements. In addition, ventilation-type PCS greatly influence the quality of air in the occupants' breathing zones. To account for the same, the studies monitored parameters such as Personal Exposure Effectiveness (PEE), Air Change Effectiveness (ACE), Intake Fraction (IF), Ventilation Effectiveness (VE), Re-inhaled Exposure Index (REI), Cross Infection Risk (CIR), Personalised Air Utilisation Efficiency (PAUE), Pollution Exposure Reduction Index (PERI), and pollutant concentration. Table 5 lists the studies referred for 'Ventilation' PCS, categorised as per the ambient air temperature $\left(\mathrm{T}_{\text {room }}\right)$ at which they are operated.

Table 5. Studies on Ventilation PCS.

\begin{tabular}{|c|c|c|}
\hline PCS Type & Ambient Temperature Range & Studies \\
\hline Ventilation & Below 18 & {$[88][89][90]$} \\
\hline
\end{tabular}




\begin{tabular}{|c|c|c|}
\hline & $18-20$ & {$[90][91][92][93][94][95]$} \\
\hline & $20-22$ & $\begin{array}{c}{[20][48][86][90][91][94][96][97]} \\
{[98][99][100][101][102][103][104][105][106]}\end{array}$ \\
\hline & $22-24$ & $\begin{array}{l}{[20][48][55][69][70][102][106]} \\
{[107][108][109][110][10][111]}\end{array}$ \\
\hline & $24-26$ & $\begin{array}{c}{[39][48][96][102][109][110][10][112]} \\
{[113][114][115][116][117][118][119][120]}\end{array}$ \\
\hline & $26-28$ & $\begin{array}{c}{[39][55][69][70][80][98][103][118][119]} \\
{[120][121][122][123][124][125][126][127][128][129]}\end{array}$ \\
\hline & $28-30$ & $\begin{array}{c}{[39][55][118][119][120][121][125]} \\
{[126][127][129][130][131][132][133][134][135]}\end{array}$ \\
\hline & $30-32$ & {$[56][121][125][126][127][128][129][130]$} \\
\hline & Above 32 & {$[130][136]$} \\
\hline
\end{tabular}

\subsection{Desktop-based Fans/Devices}

\subsubsection{Laboratory Studies with Subjects}

Hua et al. studied a desktop-mounted fan $(\mathrm{D}=370 \mathrm{~mm})$ which mimicked the wind-flow pattern of natural ventilation in a controlled environment [121]. The spectral parameters (velocity, turbulence, etc.) of the supplied air were maintained close to that of the natural wind and the subjects' responses for overall thermal sensation and comfort were recorded. At $\mathrm{T}_{\text {room }}=30^{\circ} \mathrm{C}$, the surveys found that the subjects' sensation and comfort for the simulated natural flow were more moderated than that for the mechanical airflow (without the natural wind characteristics) by $\sim 0.3$ votes. As the $\mathrm{T}_{\text {room }}$ reduced, the difference in sensation and comfort between the two cases was also found to reduce. They repeated the experiment in an actual office environment, the results of which were consistent with the lab experiment. However, despite an improvement in thermal sensation and comfort, the subjects were susceptible to nose dryness and eye irritation, which were suggested to be remediated by giving individual control of the fan velocity and direction. In another study on the air movement demand in warm indoor environments, Huang et al. studied the subjects' thermal sensation and comfort responses to a desktop mounted fan through climate controlled experiments and online surveys [130]. The results indicated that an increase in the air velocity to $2 \mathrm{~m} / \mathrm{s}$ from still-air conditions resulted in an improvement in sensation by $\sim 2$ votes, i.e., the high air velocity allowed the subjects to maintain a near-neutral thermal sensation at $T_{\text {room }}$ of up to $32^{\circ} \mathrm{C}$. Elevated air velocity also improved the thermal comfort by $\sim 1$ vote. $100 \%$ of the subjects accepted the fan to be an adequate source of cooling at $\mathrm{T}_{\text {room }}=28$ and $30^{\circ} \mathrm{C}$. However, this percentage dropped sharply at higher $\mathrm{T}_{\text {room }}$ values. The online survey showed that $98 \%$ of the respondents used electric fans in their homes and $70 \%$ of them approved of their usage in office environments [130]. They respondents also pointed out that the excessive air velocities often led to the unwanted displacement of light-weighted objects, causing occupational discomfort.

Boerstra et al. further studied the impact of a desktop-mounted fan on subjects in field conditions through subjective surveys [131]. The subjects could change the velocity and direction of the supplied air through a control unit while the $\mathrm{T}_{\text {room }}$ was fixed at $28^{\circ} \mathrm{C}$. They studied two cases - case A represented when the subjects were in control of the fan while case B represented no subjective control and fixed air flow. The 'predefined' airflow in case B was identical to the flow chosen by them in case A, the only difference being that the subjects were not aware of it. Thus, 'awareness of control' was the only contrasting factor between the two cases. Interestingly, the results revealed that more number of subjects were thermally satisfied in case B (no-control), than in case A (with-control). The subjects in case B had a more acceptable air movement preference, air quality sensation and satisfaction; these subjects also indicated to have a reduced number of sick building syndrome symptoms. However, comfort perception showed no statistical difference between the two cases, indicating a negligible impact of temperatures across the two cases. Given the small sample size, the "large interpersonal differences in terms of preferred air velocities" and "substantial differences in fan use frequency" demand further experiments. Bauman et al. studied the impact of three air movement devices - Desk Fan (DF), Floor Mounted Diffuser (FMD), and Desk Mounted Diffuser (DMD) through subjective surveys [20]. The subjects could adjust the air movement of each device as per their preference. The results indicated that subjects found each of the devices equally effective as a general consensus. However, at lower air velocities $(<0.1 \mathrm{~m} / \mathrm{s})$, subjects preferred FMD, while at high air velocities $(>0.3 \mathrm{~m} / \mathrm{s})$, DF was the most popular choice. DMD was 
dominantly used in the average velocity range $(0.1-0.3 \mathrm{~m} / \mathrm{s})$. The turbulence intensity was not shown to influence the air movement preference of the subjects. The percentage of satisfied/dissatisfied subjects was predicted using a mathematical model and found that the optimum air velocity (for the satisfaction of $90 \%$ subjects) increased exponentially from 0.3 to $1 \mathrm{~m} / \mathrm{s}$ for the operative temperature range of $24.5-28.5^{\circ} \mathrm{C}$.

Melikov et al. studied the effect of a $(30 \mathrm{~W})$ desktop fan on subjects in a controlled chamber [55]. The subjects could control the direction and velocity of the supplied air and provided responses to questions on their ambience. With the operation of a fan for over 40 minutes, the overall thermal sensation reduced by $\sim 1$ vote in comparison to the case with no fan. The overall thermal acceptability, after a 60-minute exposure was significantly higher than the 'no-fan' case. The local thermal sensation and acceptability demonstrated similar trends. The perceived air quality increased by over 0.3 votes, however, the instances of eye irritation increased almost doubly with the fan operation. Overall, over $95 \%$ of the subjects were satisfied with the fan operation in comparison to the $50 \%$ satisfied subjects for the 'no-fan' case. Zhang et al. studied a keyboard-based hand ventilation device used to cool the hands [39]. The three $2 \mathrm{~W}$ (each) fans placed beneath the keyboard tray drew air from the back of the keyboard and directed it through a small opening to cool the subjects' hands. In addition to the keyboard-based device, the setup included a set of nozzles oriented towards the head. The subjects gave responses for thermal sensation, comfort, and productivity through a computer-based questionnaire. They found that at hot, warm, and neutral ambient temperatures $\left(25-30^{\circ} \mathrm{C}\right)$, the overall thermal sensation for a fixed PCS setting was within the -1 to +1 range. Providing an individual control to the subjects over PCS improved the sensation negligibly. Providing individual control increased the overall comfort by $\sim 0.5$ votes. The subjects also reported a marginal improvement in productivity with the provision of individual control and did not experience eye-dryness. However, the difference in perceived air quality between the two cases was found to be insignificant.

\subsubsection{Laboratory Studies with Mannequins}

Faulkner et al. studied the ventilation effectiveness of a desk-edge mounted PCS through a thermal mannequin and human subject assessment [112]. They calculated the Air Change Effectiveness (ACE) of the PCS device at various flow rates and angles of device operation through a tracer gas setup. The ACE for the mannequin and human subject ranged from 1.4-2.7 and 1.3-2.3 respectively. The ACE was found to be the highest at the angle of $45^{\circ}$ (from the horizontal) and the flow rate of $4.8 \mathrm{~L} / \mathrm{s}$. The study did not mention thermal comfort in detail, however, it did point that $\mathrm{T}_{\mathrm{PCS}}$ is the only variable which impacts the thermal comfort substantially. Melikov et al. focussed on the study of five types of desk-based air terminal devices, namely - Movable Panel (MP), Computer Monitor Panel (COMP), Vertical Desk Grill (VDG), Horizontal Desk Grill (HDG), and Personal Environment Module (PEM) [86]. They measured the effectiveness of each of the devices on a breathing thermal mannequin - they calculated the Ventilation Effectiveness (VE), Personal Exposure Effectiveness (PEE), and Re-inhaled Exposure Index (REI) with the help of a tracer gas setup. The VE for each of the devices was within the range of 1-2.5, with no device distinctly outperforming the other. The PEE for MP and VDG was the highest at flow rates $>5 \mathrm{~L} / \mathrm{s}$, however, at lower flow rates, HDG was found to be the best. It was also found that increasing the cross sectional area of COMP by 50\%, increased the PEE at high flow rates significantly. The REI (at $10 \mathrm{~L} / \mathrm{s}$ ) was found to be the highest for MP and lowest for VDG. The decrease in overall $\mathrm{T}_{\text {eqv }}$, calculated from the individual body part temperatures of the mannequin, was found to be the highest for the case of VDG and PEM $\left(\sim 0.8^{\circ} \mathrm{C}\right)$, while it was the lowest for HDG and CMP $\left(\sim 0.4^{\circ} \mathrm{C}\right)$.

\subsubsection{Simulation Studies}

Gao et al. studied the impact of desk-edge PCS, rectangular MP $(240 \times 75 \mathrm{~mm})$, and a seat based PCS on a numerical thermal mannequin using CFD simulations [96]. In addition to numerically assessing the overall/local thermal comfort and sensation, they also estimated the ACE and PEE. The study also highlighted the difference between the three PCS strategies through the air profiles near the simulated mannequin - the desk-edge device impacts the lower chest and makes the air move upwards to the neck and head region. The MP flow strikes the head directly and trickles down to the chest, thighs, and back thereafter. The seat-based device utilises the model of an under-chin air terminal device, which supplies low velocities of air directly to the facial region from below. The estimated local thermal sensation of the subjects ranged between -0.2 and -1.8 votes, with the feet being the coolest, and the head, thighs, and pelvis being the warmest. The local thermal comfort profile indicates that the warmer portions of the body were the most comfortable, while the coldest were the least. The results also indicate an insignificant difference in the sensation and comfort profiles of individual body parts (except the head) with a change in flow rate and PCS supply temperature from $0.8 \mathrm{~L} / \mathrm{s}$ to $1.6 \mathrm{~L} / \mathrm{s}$, and $20^{\circ} \mathrm{C}$ to $25^{\circ} \mathrm{C}$ respectively. 
Habchi et al. compared the performance of a ceiling-mounted PCS when used in tandem with desk fans and seat fans through CFD simulations [88]. The simulation results indicated that at a flow rate of $10 \mathrm{~L} / \mathrm{s}$, the local $\mathrm{T}_{\text {skin }}$ of the hands and feet was the lowest, while the other body parts such as the chest, back, and thighs were the warmest across both the cases (desk fans and seat fans). The extent of overall thermal comfort was highest for the case utilising 'seat fans with ceiling ventilation' - this case was twice as comfortable as the case with 'only ceiling ventilation'. The overall thermal sensation for the 'only ceiling ventilation' was found to be on the warmer side in comparison to the other cases. The distance of the mannequin from the PCS assembly also had a prominent role to play in defining overall comfort and sensation. An away shift by $200 \mathrm{~mm}$ resulted in a decrease in thermal comfort by $\sim 0.3$ votes, while it also led to an increase in the thermal sensation on the warmer side by $\sim 0.4$ votes. The ventilation effectiveness of the 'seat fans with ceiling ventilation' was found to be marginally better than that of the other cases. In another simulation-based study involving the usage of desk fans in combination with ceiling mounted PCS $(\mathrm{D}=156 \mathrm{~mm})$, Makhoul et al. estimated the local and overall thermal comfort and sensation, with various ventilation-related parameters [137]. It was found that at $\mathrm{T}_{\text {room }}=20^{\circ} \mathrm{C}$, the operation of desktop based fans resulted in an improvement in the overall thermal comfort by $\sim 0.6$ votes and the overall thermal sensation by $\sim 0.4$ votes. The change in airflow rate from 5 to $10 \mathrm{~L} / \mathrm{s}$ led to a significant improvement in the thermal comfort at $\mathrm{T}_{\text {room }}=16^{\circ} \mathrm{C}$, however, the change at $\mathrm{T}_{\text {room }}=24^{\circ} \mathrm{C}$ was negligible. The study also simulated and compared the operation of a coaxial nozzle for ventilation - it was found to be significantly better ( 1.3 comfort votes) than the desk fan, specifically at air flow rates lower than 5 L/s.

Makhoul et al. also studied the movement of air with the operation of ceiling mounted PCS (D=156 mm) [138]. They studied two devices - a peripheral diffuser and a coaxial personal ventilation jet. The 'canopy' of conditioned air around the occupant reduced the transport of polluting particles from the ambience to the breathing zone of the numerical mannequin. The Intake Fraction (IF) for fine $(1 \mu \mathrm{m})$ and ultrafine $(0.01 \mu \mathrm{m})$ particles was maintained by the coaxial jet at 3.6e-4 and $2.95 \mathrm{e}-4$ respectively. The peripheral diffuser was found to be more effective with an IF of $1.9 \mathrm{e}-4$ for fine particles and proved to be less effective for ultrafine particles with an IF of 5.9e-4. Despite the low IF in the breathing zone, the pollutant deposition rate in the immediate vicinity of the subject was found to be high - which could potentially lead to discomfort. As a remedial measure, installation of exhaust vents close to the regions of the highest pollutant concentration should be considered. Shen et al. compared the performance of RMP $(95 \mathrm{~mm})$ and VDG $(220 \times 20 \mathrm{~mm})$ through a simulation-based study [89]. The two types of PCS devices were in operation with the background ventilation strategies of Displacement Ventilation (DV), Mixed Ventilation (MV), and Under-Floor Air Distribution ventilation (UFAD). The simulation was run for 'clean', 'usual', and 'polluted' cases with multiple subcases representing various airflow rates, device operation, and pollution source concentrations. The 'clean' case represented the most favourable ambient conditions, 'usual' represented the ordinary conditions, and 'polluted' represented the most unfavourable conditions. Without the use of any PCS device, the VE was found to be $0.109,0.933$, and 0.245 for DV, MV, and UFAD respectively, with DV as the best background ventilation strategy. The 'usual' case indicated that the VE increased marginally for the DV and UFAD cases, but decreased significantly for the case of MV in comparison to the cases without any PCS device in use. The 'clean' case indicated that the VE increased marginally for DV, while it decreased marginally for DV and significantly for UFAD. In the 'polluted' case, the VE increased significantly for DV and UFAD cases, while it decreased slightly for the case of MV. A comparison on the basis of the device type revealed that the RMP led to significantly higher levels VE in comparison to the VDG, specifically during the background operation of UFAD and MV. As a general conclusion, it was found favourable to operate VDG at low velocities $(<1 \mathrm{~m} / \mathrm{s})$ and RMP at high velocities $(>1 \mathrm{~m} / \mathrm{s})$.

Zhao and Guan studied the case of pollution dispersion in addition to temperature and airflow distribution around a simulated human body due to the effect of ceiling and desktop based PCS [122]. They simulated the particles ranging in the size of $0.5-10 \mu \mathrm{m}$ and found that the ones smaller than $2 \mu \mathrm{m}$ could be regarded as 'passive contaminants' which could be effectively removed by strong-enough personalised ventilation (9-17 $\mathrm{L} / \mathrm{s}$ ). Whereas, the particles sized above $2 \mu \mathrm{m}$ underwent floor deposition due to gravitational sedimentation. They also pointed out that the used PCS were ineffective against pollutant particles bigger than $7.5 \mu \mathrm{m}$. Kato and Yang studied the air movement and quality provided using a desktop based PCS through CFD simulations [113]. Used in combination with a wall-mounted DV unit, the PCS device had effective diameters of 250 and 70 $\mathrm{mm}$ for the two studied cases and supplied isothermal air to the facial region of the subject. The simulation results found that the PCS was able to significantly reduce the contribution ratio of pollution sources, more so, the larger air terminal ( $\mathrm{D}=250 \mathrm{~mm}$ with $0.5 \mathrm{~m} / \mathrm{s}$ air supply) was found to be better than the smaller air terminal. 
The difference between the multiple cases was most prominent when the pollution source was at the 'upper desk', while it was found to be the lowest in the case of 'ceiling borne' pollution. The smaller opening allowed enhanced mixing of the ambient air and led to increased spread of conditioned air plume, whereas the larger opening allowed a smaller plume which was restricted to the subject's breathing zone and therefore provided a better air quality.

\subsection{Movable Panel-based Devices}

\subsubsection{Laboratory Studies with Subjects}

Kaczmarczyk et al. studied the response of human subjects to personalised ventilation provided using a rectangular MP $(240 \times 75 \mathrm{~mm})$ [107]. The subjects could adjust the position and flow rate of the air supplied through the PCS device and marked responses on thermal comfort and air quality through a questionnaire. At $\mathrm{T}_{\text {room }}=23^{\circ} \mathrm{C}$, over $85 \%$ of the subjects marked themselves to be satisfied when the fresh outdoor air was circulated after being conditioned isothermally, whereas for the cases of DV and MV, $\sim 80 \%$ of the subjects marked themselves as satisfied. Subjects also reported an improvement in the PAQ and the least instances of sick-building syndrome symptoms for the case of fresh outdoor air supply. Li et al. studied the effect of Round Fixed Panel (RFP) $(\mathrm{D}=100 \mathrm{~mm}$ ) supplying conditioned outdoor air in combination with UFAD supplying recirculated indoor air [80]. The subjects underwent tests under controlled conditions to explore about the hypothesis - "cold draught at feet can be reduced when relatively warm air is supplied by UFAD system and uncomfortable sensation as 'warm head' can be reduced by the PCS providing cool and fresh outdoor air at the facial level." The subjective responses indicated that the case of UFAD with PCS led to an improvement in the local thermal sensation and acceptability at feet in comparison to the case of using UFAD alone. The local air movement preference was also found to be closest to the favourable 'no change' vote when the $\mathrm{T}_{\mathrm{PCS}}$ was lower than $T_{\text {room }}-$ a high flow rate $(10 \mathrm{~L} / \mathrm{s})$ was also shown to be more acceptable by the occupants and they regarded it to be 'fresh'. The overall inferences from the experiments confirmed the hypothesis and proved that "increased air temperature supplied by the UFAD system decreased the over-cooling of the feet and improved the acceptability of the local thermal sensation".

Melikov et al. analysed the effect of RMP on human subjects in controlled ambient conditions [55]. The position as well as the flow rate through the RMP could be adjusted as per the subjects' requirements. The subjects marked their responses for various comfort-related parameters and indicated the overall thermal sensation to remain $\sim 0.8$ votes lower (closer to neutral) than the scenario with no PCS. Following a similar trend, the overall thermal acceptability, local thermal sensation and local acceptability at the head were also found to be significantly better than the 'no-PCS' case. Usage of desktop fans in tandem with RMP was shown to improve all the monitored parameters. Additionally, the operation of fans with RMP increased the percentage of subjects satisfied with the air movement from $\sim 70 \%$ (only RMP) to $90 \%$ (RMP with fans). However, after prolonged exposure of $\sim 2$ hours, over $40 \%$ of the subjects indicated symptoms of eye-irritation. Melikov and Knudsen studied the impact of an RMP in combination with an under-desk ATD on human subjects through questionnaires [48]. The RMP $(D=215 \mathrm{~mm})$ and the under-desk ATD $(300 \times 20 \mathrm{~mm})$ supplied recirculated air as per the flow rate and direction decided by the seated subjects. The results revealed that the subjects were over $50 \%$ more in acceptance of their thermal ambience in the presence of the PCS. Out of all the cases studied, the highest number of subjects $(80 \%)$ were satisfied with their local thermal sensation at $\mathrm{T}_{\text {room }}=22^{\circ} \mathrm{C}$, with the PCS turned on; the reference case at the same $\mathrm{T}_{\text {room }}$ led to only $50 \%$ of the subjects being satisfied.

Sekhar et al. studied the response of a half-cylinder MP $(260 \times 100 \mathrm{~mm})$ on human subjects in controlled conditions [65]. The PCS supplied the outdoor air after conditioning it at $\mathrm{T}_{\text {room }}$ at a constant flow rate. The results revealed that the thermal acceptability and the PAQ were improved by $\sim 60 \%$ each, in comparison to the case without the PCS in use. Both the thermal acceptability and PAQ were shown to increase with the increase in the airflow rate. However, the subjects preferred to have the $\mathrm{T}_{\mathrm{PCS}}$ maintained lower than the $\mathrm{T}_{\text {room. }}$ Skwarczynski et al. studied the effect of an RMP based PCS on human subjects in controlled conditions [123]. They maintained a constant $\mathrm{T}_{\text {room }}=26^{\circ} \mathrm{C}$, while changing the $\mathrm{RH}$ from $30 \%$ to $70 \%$ to contrast the cases. The subjects could control the flow velocity of the PCS device and were supplied with a questionnaire on various subjective measures of air quality and movement. The subjects reported marginally increased levels of odour with the employment of the PCS. The acceptability of air quality was highest for the case at $\mathrm{T}_{\text {room }}=26^{\circ} \mathrm{C}$, $\mathrm{RH}=30 \%$ and PCS was not in use - this case was more acceptable than the case with the PCS in use (at $\mathrm{T}_{\text {room }}=26^{\circ} \mathrm{C}, \mathrm{RH}=70 \%$ ). The calculated percentage of dissatisfied subjects also indicated that they preferred a lower RH level over the operation of PCS at a higher RH for the same $\mathrm{T}_{\text {room }}$. 


\subsubsection{Laboratory Studies with Mannequins}

Bolashikov et al. conducted controlled experiments on a thermal mannequin subject to an RMP ( $\mathrm{D}=180 \mathrm{~mm}$ ) and an under-desk ventilation system with 6 suction fans (1.4 W each) on the front and rear, which worked as an exhaust to the heat generated by the lower body [98]. They calculated and compared the PEE for each of the studied cases. They utilized two types of plastic 'cut boards' as mechanical barriers to separate the upper and lower bodies from the two types of ventilation strategies - the first case of board had a straight front edge, while the second had a semi-circular cut so that it could fit in at the mannequin's waist, creating a more effective separation between the top and bottom zones. The results indicated that the difference between the cut-board types did not bring any difference in PEE at any $\mathrm{T}_{\text {room }}$ condition. At moderate flow rates $(\sim 6 \mathrm{~L} / \mathrm{s})$, placing a straight board improved the PEE from $31.2 \%$ to $92.4 \%$ while the operation of under-desk suction fans did not bring a significant difference in the PEE either.

Cermak et al. studied the performance of an RMP $(\mathrm{D}=185 \mathrm{~mm})$ and a VDG $(22 \times 2 \mathrm{~mm})$ used with a UFAD system through a breathing thermal mannequin and a tracer gas setup [99]. The resultant velocity contours indicated a range of $0.1-0.5 \mathrm{~m} / \mathrm{s}$ for the various airflow rates, across devices. They found that the exposure of mannequins to exhaled air due to the PCS-driven mixing was independent of the location of source workstation of the contaminant. Both the PCS devices indicated a similar spread of pollution concentrations and were effective in keeping the breathing zone of the mannequin within comfortable limits. It was also found that the use of PCS at one workstation did not affect the pollutant concentration at the surrounding workstations at the floor level. However, at the head level, pollutant mixing was observed. Cermak et al. in another study, analysed the performance of the same two PCS devices, used with MV [100]. In addition to the pollutant concentration at various heights, they monitored the overall and local $\mathrm{T}_{\text {eqv }}$ using thermal mannequins. They found that at the flow rate of $15 \mathrm{~L} / \mathrm{s}$, the whole body and local $\mathrm{T}_{\text {eqv }}$ were the lowest for the case of 'RMP with MV', while they were the highest for the case of 'only MV'. The local $\mathrm{T}_{\text {eqv }}$ of the head was found to be up to $6^{\circ} \mathrm{C}$ cooler with the operation of PCS whereas the $\mathrm{T}_{\text {eqv }}$ at feet, legs, and thighs did not indicate any change.

Halvonova and Melikov studied the performance of ductless RMP operated with DV and analysed the impact of intake height, walking people, and workstation layouts on thermal mannequins [139], [140]. The RMP supplied $15 \mathrm{~L} / \mathrm{s}$ of air, while the DV unit supplied $60 \mathrm{~L} / \mathrm{s}$. The $\mathrm{T}_{\mathrm{PCS}}$ was kept between $18-20^{\circ} \mathrm{C}$ while the room exhaust was maintained at $26^{\circ} \mathrm{C}$. A tracer gas setup helped ascertain the concentration of pollutants. The results indicated that the operation of 'PCS+DV' was just as efficient in providing clean air to the breathing zone as 'only DV'. However, when the pollution source was kept close to the mannequin, the inhaled air was found to be significantly less polluted for 'PCS+DV' in comparison to 'only DV'. The former case was also found to have a superior PAQ throughout all the tested cases. When assessing the impact of height on the PCS performance, it was found that there was no significant difference in the pollutant concentration and $\mathrm{T}_{\text {room }}$ with the PCS positioned at the floor level or up to $0.2 \mathrm{~m}$ higher than that. The movement of occupants resulted in increased mixing of clean and polluted air and negatively affected DV, the increased mixing of air also led to a more homogeneous thermal distribution and consequently led to increased temperature of the inhaled air. Under these conditions, the case of 'PCS+DV' was found to be better than 'only DV' in regard to providing better air quality and thermal comfort. The study of workstation layout recommended a strategy in which either the occupants should be made to sit back-to-back with a high enough distance $(\sim 3000 \mathrm{~mm})$ between the workstation or they should be seated side-by-side (independent of distance). The study also recommended the usage of workstation partitions particularly for the occupants who chose not to operate their PCS.

Khalifa et al. studied the effect of a novel nozzle-based PCS $\left(D_{\text {primary }}=50.8 \mathrm{~mm}, \mathrm{D}_{\text {secondary }}=105.6 \mathrm{~mm}\right)$ on a breathing thermal mannequin [114]. The results indicated that the co-flow nozzle used in this study was able to achieve a VE of $\sim 7$ at a low flow rate of $2.4 \mathrm{~L} / \mathrm{s}$; in comparison, a conventional nozzle had ventilation effectiveness of only $\sim 2$. The co-flow nozzle was able to provide a higher IAQ in comparison to a primary flow nozzle at the same $\mathrm{T}_{\text {room }}$ and flow-rate. A simulation-based study on the same setup by Russo et al. confirmed the experimental findings through CFD simulations [115]. Lipczynska et al. studied the usage of RMP based PCS in combination with Chilled Ceiling (CC) and MV [132]. The $\mathrm{CC}_{\text {surface }}$ was maintained between $18-22^{\circ} \mathrm{C}$, while the flow rate of the MV was kept constant at $12 \mathrm{~L} / \mathrm{s}$ throughout all the studied cases. The $\mathrm{T}_{\text {eqv }}$ results indicated that the cases utilising PCS at a flow rate of $13 \mathrm{~L} / \mathrm{s}$ or higher resulted in a significantly low local $\mathrm{T}_{\text {eqv }}$ for the neck and the facial region. In regard to the air quality, the operation of PCS with MV and CC was able to reduce the extent of pollutants in the breathing zone in comparison to the cases with 'only $\mathrm{MV}$ ' and only ' $\mathrm{CC}+\mathrm{MV}$ ' - it was observed in the noticeable difference in the parameters such as cross infection risk (CRI), 
ACE and pollutant concentration. The operation of PCS above $13 \mathrm{~L} / \mathrm{s}$ does not result in any major changes in these parameters.

\subsubsection{Simulation Studies}

He et al. studied the transmission of air between seated occupants in the presence of an RMP (D=190 mm) based PCS through CFD simulations [101]. The PCS was used in combination with three types of total volume ventilation (TVV) strategies - MV, DV, and UFAD. The simulation results showed that the PCS airflow was capable of reducing the concentrations of particles of the size 0.8 and $5 \mu \mathrm{m}$ across all the three TVV strategies. However, the results also indicated that a higher flow rate implied a higher IF of the pollutants. The personalised flow was shown to increase the extent of mixing of particles more significantly with the DV and UFAD in comparison to MV. The increase of PCS airflow rate from 14 to $30 \mathrm{~L} / \mathrm{s}$ did not contribute to a significant change in the pollutant concentration. Kanaan et al. simulated the combination of DV and a facially oriented RFP $(\mathrm{D}=50 \mathrm{~mm})$ through a simplified CFD model [92]. The study found that the performance of the two systems in combination depended on the position of the PV with respect to the subject's face - a small gap (300-400 mm) resulted in a better inhaled air quality, whereas as the gap was increased (to $500 \mathrm{~mm}$ ), the chances of pollutant entrainment increased too. They concluded that a PCS supply temperature within the range of $3-4^{\circ} \mathrm{C}$ lower than the $\mathrm{T}_{\text {room }}$, at flow rates of $8-10 \mathrm{~L} / \mathrm{s}$ was likely to provide the optimum air quality with this setup.

Gao et al. studied the difference between the operation of a (D=200 mm) MP-based PCS with DV and MV through CFD simulations [90]. The DV was simulated by modelling a wall-mounted diffuser at the floor level with a floor-level exhaust, while the MV was modelled with an inlet diffuser and a small opening at the upper level on the wall. They found that DV could provide better air quality by reducing the pollutant concentration in the breathing zone. In contrast, given that MV targeted the entire built volume, its effectiveness in the breathing space was relatively lower. The results also indicated that the operation of PCS could increase the acceptable thermal stratification by up to $6^{\circ} \mathrm{C}$; however, the subjects' sensation and comfort were also dependent on $\mathrm{T}_{\text {room }}$ and $\mathrm{T}_{\mathrm{PCS}}-$ which were beyond the scope of this study.

\subsection{Fixed Panel or Nozzle-based Devices}

\subsubsection{Laboratory Studies with Subjects}

Arens et al. studied the impact of facially directed recirculated air on human subjects. The PCS consisted of four nozzles - two of them with a $D=102 \mathrm{~mm}$, while the other two with $\mathrm{D}=51 \mathrm{~mm}$ [133]. They studied various comfort and air quality parameters with multiple cases involving the operation of various combinations of fans and user control. The overall thermal sensation was found to be the best when the subjects had complete control of the PCS as well as when the two nozzles $(D=101.6 \mathrm{~mm})$ supplied air at $1 \mathrm{~m} / \mathrm{s}$. The sensation was on the warmest side when the PCS was not operated at all. The thermal comfort followed the same trend as the sensation. The subjects marked themselves as comfortable when the sensation ranged between 'slightly warm' and 'neutral'. In regard to the perceived air quality, even a low air velocity of $0.6 \mathrm{~m} / \mathrm{s}$ was shown to increase the PAQ significantly. Thermal comfort and the perceived air quality showed to have a strong correlation and the improvement in one indicates an improvement in the other one.

Huang et al. studied the perceptible frequency of airflow variation through a duct based PCS on human subjects [134]. The air was supplied to the RFP based PCS through an axial fan assembly, which was operated at 20 predefined frequencies ranging from 0.005 to $2.5 \mathrm{~Hz}$ at a random sequence. At $\mathrm{T}_{\text {room }}=28^{\circ} \mathrm{C}$, the subjects were able to perceive the change in frequencies when they were in the range of $0.3-1.2 \mathrm{~Hz}$ only. Increasing the $\mathrm{T}_{\text {room }}$ by $2{ }^{\circ} \mathrm{C}$ marginally reduced the number of subjects who could perceive the change in frequency. At $\mathrm{T}_{\text {room }}=28^{\circ} \mathrm{C}$, the overall thermal sensation was found to sway away from the neutral (on the colder side) when the airflow frequency was in the perceivable range, consequently, the overall comfort was found to be the highest in the same frequency range. On the contrary, at $\mathrm{T}_{\text {room }}=30^{\circ} \mathrm{C}$, the overall thermal sensation was found to reduce to a relatively more neutral sensation in the perceivable range of frequency, while the overall thermal comfort in this frequency range was found to be the lowest in comparison to the higher or lower air change frequencies.

Melikov et al. studied the effect of headrest-mounted PCS $(100 \times 140 \mathrm{~mm})$ using a breathing thermal mannequin and human subjects [102]. They studied the thermal comfort performance of the setup on the human subjects through questionnaires and performed the air movement/quality studies on the mannequin using a tracer gas setup. While studying the air quality, the PEE was found to be the highest for the PCS setup at $\mathrm{T}_{\text {room }}=26^{\circ} \mathrm{C}$ at the highest flow rate of $10 \mathrm{~L} / \mathrm{s}$ and clothing insulation (CLO) of $0.78 \mathrm{clo}$. They found that clothing also had a role to play in the subjects' exposure to the ventilation. At a fixed flow rate and $\mathrm{T}_{\mathrm{PCS}}$, the PEE was shown to increase 
sharply as the CLO was increased from 0.8 to 1 clo. A further increase in CLO (from 1 to 1.4 clo) resulted in a negligible change in the PEE. The air quality across all the cases was continuously found within the acceptable range. The human subjects marked themselves as comfortable with their local thermal sensation (for the head) remaining between 'slightly warm' and 'slightly cool' throughout the range of experiments. Conclusively, they indicated that the headrest mounted PCS assembly could perform the best at $\mathrm{T}_{\text {room }}>26^{\circ} \mathrm{C}$, with the $\mathrm{T}_{\mathrm{PCS}}$ being 2$3^{\circ} \mathrm{C}$ cooler. Zhang et al. studied the response of human subjects to the operation of two head-oriented nozzle supplies $(\mathrm{D}=51 \mathrm{~mm})$, providing recirculated air from the sides at a total flow rate of $24 \mathrm{~L} / \mathrm{s}$ [39]. When comparing the cases of 'no PCS', 'fixed PCS', and 'used-controlled PCS', the subjective responses were statistically indistinguishable for 'fixed PCS' and 'user-controlled PCS' cases, whereas the subjects indicated to experience a lack of air movement when the PCS was not in operation. Given the side entry of the PCS air supply, the subjects did not experience dry eye discomfort in any of the three cases. In regard to the thermal performance of the PCS assembly, the user-control did not indicate any statistical improvement. The subjects found their thermal ambience unacceptable at $\mathrm{T}_{\text {room }} \geq 28^{\circ} \mathrm{C}$, when the PCS was not in operation.

\subsubsection{Laboratory Studies with Mannequins}

Bolashikov et al. studied the case of headrest incorporated PCS device in combination with mixing ventilation on a thermal mannequin [103]. The front portion of the headrest-incorporated PCS supplied clean conditioned air to the side of the face of the thermal mannequin while the lower portion of the headrest, placed right above the shoulders of the mannequin, worked as a control strategy by operating on 'suction' and 'blowing' modes. The headrest-incorporated supply nozzles could be rotated by $90^{\circ}$. This setup was studied at various operational conditions and the air quality was measured by calculating the PEE. The PEE was found to be better for the nozzles oriented at $90^{\circ}$, supplying air along the cheeks of the subject. In comparison, the PEE at the angle of $45^{\circ}$ was found to be lower by $40-50 \%$ (at $6-8 \mathrm{~L} / \mathrm{s}$ ). However, at a low flow rate of $4 \mathrm{~L} / \mathrm{s}$, the $45^{\circ}$ orientation proved to be better. The 'large' nozzles $\left(\mathrm{CSA}=12000 \mathrm{~mm}^{2}\right)$ were found to be significantly more effective than the 'small' nozzles $\left(\mathrm{CSA}=0.0064 \mathrm{~m}^{2}\right)$ at the same airflow rate and temperature conditions. Operation of 'exhaust' portion further improved the PEE across all operational conditions. The supply of fresh air through the PCS assembly increased the PEE up to $80 \%$ in comparison to the $~ 50 \%$ PEE for the supply of recirculated air. The best control strategy was found to be 'blowing' at $4.5 \mathrm{~L} / \mathrm{s}$ to be used in tandem with primary nozzles operating at $6 \mathrm{~L} / \mathrm{s}$. The supply air temperature did not have a drastic effect on the PEE at higher flow rates, however, at low flow rates with no control strategy, the $20^{\circ} \mathrm{C}$ condition had a $\sim 20 \%$ higher PEE.

Bolashikov et al. studied a face-oriented PCS device with circular and elliptical nozzle sizes ranging from 25 , 30 , and $35 \mathrm{~mm}$ in diameter [104]. They measured the air quality through a tracer gas setup and a breathing thermal mannequin, orienting the nozzle at various facial positions. The results indicated that the extent of fresh air inhaled by the breathing thermal mannequin was the highest when the nozzle was placed at a $45^{\circ}$ angle from the mannequin's face. In addition, elliptical nozzles provided a larger portion of fresh air in comparison to circular nozzles, for the same equivalent diameter. The nozzles were also found to be the most effective when placed at a distance of $20 \mathrm{~mm}$ from the mannequin's face; increasing the distance to $60 \mathrm{~mm}$ resulted in a decrease in the PEE by $\sim 50 \%$.

Dygert and Dang studied the air quality of an aircraft cabin ventilated with the help of a seat-based PCS using a breathing thermal mannequin [108]. The PCS device worked as an exhaust in combination with the floor-based exhaust system and focussed on limiting the cross-contamination - this was analysed using a tracer gas setup. The PCS exhaust orifices were incorporated in the seat, right above the shoulders of the mannequin and were found to reduce the pollution exposure by $\sim 30 \%$ in comparison to the case with no PCS in use. The provision of an overhead exhaust unit in combination with the floor setup and a mechanical partition (privacy shell used in aircraft cabins) was able to provide a pollutant exposure reduction by $\sim 60 \%$. Without the floor-based exhaust system, the pollutant exposure for the seat-based and overhead exhaust systems was found to reduce by $65 \%$ and 90\%, respectively. Another CFD-based simulation study by Dygert and Dang validated the same findings[141]. Yang et al. studied the impact of ceiling mounted nozzles ( $D=350-500 \mathrm{~mm}$ ) on a seated thermal mannequin [70]. The nozzles provided airflow affecting the head and shoulders of the mannequin. The results for a flow rate of 8-16 L/s indicated that the body parts exposed to the air coming from the top experienced $\mathrm{T}_{\text {skin }}$ reductions in the range of $4-6^{\circ} \mathrm{C}$. The head, face, neck and chest were found to be the coolest, while unexposed body parts such as the feet, calves, and rear part of the body experienced minimal thermal reductions. Lower flow rate $(4 \mathrm{~L} / \mathrm{s})$ led to insignificant thermal reductions throughout the body. The best possible results were obtained at $\mathrm{T}_{\text {room }}=23.5^{\circ} \mathrm{C}$ and $\mathrm{T}_{\mathrm{PCS}}=21^{\circ} \mathrm{C}$. 


\subsubsection{Simulation Studies}

Gao and Niu studied a PCS device with an under-chin air terminal ( $\mathrm{D}=80 \mathrm{~mm})$ through CFD simulations [116]. The circular air terminal was placed at the distance of $\sim 100 \mathrm{~mm}$ under the nostrils and supplied with flow rates in the range of 0.1-3 L/s. The simulation results indicated that at $\mathrm{T}_{\text {room }}=24^{\circ} \mathrm{C}$ and $\mathrm{T}_{\mathrm{PCS}}=20^{\circ} \mathrm{C}$, the inhaled air temperature was found to be the lowest $\left(\sim 26^{\circ} \mathrm{C}\right)$ at the airflow rate of $0.8 \mathrm{~L} / \mathrm{s}$, while the Personalised Air Utilisation Efficiency (PAUE) was found to be the highest $(\sim 16 \%)$ at the airflow rate of $0.6 \mathrm{~L} / \mathrm{s}$. A higher airflow rate resulted in a sharp decrease in the PAUE - which was the lowest $(\sim 2 \%)$ at the highest simulated airflow rate of $3 \mathrm{~L} / \mathrm{s}$. Given a local air terminal device, the PCS was found to impact the $\mathrm{T}_{\text {skin }}$ of the facial region, with a minimal impact on the other body parts. To further the understanding on the theme, Gao and Niu performed additional experiments by changing the turbulence model from a standard k-epsilon turbulence model to an RNG (Re-Normalisation Group) k-epsilon model and applying 'enhanced wall treatment' [117]. Rest of the boundary conditions were the same as the former study. The results indicated that the Pollution Exposure Reduction (PER) index was found to increase by $\sim 15 \%$ with a $2^{\circ} \mathrm{C}$ decrease in $\mathrm{T}_{\mathrm{PCS}}$. The increase in airflow rate by twice also resulted in an increase in PER by $\sim 27 \%$. However, the change in turbulence intensity of the supplied PCS flow by $10 \%$ resulted in a negligible change in the PER. In another study, the same authors utilised the same setup to study the transport of pollutants in an aircraft cabin in combination with MV [93]. The simulation results found that the transport of pollutants from a simulated subject (through sneezing) could result in deposition at various points $-30-40 \%$ of the pollutants were found to be deposited on the other subjects' bodies. This fraction was found to be reduced by $60 \%$ due to the action of chin-based PCS strategy as discussed in the previous two studies.

$\mathrm{Li}$ et al. studied the cases of the aforementioned under-chin PCS device and a desk-based PCS used by Melikov et al. through CFD simulations [14],[94]. The latter PCS comprised of HDG, VDG, CMP, and MP. The two PCS strategies operated at $\mathrm{T}_{\mathrm{PCS}}=20$ and $25^{\circ} \mathrm{C}$ and were used in tandem with MV and DV strategies operated at $\mathrm{T}_{\text {room }}=20$ and $18^{\circ} \mathrm{C}$ respectively. The study analysed the pollutant concentration due to the independent PCS operation of a simulated contaminating subject and a healthy subject. The results found that the PCS operation reduced the extent of cross contamination - a higher flow rate was favourable. In DV, when both the contaminating and the healthy subjects used the PCS, the exposure to pollutants increased for the adjacent healthy subject, but the IF remained the same. Whereas, PCS operation by either of the subjects under MV did not contribute to any increase in either the exposure or the IF of the pollutant. Naiping and Jianlei studied the case of an under-chin PCS device to provide humidified air and help increase the air quality and thermal comfort in aircraft cabins [95]. The CFD-simulation based study modelled the same PCS setup as used by Gao and Niu [116]. The simulations indicated that the PCS based device maintained the Predicted Mean Vote (PMV) of the breathing zone in the comfortable range of -0.6 to +0.5 . The mass fraction of the pollutant decreased by $\sim 50 \%$ with the PCS operation for particles of all sizes. The supply RH of $40 \%$, upon reaching the subject's face was reduced to $\sim 30 \%$, in the ambient RH of $10 \%$, thereby achieving a comfortable moisture level in the inhaled air.

Adamu et al. studied the airflow within individual hospital rooms using dynamic thermal simulation and CFD [124]. They showed that the direct delivery of conditioned air into the subjects' breathing zone is possible through buoyancy driven natural ventilation. They assessed the contaminant removal efficiency of the three cases of the wall and ceiling-mounted air inlets, with a $3000 \mathrm{~mm}$ high ceiling-mounted natural exhaust. The results indicated that the studied cases could be used for 8 months of the year without the need for additional heating, within a $\mathrm{T}_{\text {room }}$ range of $18-28^{\circ} \mathrm{C}$. The case with the air supply right above the patients' breathing zone was found to be the best in regard to prioritising the ventilation for immune-suppressed patients. They also found the buoyancy-driven natural ventilation to be effective in ventilating the space. Yang and Sekhar studied the two cases of ceiling and wall mounted personal air terminals using CFD simulations [142]. Nine ceilingmounted circular $(D=40 \mathrm{~mm})$ terminals provided air at $5.04 \mathrm{~m} / \mathrm{s}$, while the 6 wall-mounted rectangular inlets $(200 \times 100 \mathrm{~mm})$ provided PCS air at $0.48 \mathrm{~m} / \mathrm{s}$. The ambient air inlets $(600 \times 600 \mathrm{~mm})$ constantly provided $0.8 \mathrm{~m} / \mathrm{s}$ velocity air for both the cases. The results indicated that the rectangular air terminals distributed the fresh air throughout the room, instead of confined spaces. The personalised exposure was found to be the highest at the height of $1600 \mathrm{~mm}$ from the floor level - close to the breathing space of the subjects. They also found that as the subject moved through the room, the exposure to conditioned air varied insignificantly - i.e. the personalised air distribution was homogeneous throughout the room.

Yang and Sekhar studied the air velocity and percentage of fresh air provided with the help of PCS nozzles through CFD simulations and field measurements [143]. They simulated two cases of PCS nozzles ( $D=50 \mathrm{~mm})$, 
oriented at the angles of $45^{\circ}$ and $90^{\circ}$ to the ceiling surface, which carried the PCS air from the ceiling-mounted air supply to the subject, and compared these cases to the base case (without a PCS nozzle). They found that the simulated cases provided conditioned air to the subjects without causing an excessive draught. The salient features of the devised PCS systems included a longer fresh air jet, small blade angle of the recirculated air and high fresh air inlet velocity. Additionally, they concluded that manoeuvrability of the supply nozzle at various angles could help increase the adaptability of the system. Pang et al. studied the movement of air in an aircraft cabin due to the effect of seat mounted PCS devices through 'flow visualisation with green laser' and CFD simulations [144]. They tested various configurations of air inlet and outlet to find that the 'top-in, side-bottom out' approach was not efficient as it supplied the conditioned air to the subjects through an indirect path. Instead, a 'bottom-in, top-out' approach helped achieve a higher fresh air utilisation with direct air supply to the breathing zone and had a low potential of contaminant spread. The simulation results indicated that optimising the supply air angle (by $10^{\circ}$ towards the subject's face) would result in a significantly improved performance and require a lower air supply. The pollution exposure effectiveness of the optimized setup was found to be in the range of $80-95 \%$, while the other simulated cases were found to be $\leq 50 \%$.

Yang and Sekhar studied the impact of ceiling mounted PCS in combination with the effect of moving person using CFD simulations [145]. The nine symmetrically mounted PCS terminals had a diameter of $50 \mathrm{~mm}$ each and the modelled subject was placed right beneath one of the terminals. The ambient air terminal had the dimensions of $600 \times 300 \mathrm{~mm}$ and supplied air at the velocity of $0.65 \mathrm{~m} / \mathrm{s}$. The results found that a moving person would affect the breathing zone of a seated subject as he/she reached within $400 \mathrm{~mm}$ of the ATD, beyond that distance, the change in PEE was found to be less than 20\%. The highest level of PEE was found at the height of $1600 \mathrm{~mm}$ from the floor (in the breathing zone for a standing subject) and an increase in the moving velocity did not cause a significant change in the PEE.

\subsection{Mechanical Fans}

\subsubsection{Laboratory Studies with Subjects}

Arens et al. studied the impact of pedestal fans on thermal sensation, preference, and air movement preference of human subjects in controlled conditions through surveys [118]. The fan used in the study supplied air in a pattern similar to 'naturally fluctuating outdoor wind' as well as at 'constant velocity'. The subjects could choose the fan speed and direction. The results indicated that subjects experienced comfortable thermal conditions up to $\mathrm{T}_{\text {room }}=31^{\circ} \mathrm{C}$ upon the supply of airflow at $1 \mathrm{~m} / \mathrm{s}$ or more for sedentary activity levels. The subjects preferred a constant airflow over a fluctuating one as the latter led to distraction, disturbed hair, and eye irritation. Schiavon et al. also studied the impact of pedestal fans on human subjects in tropical climates in controlled conditions [146]. The fans supplied air $(0.5-2.5 \mathrm{~m} / \mathrm{s})$ to the seated subjects at $\mathrm{T}_{\text {room }}=23,26,29^{\circ} \mathrm{C}$. The subjects preferred the air movement at the elevated temperatures in comparison to at $23^{\circ} \mathrm{C}$. Given that the subjects were tropically acclimatised, most of them preferred their thermal ambience at $26^{\circ} \mathrm{C}$ (both with and without the fan) in comparison to that of $23^{\circ} \mathrm{C}$. Barwood et al. studied the cooling effect of a whole-body fan and a face-oriented fan on human subjects at high metabolic states in hot and humid conditions at a core temperature of $38.5^{\circ} \mathrm{C}$ [56]. Seated at a distance of $1200 \mathrm{~mm}$, the whole-body and face-oriented fans provided the air in the velocity ranges of 3.5-3.8 m/s and 2-2.5 m/s respectively. The whole-body flow was separated from the face flow with the help of a flexible mat. The results indicated that the whole-body fanning led to a $\sim 0.7^{\circ} \mathrm{C}$ reduction in the $\mathrm{T}_{\text {core }}$ within 15 minutes of operation, while the $\mathrm{T}_{\text {skin }}$ experienced a reduction of $\sim 2^{\circ} \mathrm{C}$. The study did not present the results for face-fanning but concluded that its effect could have been negligible due to the action of other cooling methods.

Kubo et al. studied the effects of a $(1400 \times 70 \mathrm{~mm})$ whole-body fan on human subjects in various ambient conditions in a controlled environment [125]. The fan, placed at $\sim 1000 \mathrm{~mm}$ away from the subject could be controlled as per the subject's comfort. The results indicated that the subjects preferred higher air speeds with an increase in $\mathrm{T}_{\text {room }}$ and $\mathrm{RH}$. For instance, when the $\mathrm{RH}$ varied from $50 \%$ to $80 \%$ at $\mathrm{T}_{\text {room }}=30^{\circ} \mathrm{C}$, the preferred air velocity changed from $1.07 \mathrm{~m} / \mathrm{s}$ to $1.27 \mathrm{~m} / \mathrm{s}$. In general, an increase in the $\mathrm{T}_{\text {room }}$ by $2{ }^{\circ} \mathrm{C}$ could be balanced by increasing the air velocity by $0.2 \mathrm{~m} / \mathrm{s}$ (with $0.5 \mathrm{~m} / \mathrm{s}$ as the base velocity). The subjects were found to be comfortable at a 'slightly cool' sensation created at elevated air velocities. As a recommendation, the study indicated the older subjects (age>60 years) to operate the fans at $0.2 \mathrm{~m} / \mathrm{s}$ lower than the conventional air speeds. Pasut et al. studied the effects of various configurations of a ceiling-mounted oscillating fan on human subjects in controlled conditions [135]. The three positions were such that the subject was in the front, side, and beneath the ceiling mounted fan for each case. They tested the subjects for thermal comfort, sensation, acceptability and 
air quality/movement parameters with questionnaires. The results found that the oscillating fan did not have a statistically significant impact on the subject's thermal comfort and sensation at $\mathrm{T}_{\text {room }}=28^{\circ} \mathrm{C}$. However, a nonoscillating, constant-velocity fan, providing air at $\sim 0.8 \mathrm{~m} / \mathrm{s}$ led to improved thermal sensation, comfort, and acceptability. The air quality acceptability was found to be independent of the thermal acceptability of the subjects - they reported to be satisfied with the air quality while being dissatisfied with the thermal conditions even at low air velocities $(\sim 0.2 \mathrm{~m} / \mathrm{s})$. Additionally, the fans did not contribute to any sort of discomfort like dryeyes at the air speed of up to $0.9 \mathrm{~m} / \mathrm{s}$.

Rohles studied the impact of ceiling fans on subjects at various ambient conditions in a controlled environment [119]. He marked the thermal sensation, comfort, and preference in addition to the air quality responses through questionnaires. The ceiling fan $(\mathrm{D}=1320 \mathrm{~mm})$ was at a height of $\sim 1800 \mathrm{~mm}$ from the subjects. Over $75 \%$ of the subjects were found to be comfortable at $\mathrm{T}_{\text {room }}=29.4^{\circ} \mathrm{C}$ due to the fan operation at velocities $>0.25 \mathrm{~m} / \mathrm{s}$; in comparison, only $50 \%$ subjects were found to be comfortable in the control case (without the fan operation). However, at $\mathrm{T}_{\text {room }}=24.4^{\circ} \mathrm{C}$, the highest fan speed was found to be the most uncomfortable (40\% subjects comfortable), while the control case was the most comfortable ( $70 \%$ subjects comfortable). The air quality also followed the same trend. Yang et al. studied a ceiling-mounted PCS which supplied conditioned outdoor air to improve the thermal comfort and air quality/movement around the seated subjects in controlled conditions [69]. The subjects could not control the velocity or direction of the supplied air and provided responses on their thermal sensation, comfort, air quality and movement through questionnaires. The results indicated that the subjects preferred the airflow in the range of $4-8 \mathrm{~L} / \mathrm{s}$ in a majority of the cases, the results also indicated that $\mathrm{T}_{\mathrm{PCS}}$ had a more pronounced effect on the subject at low PCS airflow rates in comparison to the $\mathrm{T}_{\text {room. }}$ The inhaled air was perceived to be cooler at higher flow rates and lower $\mathrm{T}_{\mathrm{PCS}}$, and therefore improved the PAQ. Interestingly, the rate of improvement of PAQ in reference to flow rate was constant throughout all the studied combinations of $\mathrm{T}_{\text {room }}$ and $\mathrm{T}_{\mathrm{PCS}}$. As a recommendation, the study motivated the ambience to be maintained at $\sim 26^{\circ} \mathrm{C}$ with the PCS operating at a $2-3^{\circ} \mathrm{C}$ lower temperature at flow rates of $4-8 \mathrm{~L} / \mathrm{s}$ and the subjects having the control of the direction and flow rate.

Zhai et al. studied the impact of pedestal fans on human subjects through questionnaire based surveys in controlled warm-humid ambient conditions [126]. The fans were placed $1500 \mathrm{~mm}$ away from the subjects and the air speeds could be controlled as per their preferences. The results indicated that the fans were able to keep over $80 \%$ of the subjects comfortable at $\mathrm{T}_{\text {room }}=30^{\circ} \mathrm{C}$ and $\mathrm{RH}=60 \%$, while keeping the air quality in the acceptable range for $\mathrm{T}_{\text {room }}=30^{\circ} \mathrm{C}$ and $\mathrm{RH}=80 \%$ without leading to any symptoms like eye dryness. The amount of time taken for the subjects to experience the effect of the PCS assembly was as low as 5 minutes. Despite the appreciable conclusions, the subjects were not acclimatised to the experimental chamber prior to conducting the experiment, which could lead to varying inferences when replicated in a real-world scenario. As an extension of the same set of subjects and methodology, Zhai et al. studied the impact of ceiling fans in another study [127]. The ceiling fans were placed directly overhead the seated subjects at a height of $\sim 2000 \mathrm{~mm}$. The subjects were found to be comfortable at the head level at $\mathrm{T}_{\text {room }}=30^{\circ} \mathrm{C}$ and $\mathrm{RH}=80 \%$ with the PCS supply velocity at $1.2 \mathrm{~m} / \mathrm{s}$. The air quality was also maintained in the acceptable range (80\% satisfaction) across all the air velocities; in comparison, the air quality without the fans led to $\sim 40 \%$ satisfaction at $\mathrm{T}_{\text {room }}=30^{\circ} \mathrm{C}$.

He et al., in their review of fan usage in field and lab settings found that they were capable of increasing the average neutral temperature by $\sim 3^{\circ} \mathrm{C}$ [147]. They also found that the usage of fans reduced the use of air conditioners in buildings operating on mixed-mode ventilation by $\sim 20 \%$. Zhou et al. studied the response of human subjects to the fluctuating variation of airflow in controlled conditions [128]. The subjects were seated at a distance of $1700 \mathrm{~mm}$ along the central axis of the full-body fan. They studied three cases - constant airflow, simulated natural airflow, and sinusoidal airflow and distinguished between them on the basis of their calculated 'turbulence amplitude'. The surveys indicated that the dynamic airflows with a higher turbulence amplitude were found to be cooler by the subjects, and led to a greater extent of thermal comfort. The dynamic flows also led to fewer instances of draught-induced discomfort and eye-dryness. The subjects preferred a constant airflow at $\mathrm{T}_{\text {room }}=26^{\circ} \mathrm{C}$, while at $\mathrm{T}_{\text {room }}=30^{\circ} \mathrm{C}$, the simulated natural airflow was more widely acceptable.

\subsubsection{Laboratory Study with Mannequins}

Yang et al. studied the impact of pedestal fans on a thermal mannequin in controlled conditions through skin temperature measurements [120]. The pedestal fan was a 3-phase brushless DC fan, which could be operated on six speed settings and was placed $\sim 1 \mathrm{~m}$ away from the mannequin. The various cases of experiments studied the multiple orientations of the mannequin subjected to various fan settings in multiple ambient thermal conditions. 
The measured $\mathrm{T}_{\text {skin }}$ revealed that the body parts directly exposed to the airflow experienced a greater extent of cooling $\left(2-4^{\circ} \mathrm{C}\right)$ when comparing between the 'front' and 'side' seating orientations of the mannequin. However, there was no statistical difference between the calculated cooling efficiency for the two cases. The $T_{\text {skin }}$ reduction was directly proportional to the fan speed whereas it was inversely proportional to the ambient air temperature. The cooling efficiency of the fan, when the mannequin was placed at a $1000 \mathrm{~mm}$ distance was $\sim 0.35$, while at a $2000 \mathrm{~mm}$ distance, it reduced to $\sim 0.21$.

\subsubsection{Simulation Study}

Ho et al. conducted a CFD-based simulation study on the effect of a ceiling fan on a numerical model of a human [109]. The operation of fans at various speeds $(1.1-1.5 \mathrm{~m} / \mathrm{s})$ and $\mathrm{T}_{\text {room }}\left(23.4-25.2^{\circ} \mathrm{C}\right)$ and elevated $\mathrm{RH}$ levels $(75-84 \%)$. The results indicated that the PMV, in the control case (without fan operation) was close to 0 (neutral), the operation of fan provided additional cooling and reduced the PMV further in the range of - 0.3 to 0.4. The fan, therefore was found to lead to 'overcooling' to the extent of creating discomfort.

\subsection{Seats}

\subsubsection{Laboratory Studies with Subjects}

Sun et al. studied the impact of a seat-based PCS on human subjects in controlled conditions [110]. The four fans $(D=80 \mathrm{~mm}$ each), mounted at the edges of a seat, redirected the cooler air (supplied using floor based ventilation system) towards the subject. The subjects could control the speed of the fans as per their comfort. The local thermal sensation of the case with the fan operation was found to be significantly on the cooler side the waist, arms, and hands were found to be the most affected body parts, while the head, back, chest, and lower legs were not affected at all. At $\mathrm{T}_{\text {room }}=26^{\circ} \mathrm{C}$, the overall thermal sensation was found to reduce by $\sim 1$ sensation vote towards the neutral side, thus indicating the efficiency of the PCS system. The study conclusively recommends the velocity ranges of $0-0.5 \mathrm{~m} / \mathrm{s}$ (at $22^{\circ} \mathrm{C}$ ), $0.5-1.2 \mathrm{~m} / \mathrm{s}$ (at $24^{\circ} \mathrm{C}$ ), and $1.2-1.9 \mathrm{~m} / \mathrm{s}\left(\right.$ at $26^{\circ} \mathrm{C}$ ). Watanabe et al. studied two cases of a seat-type PCS device embedded with fans of two sizes $(\mathrm{D}=110,75 \mathrm{~mm})$ ) on human subjects in controlled conditions [129]. The fans were embedded in the seat and backrest, and their flow rates could be controlled by the subjects as per their comfort. The results indicated that the thermal sensation for seat $A(D=110 \mathrm{~mm})$ was on the cooler side in comparison to the seat $B(D=75 \mathrm{~mm})$ and a control seat with no fans - this change was most prominent at $\mathrm{T}_{\text {room }}=30^{\circ} \mathrm{C}$. The thermal sensation of subjects at seat $\mathrm{B}$ was found to be similar to that of the control seat, with insignificant differences at higher $\mathrm{T}_{\text {room }}$. The seat $\mathrm{A}$, with the larger fans, was found to be more comfortable and acceptable by the subjects - at $\mathrm{T}_{\text {room }}=30^{\circ} \mathrm{C}, 100 \%$ of the subjects found their thermal ambience 'acceptable' when seated on seat A, in comparison to the $85 \%$ for case B and $55 \%$ for control case. The seat was able to effectively cool the back and lower back, while maintaining a high thermal sensation for the body parts not in contact with the seat. The seat was, however, not found to be efficient when $\mathrm{T}_{\text {room }}$ was beyond $30^{\circ}$. In a field-based study, Kim et al. studied the effect of a subject-operated PCS seat on the thermal comfort through surveys [10]. The seat had embedded fans for cooling and was found to result in over $96 \%$ of comfort satisfaction in the $\mathrm{T}_{\text {room }}$ range of $21.9-25.3^{\circ} \mathrm{C}$. The subjects found the preferred air temperature to be $23^{\circ} \mathrm{C}$ with the PCS in use.

\subsubsection{Laboratory Studies with Mannequins}

Jacobs and Gids studied headrest mounted PCS device in an aircraft cabin providing conditioned air to the breathing space, parallel to the cheeks of thermal mannequins in controlled conditions [111]. They tested the effectiveness of this PCS system using a tracer gas setup to understand the movement of polluting particles. The concentrations were found to vary with time, as per the varying ventilation efficiency of the device. The concentration reduction for seats at various positions was found to be in the range of 57-97\%, with the highest reduction for the seat farthest from the aisle, and the lowest for the seat next to the aisle. On prolonged seating, the seat temperature was found to reach as high as $36^{\circ} \mathrm{C}$ (close to the $\mathrm{T}_{\text {core }}$ ), to resolve this, they tested an exhaust mechanism by placing an exhaust plenum in the seat, between the layers of seat cloth and foam. When operated (at $2 \mathrm{~L} / \mathrm{s}$ ), the exhaust mechanism led to thermal reductions of up to $2{ }^{\circ} \mathrm{C}$ between the subject and the seat, and contributed to local comfort (at buttocks and upper thighs) with control of bodily odours. Madsen studied the impact of a ventilated car seat on the skin temperature of a thermal mannequin in controlled conditions [105]. The seat consisted of ventilation tubes with a layer of animal bristles and a cloth cover and operated at ventilation rates in the range of 1.9-5.8 L/s. The results indicated that the heat loss from the back and thighs increased significantly $(100-150 \%)$ as the seat was put into use at the flow rate of $1.9 \mathrm{~L} / \mathrm{s}$. However, increasing the flow rate beyond $2.8 \mathrm{~L} / \mathrm{s}$ up to5.8 L/s led to an insignificant change in the heat loss and therefore 
should be avoided. He also found that the operation of seat-based ventilation while the subject is sweating, tremendously increased the heat loss by $\sim 250 \%$ and led to local $\mathrm{T}_{\text {skin }}$ reductions in the range of $10-12^{\circ} \mathrm{C}$.

\subsubsection{Simulation Study}

Zitek et al. studied the case of seat-based PCS device used in combination with ceiling-based ventilation in an aircraft cabin through CFD simulations [106]. The PCS unit was modelled to be placed at the back of a seat - it included a supply nozzle $\left(\mathrm{CSA}=6000 \mathrm{~mm}^{2}\right)$ at the face level and an exhaust nozzle at the waist level to maintain a continuous cycle of fresh air exchange. The velocity of the air supply plume near the subject's face did not exceed $0.2 \mathrm{~m} / \mathrm{s}$. More detailed simulations, including the exhalation of the thermal mannequin indicates that the airflow might be able to restrict the possibility of cross-contamination. They also concluded that the RH of the airflow could be regulated to keep the subject's breathing space appropriately humid, while maintaining dry cabin conditions.

\subsection{Garment}

Barwood et al. studied the effect of an air cooled garment on human subjects post exercise in controlled conditions [56]. The garment covered the torso and had a fan on the front and back which distributed the ambient air inside the garment. The garment was affixed to the subject's body using Velcro straps and weighed $1 \mathrm{~kg}$. With a 15 -minute operation, the garment was found to reduce the $\mathrm{T}_{\text {core }}$ by $\sim 0.3^{\circ} \mathrm{C}$. With a 30 -minute operation (including a 15-minute exposure to ventilation), the $\mathrm{T}_{\text {core }}$ as well as the overall $\mathrm{T}_{\text {skin }}$ were found to be reduced by $\sim 1^{\circ} \mathrm{C}$. A reduction by $\sim 1^{\circ} \mathrm{C}$ in the overall $\mathrm{T}_{\text {core }}$ and $\mathrm{T}_{\text {skin }}$ is substantial and is likely to cause overcooling. However, given the subjects' $\mathrm{T}_{\text {core }}$ and $\mathrm{T}_{\text {skin }}$ were high at first, due to the increased metabolic rate caused because of exercise, these results are not applicable when the subjects are involved in light activity or are at rest.

Yi et al. studied various types of air cooled garments for their cooling performance, work duration, and airflow rates using a thermal mannequin [136]. They found that the typical battery operated garments could operate for 4-7 hours, however, when operated at a 60\% output power, their duration could be extended up to 18 hours. They typically handled air flows in the range of 8-22 L/s, and provide a cooling power of 50-68 W. It was also found out, that as the battery levels of the garment reduced, the airflow was also found to reduce linearly. Sakoi et al. also studied a ventilated garment under controlled conditions [148]. The garment included a water supply through a portable bottle and an embedded fan. The water was supplied to the exterior surface of the underwear of the subject through hollow tubes and the fan embedded on the external garment facilitated airflow between the inner surface of the garment and the underwear, causing evaporative cooling. The subjects could operate the embedded fan at the two speed settings of medium and strong. The tests were conducted at $\mathrm{T}_{\text {room }}=29^{\circ} \mathrm{C}$ and two RH values of $40 \%$ and $60 \%$. The subjects were found to have a close to neutral sensation (between 0 to -1 sensation votes) for $\mathrm{RH}=40 \%$, while it was above 1 sensation vote, for the case with $\mathrm{RH}=60 \%$.

\section{Effectiveness of PCS in achieving energy savings}

The energy and power aspects of PCS can be divided into two main parts. The first part is the effects of PCS on building (HVAC system) energy use and the second part is the energy use and power requirements of the PCS itself. These two aspects are strongly related. The studies discussed in the following are studies in which the energy saving potential was not only mentioned but also quantified.

Even though, it is not the main function of PCS to be an energy saving component and most of the studies do not specify the main function of PCS as energy savings, several studies point out the energy saving potential of PCS, when applied properly. The growing consciousness about climate and the effect of energy efficient building components has also brought a strong motivation from the industry in order to achieve energy savings in all ways possible. For PCS, these energy savings are mainly due to the following:

- Flexibility in space heating and cooling temperature setpoints (possibility of extended setpoints compared to traditional systems such as extending the room temperatures below $20^{\circ} \mathrm{C}$ in the heating season and extending the room temperatures above $26^{\circ} \mathrm{C}$ in the cooling season - these temperatures follow Category 2 of EN 15251:2007 [149]);

- Lowered supply airflow rates into the space (for personalized ventilation systems);

- Possibility of reduced capacities of the heating and cooling plants for the ambient control systems. Some studies also mention the possibility of supplying air only when occupants are at their workstations as one of the reasons for energy savings [150], [151]. 
As early as in 1979, Lund Madsen and Saxhof reported on a personalized heating system (a heated seat) [5]. In this study, the authors showed that a setpoint change of $1 \mathrm{~K}$ in the room temperature would correspond to an energy saving of about 10\% (for the heating mode). Seem and Braun identified the possibility of increased energy use due to the use of PCS. The authors found that the effects of PCS could range between $7 \%$ saving and $15 \%$ increase in the building HVAC and lighting energy use [152]. However, the authors also argue that about a $0.08 \%$ increase in worker productivity associated with PCS can offset the energy increase of $15 \%$. Heidarinejad et al. also found that the use of personalized conditioning could result in a $7 \%$ energy increase, mainly due to the increase in the internal equipment energy [153].

Bauman et al. showed that a desktop PCS system could save annually up to $18 \%$ of the cooling energy and distribution energy (fans and pumps), $10 \%$ of the total electricity use and $9 \%$ of the total electricity cost in the climate conditions of San Jose, CA, USA, compared to an overhead air distribution system [68]. Glicksman and Taub showed that a properly designed, occupant-controlled HVAC system could reduce energy use by 5-16\% (savings up to $20 \%$ if the lighting and plug loads are considered as well) [154]. The authors also identified an energy increase due to non-uniform temperatures around $10 \%$, but concluded that this effect was not enough to counteract the savings. Sekhar et al. compared the energy use of a personalized ventilation system to a conventional system (ceiling supply mixing ventilation system) [65]. The authors identified that the energy savings were mainly due to higher background temperatures and the reduction in the total amount of air supplied. They showed energy savings of $15 \%$ and $30 \%$ compared to the conventional system depending on the total ventilation rates (energy savings refer to the saving on the cooling coil in the air-handling unit).

Schiavon and Melikov studied the effects of increased air movement, which can be provided by fans or by other personalized means, on energy use and showed cooling energy savings between 17 and 48\%, and maximum cooling power reductions between 8 and 22\% [146]. These numbers are not applicable in real air conditioned buildings since the comparison case used in the study is idealistic. They also showed that there is a critical value of fan power if energy savings are to be achieved. They showed that under the conditions of their study, there is always energy savings for a fan power lower than $15 \mathrm{~W}$. It was not possible to save energy if the fan power was higher than $60 \mathrm{~W}$. Under the most common values of COP and system losses the authors assumed, the fan power had to be below $20 \mathrm{~W}$ if energy savings were to be achieved.

Schiavon and Melikov also studied the possibility of energy savings with personalized ventilation in cold climates and they showed that if energy saving strategies are not applied, the energy use might increase by 61 to $268 \%$ compared to the reference case (mixing ventilation supplying air with constant temperature all year) [150]. Schiavon et al. also studied the energy performance of personalized ventilation in hot and humid climates [151]. They showed that the use of personalized ventilation could lead to energy savings up to $51 \%$ compared to the reference case with mixing ventilation (savings vary between 1 and 36\%, and between 25 and $51 \%$ depending on the occupancy profiles). Zhang et al. showed that a PCS assisted HVAC system uses between 17 to $65 \%$ less seasonal energy [39]. They also showed $40 \%$ and $30 \%$ annual HVAC energy savings for different ambient temperature ranges of 18 to $30^{\circ} \mathrm{C}$ and 20 to $28^{\circ} \mathrm{C}$, respectively.

Chakroun et al. showed that the integration of a personalized evaporative cooler with a chilled ceiling and displacement ventilation system could reduce energy use by $18 \%$ compared to a chilled ceiling and displacement ventilation system alone [155]. Additional savings of $25 \%$ were possible if there was recirculation instead of $100 \%$ fresh air supply. Makhoul et al. showed that personalized ventilation may reduce energy use by $27 \%$ when used in combination with displacement ventilation, compared to displacement ventilation alone [97]. Vesely and Zeiler, in their review of 77 studies, pointed out that the energy savings potential of different personalized conditioning systems was in the range of 4 to $60 \%$ [17]. The authors also concluded that for cooling, the energy saving potential is between 4 to $51 \%$, when the cooling setpoint is increased by 2.5 to $6^{\circ} \mathrm{C}$. The authors also indicate that the number of studies that deal with personalized heating is much lower than the cooling cases. Verhaart et al. showed that personalized heating can save up to $34 \%$ of HVAC energy use during winter [33].

Zhang et al. suggests a generic value of $10 \%$ HVAC system energy savings per K setpoint relaxation in both heating and cooling conditions (this same relation was shown by Lund Madsen and Saxhof earlier in a 1979 study for heating condition [5], [22]). Although it is clear that this is a generic suggestion, it should be noted that the actual value would be different depending on several factors such as system type, building type and usage, climate, and so forth. He et al. showed that a heated seat could save $61 \%$, and a combination of a heated seat and leg warmers could save $71 \%$ of the heating energy [156]. 
The majority of the studies confirm that the use of PCS can result in significant HVAC system energy use savings (even though the values of possible energy savings given in the literature vary in a large range). However, several studies also point out that if PCS is not designed and operated correctly, there will be increased energy use instead of the intended energy savings. Since most of the studies focused on the thermal comfort and air quality aspects of PCS, there has been little focus on the power use of the PCS itself. Table 6 summarizes the power requirements of different PCS found in literature.

Table 6. Power requirement of various PCS devices

\begin{tabular}{|c|c|c|}
\hline Study & PCS device & Power requirement of the $\mathrm{PCS}$ \\
\hline$[157]$ & Localized floor heating & Between 112 and $474 \mathrm{~W}$ depending on the configuration \\
\hline$[156]$ & $\begin{array}{l}\text { Heating chair assisted } \\
\text { by leg-warmer }\end{array}$ & $\begin{array}{l}\text { Maximum heating power of the heating chairs was } 55 \mathrm{~W} \text { and } \\
\text { maximum heating power of the leg-warmers was } 80 \mathrm{~W}\end{array}$ \\
\hline$[42]$ & $\begin{array}{l}\text { Heating and cooling } \\
\text { chair }\end{array}$ & $\begin{array}{l}\text { Measured power was } 42 \mathrm{~W} \text { at maximum heating and } 74 \mathrm{~W} \text { at } \\
\text { maximum cooling. Average values were } 27 \mathrm{~W} \text { in heating and } 45 \mathrm{~W} \\
\text { in cooling operation. }\end{array}$ \\
\hline$[158]$ & $\begin{array}{l}\text { Portable personal } \\
\text { conditioning system }\end{array}$ & $\begin{array}{l}\text { Average power required by different cooling options was between } \\
14.7 \text { to } 56 \mathrm{~W} \text {. }\end{array}$ \\
\hline$[159]$ & Heating chair & $\begin{array}{l}\text { Heating pads in the backrest and in the chair (up to } 30 \mathrm{~W} \text { can be } \\
\text { used by each pad) }\end{array}$ \\
\hline$[160]$ & $\begin{array}{l}\text { Personal heating and } \\
\text { cooling system }\end{array}$ & $\begin{array}{l}\text { Power requirements were } 3.5 \mathrm{~W} \text { for the control (actuation box, } \\
\text { control circuit, etc.), between } 8 \text { to } 15 \mathrm{~W} \text { for the fan (depending on } \\
\text { the speed), and } 700 \mathrm{~W} \text { for the heating coil }\end{array}$ \\
\hline [19] & $\begin{array}{l}\text { Radiant cooling desk } \\
\text { and desk fans }\end{array}$ & Desk fans required 2 or $3 \mathrm{~W}$ depending on the speed \\
\hline$[35]$ & Warm-barrel (huotong) & $\begin{array}{l}\text { Power up to } 1000 \mathrm{~W} \text {. Average power was between } 53.4 \text { to } 165.6 \mathrm{~W} \\
\text { per person. }\end{array}$ \\
\hline$[161]$ & Cooling chair & $\begin{array}{l}\text { Two fans in the armrests required } 3.6 \mathrm{~W} \text { each and the fan in the seat } \\
\text { required } 1.4 \mathrm{~W} \text { (total of } 8.6 \mathrm{~W} \text { ) }\end{array}$ \\
\hline [85] & Local cooling & Fans required $2.5 \mathrm{~W}$ (USB fan) and $40 \mathrm{~W}$ (large desk fan) \\
\hline$[55]$ & $\begin{array}{l}\text { Various personalized } \\
\text { conditioning systems }\end{array}$ & Personal desktop fan required $30 \mathrm{~W}$ \\
\hline$[5]$ & Heating chair & $\begin{array}{l}\text { Total of } 78 \mathrm{~W} \text { (electric heating elements of } 4 \mathrm{~W} \text { in the seat and in } \\
\text { the backrest, and a } 70 \mathrm{~W} \text { lamp under the seat) }\end{array}$ \\
\hline$[78]$ & $\begin{array}{l}\text { Desktop task } \\
\text { conditioning system } \\
\text { (DTC) }\end{array}$ & $\begin{array}{l}\text { DTC used } 5 \mathrm{~W} \text { when it was deactivated and it used } 20 \mathrm{~W} \text { as a } \\
\text { minimum (all control settings at minimum). The fan used maximum } \\
70 \mathrm{~W} \text {. Task light used maximum } 50 \mathrm{~W} \text {. The heating panel used } \\
\text { maximum } 200 \mathrm{~W} \text {. }\end{array}$ \\
\hline$[162]$ & $\begin{array}{l}\text { Desktop task } \\
\text { conditioning system } \\
\text { (DTC) }\end{array}$ & $\begin{array}{l}\text { Average power use during a day (during occupancy) for four units } \\
\text { was } 337 \mathrm{~W} \text { when controlled by occupancy sensors, compared to a } \\
\text { maximum power use of } 488 \mathrm{~W}\end{array}$ \\
\hline [98] & Personalized ventilation & $\begin{array}{l}9.2 \mathrm{~W} \text { in total (1.4 } \mathrm{W} \times 3 \text { fans for controlling the convection flow } \\
\text { around the human body and } 5 \mathrm{~W} \text { for the supply fan) compared to } 16 \\
\mathrm{~W} \text { that would have been required if there were no control of the } \\
\text { convection flow around the human body }\end{array}$ \\
\hline$[33]$ & Personalized heating & $\begin{array}{l}288 \mathrm{~W} \text { in total (desk heater } 36 \mathrm{~W} \times 3,60 \mathrm{~W} \text { radiation heating bulb } \\
\text { at the neck level and } 120 \mathrm{~W} \text { radiation heating aimed at the feet) }\end{array}$ \\
\hline$[43]$ & $\begin{array}{l}\text { Heating and cooling } \\
\text { chair with desk fan }\end{array}$ & $\begin{array}{l}\text { Maximum } 16 \mathrm{~W} \text { in heating and maximum } 4.8 \mathrm{~W} \text { in cooling mode } \\
(3.6 \mathrm{~W} \text { for the chair and } 1.2 \mathrm{~W} \text { for the desk fan) }\end{array}$ \\
\hline $\begin{array}{l}{[88]} \\
{[137]}\end{array}$ & $\begin{array}{l}\text { Ceiling personalized } \\
\text { ventilation assisted with } \\
\text { desk fan or chair fans }\end{array}$ & $\begin{array}{l}\text { The desk and chair fans had a maximum power of } 10 \mathrm{~W} \text { and the } \\
\text { ceiling personalized ventilation fans had a maximum power of } 15 \\
\text { W }\end{array}$ \\
\hline$[8]$ & Foot warmer & $\begin{array}{l}\text { Maximum power of } 160 \mathrm{~W} \text { (depending on the bulbs selected), on } \\
\text { average between } 3 \text { and } 21 \mathrm{~W} \text {. }\end{array}$ \\
\hline$[39]$ & $\begin{array}{l}\text { Task-ambient } \\
\text { conditioning system } \\
\text { consisting of palm } \\
\text { warmer and heated }\end{array}$ & $\begin{array}{l}\text { The maximum power use of the system was } 41 \mathrm{~W} \text { in cooling }(35 \mathrm{~W} \\
\text { for the head ventilation device and } 6 \mathrm{~W} \text { for the hand cooling device, } \\
2 \mathrm{~W} \times 3 \text { fans }) \text { and } 59 \mathrm{~W} \text { in heating mode }(25.6 \mathrm{~W} \text { for the palm } \\
\text { warmer, } 3 \mathrm{~W} \text { for the heated keyboard, and } 30.8 \mathrm{~W} \text { for the foot }\end{array}$ \\
\hline
\end{tabular}




\begin{tabular}{|c|l|l|}
\hline & $\begin{array}{l}\text { keyboard, foot warmer, } \\
\text { head ventilation device, } \\
\text { and hand cooling device }\end{array}$ & $\begin{array}{l}\text { warmer, although the heating lamp in the foot warmer has a } \\
\text { maximum power of 123 W) }\end{array}$ \\
\hline$[69]$ & $\begin{array}{l}\text { Ceiling mounted } \\
\text { personalized ventilation, } \\
\text { desk fans }\end{array}$ & Power use of each desk fan was $30 \mathrm{~W}$ \\
\hline$[163]$ & Personalized heating & $\begin{array}{l}36 \mathrm{~W}, 80 \mathrm{~W} \text { and } 100 \mathrm{~W} \text { maximum power use for the heated chair, } \\
\text { heated desk mat, and heated floor mat, respectively }\end{array}$ \\
\hline$[152]$ & $\begin{array}{l}\text { Personal environmental } \\
\text { control system }\end{array}$ & $\begin{array}{l}\text { The radiant panel had a maximum power use of 175 W. The power } \\
\text { use of the PEC fan and electronics were } 84 \mathrm{~W}, 66 \mathrm{~W} \text { and } 35 \mathrm{~W}, \text { for } \\
\text { the high, mid, and low settings. }\end{array}$ \\
\hline$[51]$ & $\begin{array}{l}\text { Three different } \\
\text { personalized } \\
\text { conditioning systems }\end{array}$ & $\begin{array}{l}\text { Two of the systems were equipped with 200 W heating elements } \\
\text { (one is a panel standing vertically on the floor and the other one is } \\
\text { attached to the lower side of the desk) }\end{array}$ \\
\hline$[146]$ & Fans & $\begin{array}{l}\text { Ceiling fans }(70 \mathrm{~W}), \text { standing fans (50 W), tower fans (40 W), and } \\
\text { desk fans }(30 \mathrm{~W})\end{array}$ \\
\hline
\end{tabular}

As Table 6 shows, the power requirements of different personal comfort systems vary in a large range, similar to the energy savings indicated by different studies. The optimal system would be the one that has the lowest power use but still able to address the thermal and air quality concerns (personalized systems could include light and acoustic aspects too). It is likely that with the increasing technology, the power requirements of different components of PCS will decrease.

If the energy savings claimed by different studies are to be achieved, the power use of PCS is a crucial parameter to consider together with the control of PCS. Control refers to both the control of PCS itself (on/off, proportional control, user-controlled, occupancy-controlled, automatic control, etc.), but also its interaction and integration with the ambient conditioning system.

\section{Economics of PCS}

Besides the effect on thermal perception and energy use in buildings, the economics of personalized comfort systems is an important aspect to evaluate their potential application beyond research. Still, this dimension is not assessed frequently: in total 188 references were analysed whether they mention the costs of their systems or other aspects related to costs. Out of these studies, only $30(16 \%)$ mentioned costs, which is not surprising given the focus on aspects related to energy and comfort. Figure 4 summarizes the aspects mentioned in these 30 studies. Note that some studies mentioned more than one aspect.

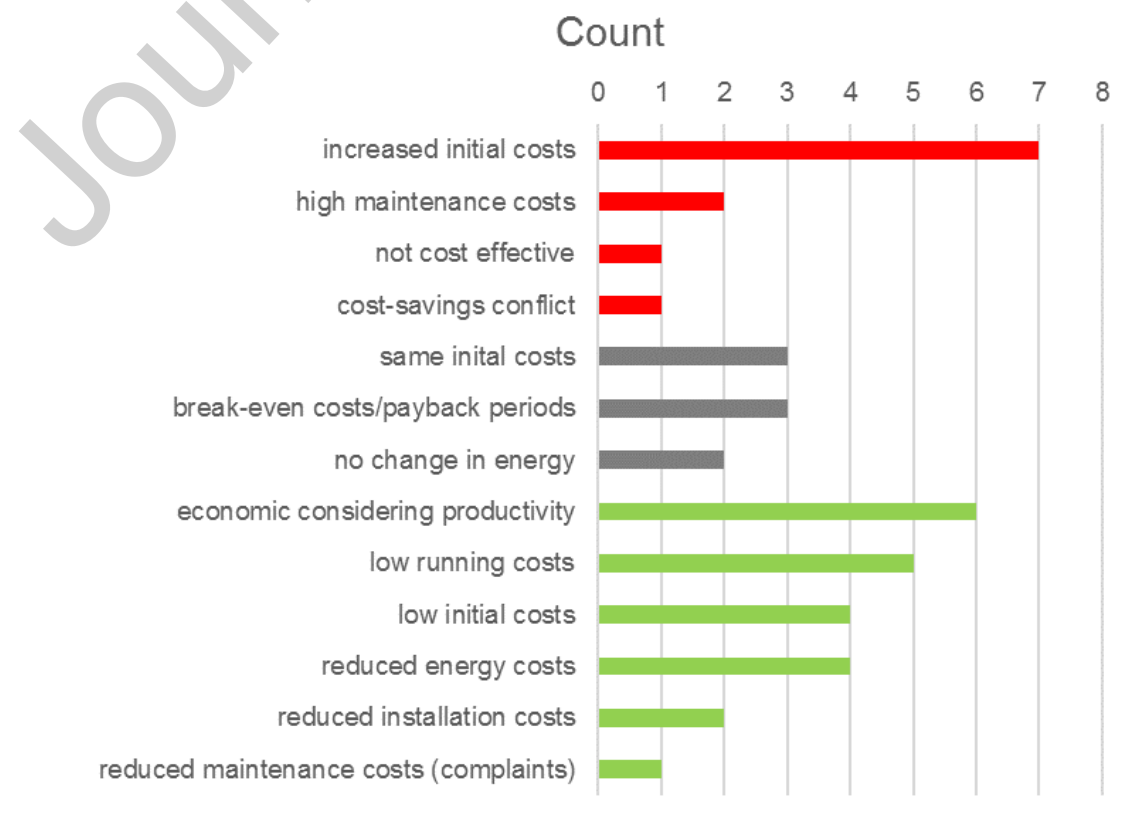


Figure 4. Number of times a cost-related aspect was mentioned in a paper.

The cost-negative aspect mentioned most often was the increased initial costs, which was mainly related to ventilation PCS and their required additional duct work [14], [46], [61], [164], [165], or high costs of individual devices [159], [166]. Additional cost-negative aspects mentioned were high maintenance costs [164], [167], an assumption of non-cost-effectiveness [168], and the conflict between tenants, buying PCS and property owners benefitting from energy savings [22]. The last point is valid solely for areas, where property owners would benefit from energy savings, because e.g. in many countries, tenants are required to pay for their energy and would benefit directly from energy savings.

Three aspects are named which can be considered as neither positive nor negative. No change in initial costs [48], [61], [75] can be realized by careful design of installation and systems, e.g. through ductless ventilation systems [61]. No change in energy costs was accounted to the same ventilation rates with and without personalized ventilation and thereby clearly looking solely at the running energy costs [71], [93]. Few papers conducted payback or break-even-costs analysis concluding that for a given autonomously heated and cooled office seat, the break-even-costs range between 50US\$ and 200US\$ [40] and that the payback period for portable PCS are between 1 year and 6 years [158], [169]. Both break-even-costs and payback periods were analyzed for an US-American context related to energy costs and shown to be highly dependent on the outdoor climatic conditions.

In addition, there are six aspects mentioned, which suggest a positive impact of PCS on costs. Firstly and mentioned most often is a positive overall economic effect when considering the potential increase in workers productivity [75], [162], [164], [165], [167], [170]. Such a relationship was mentioned by few studies, however, in most studies the cost benefits are assumed and the single attempt found by the authors of this review to quantify them, is from the year 1994 and leads to an estimate of minimum 2\% [21]. The example by Kroner and Stark-Martin [21] is based on the number of files processed during a workday in an underwriting department, i.e. a rather simple standardized routine work. Assessing changes in productivity for more complex types of work is a complex task, which is likely the reason for the low number of studies quantifying this type of cost benefits of PCS.

The second aspect stated are low to marginal running costs [35], [109], [160], [171], [172]. All of these studies refer to small devices such as foot warmers, fans, etc. with running costs between $0.5 \$ /$ month [160] to $0.75 \$ / \mathrm{hr}$ [171]. Note that the latter is likely not valid anymore due to changes in energy costs and the improved efficiency of such devices since 1983. For the same type of devices, i.e. small mainly portable PCS such as foot warmers or fans, low initial costs are claimed next often [36], [130], [160], [173]. In contrast to studies mentioned earlier, reduced installation costs [146], [172] and energy costs [153], [159], [165], [167] are mentioned. Such statements are based on comparisons between systems with and without the implementation of PCS. For example, reduced initial costs can be achieved by a reduced chiller size due to a lower cooling power required when the provision of elevated air movement is provided by fans [146]. Total energy reduction is achieved by offsetting the additional energy required for an energy-efficient PCS by the reduction in energy use of the global conditioning system [165]. The last point mentioned is a cost reduction in maintenance [167], based on the observation, that PCS can reduce thermal discomfort leading to fewer complains by office workers and reduced labour costs of maintenance staff to deal with such complaints.

The following observations can be made - besides Bauman and Arens [167] demand for more systematic research on life-cycle economic analysis of PCS already in 1996, i.e. more than 20 years ago, only a few studies are considering cost aspects related to the implementation of PCS holistically; most of them consider one aspect of all considerations to be done. Therefore, Table 7 presents a framework to assess the cost effectiveness of PCS. Note that the result of such analysis will heavily depend on local labour, energy, and other cost schemes, climatic conditions and individual characteristics of the system under consideration. The framework is based on a comparison between a system including PCS and an alternative "classic" system without PCS. The authors encourage such work in future research activities because many decisions during the design of new or retrofitted buildings depend on cost effectiveness. Such approaches, coupled with the standards such as the underdevelopment ISO/TR 16596 (on the development of individually-controlled workstations and other adaptive behaviours which can provide thermal comfort at a range of ambient thermal conditions [174]) can yield improved thermal comfort and energy savings. 
When mentioning the factors contributing to the cost, it is also important to mention of the rebound effect - one of the primary purposes of having a PCS over a conventional HVAC system is the reduction of operational energy. The PCS users, being aware of the fact that PCS consume lesser energy, might be motivated to operate the PCS for increased number of hours, and at temperatures which might lead to overheating or overcooling. However, if operated uncontrolled, the energy savings due to PCS might be insignificant when compared to HVAC systems. This calls for the adoption of smart control systems with PCS and paves the way for further research into the topic of optimised control systems for PCS in various climatic and occupancy settings. 
Table 7. Proposed framework for assessing the cost effectiveness of a PCS solution.

\begin{tabular}{|c|c|c|c|}
\hline & \multicolumn{3}{|c|}{ Type of solution } \\
\hline & $\begin{array}{l}\text { Standalone PCS } \\
\text { solution }\end{array}$ & $\begin{array}{l}\text { Combination of PCS } \\
\text { and conventional } \\
\text { system }^{\text {a) }}\end{array}$ & $\begin{array}{l}\text { Conventional system } \\
\text { without PCS }\end{array}$ \\
\hline $\begin{array}{l}\text { Direct installation costs } \\
\text { (the system itself) }\end{array}$ & $\begin{array}{l}\mathrm{X}^{\mathrm{b})} \text { times costs of } \\
\mathrm{PCS}\end{array}$ & $\begin{array}{l}\text { X times costs of PCS }+1 \\
\text { time (reduced) costs of } \\
\text { central system }\end{array}$ & $\begin{array}{l}1 \text { time costs of central } \\
\text { system }\end{array}$ \\
\hline $\begin{array}{l}\text { Indirect installation costs } \\
\text { (ductwork, installations, etc.) }\end{array}$ & $\begin{array}{l}\text { X times costs for } \\
\text { PCS }\end{array}$ & $\begin{array}{l}\mathrm{X} \text { times costs for } \mathrm{PCS}+ \\
\mathrm{Y}^{\mathrm{c})} \text { times costs for central } \\
\text { system }\end{array}$ & $\begin{array}{l}\text { Y times costs for central } \\
\text { system }\end{array}$ \\
\hline \multicolumn{4}{|l|}{$\begin{array}{l}\text { Maintenance and operation } \\
\text { costs }\end{array}$} \\
\hline - Maintenance & $\begin{array}{l}\text { Maintenance costs of } \\
\text { PCS }\end{array}$ & $\begin{array}{l}\text { Maintenance costs of } \\
\text { PCS + (reduced) costs } \\
\text { for conventional system }\end{array}$ & $\begin{array}{l}\text { Maintenance costs of } \\
\text { conventional system }\end{array}$ \\
\hline - Operation & $\begin{array}{l}\text { Increase or reduction } \\
\text { of operation costs, } \\
\text { e.g. less maintenance } \\
\text { calls per months with } \\
\text { PCS [175] }\end{array}$ & $\begin{array}{l}\text { Increased or decreased } \\
\text { operation costs }\end{array}$ & $\begin{array}{l}\text { Operation costs of } \\
\text { conventional system }\end{array}$ \\
\hline Energy costs & $\begin{array}{l}\text { Energy costs to drive } \\
\text { PCS }\end{array}$ & $\begin{array}{l}\text { Savings in overall } \\
\text { conditions } \\
\text { Extra energy costs to } \\
\text { drive PCS }\end{array}$ & $\begin{array}{l}\text { Energy costs for } \\
\text { conventional system }\end{array}$ \\
\hline Labour costs & \multicolumn{3}{|c|}{ Potentially increased productivity through PCS } \\
\hline
\end{tabular}

\section{Discussion and Summary}

\subsection{PCS and Thermal Comfort}

The referred literature establishes PCS, in general, as an effective way of attaining comfort conditions on a personal level. The studies have shown that PCS, in addition to providing comfort conditions, help improve the air quality by providing fresh air directly in the occupants' breathing space. PCS also offer the occupants the psychological delight of being able to moderate their immediate thermal ambience themselves. The tandem of these benefits results in an increase in the productivity and workplace satisfaction of the occupants.

Although PCS can be used for both heating and cooling dominated environments, a majority of the literature was found to be concentrated on cooling dominated environments. For such environments, PCS followed the three approaches of: (i) cooling, (ii) cooling with ventilation, and (iii) ventilation alone. The first approach of 'cooling' was achieved using devices such as air sleeves, cooled seats, radiant panels, and phase change garments. These devices were majorly operated in the $\mathrm{T}_{\text {room }}$ range of $28-32^{\circ} \mathrm{C}$, and were found to keep the occupants comfortable. However, this was found to restrict their movement. Some instances of increased exposure of the body parts in direct contact with the device resulted in an excessively cool local thermal sensation, eventually leading to local discomfort.

The second approach of 'cooling with ventilation' was applied using desktop mounted nozzle based devices, round or cylindrical movable panels, floor/ceiling mounted air outlets, radiant panels with fans, and cooled and ventilated seats. The typical $\mathrm{T}_{\text {room }}$ range for these devices was $23-28^{\circ} \mathrm{C}$. Out of the mentioned devices, the devices with movable air terminal units were generally found to be the most effective in comparison as they offered the option of personalising the direction and intensity of the cooled airflow. The third, 'ventilation alone' approach, was found to be the most widely studied. The devices were similar to those used as per the second approach, with the addition of mechanical fans, ventilated seats, and exclusion of radiant panels. The $\mathrm{T}_{\text {room }}$ range for this approach was the widest and majorly remained between $22-30^{\circ} \mathrm{C}$. The RMP and nozzlebased devices were found to operate on the cooler side of this range, while the mechanical fans were found to be 
used on the higher side. The garments with embedded devices facilitating air movement were, as an exception, tested in $\mathrm{T}_{\text {room }}$ conditions of up to $34^{\circ} \mathrm{C}$ and found to maintain comfortable conditions.

For the environments requiring heating, the two approaches followed were: (i) heating, and (ii) heating with ventilation. The first approach utilised devices such as air sleeves, heated seats, radiant panels, and foot heaters. They were majorly operated in the $\mathrm{T}_{\text {room }}$ range of $10-18^{\circ} \mathrm{C}$. Most of the referred studies utilised a heated seat which was found to improve the overall and local thermal comfort while keeping the sensation close to neutral. Other devices such as foot heaters and radiant panels were effective in keeping the local sensation moderated, while the overall sensation still remained in the undesirable spectrum. The second approach of 'heating with ventilation' incorporated desktop mounted nozzle based devices, movable panels, and heated seats in combination with radiant panels and movable panels. This approach was found to be better than the former, as it allowed the scope of personalisation of the temperature and flow of warm air for most of the cases. The air movement also ensured a better spread of the warmth to all the body parts and the results indicated satisfactory levels of both local and overall thermal comfort.

Out of the 141 individual 'instances' of PCS operation studied in this paper, the local thermal variables were under study for only 56 times, while the respective modes of heat transfer were studied under the various categories as shown in Figure 5. A typical reviewed study can have multiple 'instances' of PCS operation in the either of the heating, cooling, ventilation, or combination modes, depending on the device type and its $T_{\text {PCS }}$ range. As mentioned earlier, 'Ventilation' and 'Cooling with Ventilation' were the most widely documented PCS categories which utilised convective heat transfer to offer thermal comfort. More than half of these studies were conducted on thermal mannequins in controlled conditions. Yet, the heat transfer using the heat transfer modes of conduction and radiation remains under-explored. One of the important outcomes of this paper, therefore, is the identification of prospective PCS which utilise conduction and radiation for heat transfer.

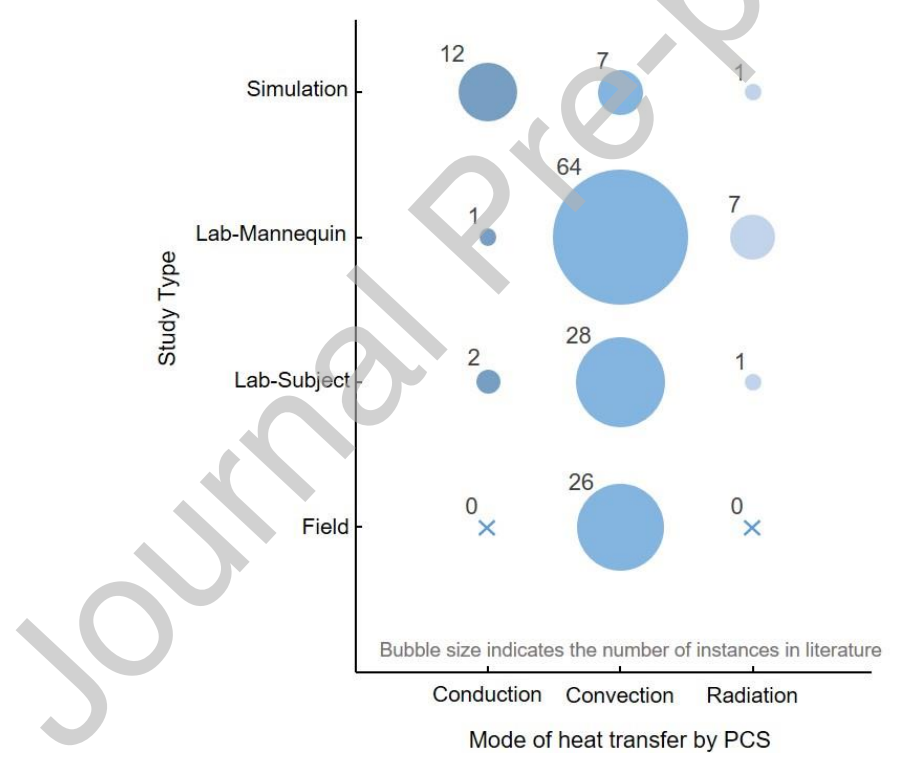

Figure 5. The number of instances in referred literature for each of the four categories of reviewed studies ( $Y$ axis) against the three modes of heat transfer (X-axis).

\subsection{PCS and Energy Savings}

In combination with the study of thermal comfort and air quality, studying the energy savings is critical to the understanding of efficient PCS. While this study discusses the efficiency of a variety of PCS devices, it is important to note that since each study primarily explores a single type of PCS device, it is difficult to derive direct comparisons between their efficiencies. The PCS performance indicators, in the form of comfort parameters and actual energy consumption, depend largely on the climatic, cultural, and individual differences which were inherent to the original test conditions. The studies also use different instances as their 'reference cases', therefore, a direct comparison between them regarding energy savings will not be realistic.

The scaling and comparing the performance of various PCS devices with a comparable reference holds a prospect for future research. The main reason for achieving energy savings with the use of PCS is the possibility 
of relaxing the ambient temperatures, i.e. possibility of using lower room temperatures in the heating dominated environment and using higher room temperatures in the cooling dominated environment. An estimate of possible HVAC energy savings is $10 \%$ per K setpoint relaxation [5], [22].

It is crucial to properly control the PCS together with the ambient conditioning system, and to minimize the energy use and power requirements of the individual components of the PCS to avoid an increase in energy use and to achieve the largest possible energy savings. This becomes especially important when it is considered that the PCS could be implemented in large numbers in offices (e.g. in open-plan offices). It should be noted that a small improvement in occupant productivity is enough to compensate for the possible increase in energy use due to PCS as the cost of conditioning the indoor environment is about $1 \%$ of the labour cost in developed countries [165]. However, energy use of the PCS should still be kept to a minimum by careful selection of the individual components of PCS, design and operation to limit effects of excessive energy use on the environment.

As a suggestion, it will be greatly beneficial if a consistent framework is adopted by researchers to arrive at direct and indirect costs. Linking the costs of installation, operation, and maintenance with the metrics of user productivity and satisfaction will provide the needed perspective on the utility of PCS. Additionally, the topic of decrease in energy savings due to installed capacity is yet to be researched in depth, a detailed discourse on the same may help establish the prominence of PCS over conventional air conditioning methods.

\subsection{Considerations for PCS Studies}

A study on PCS should typically incorporate the following parameters in order to become a relevant source of data and facilitate further meta-analysis and comparison:

i. Ambient Environment Parameters: $\mathrm{V}_{\text {air }}, \mathrm{RH}, \mathrm{T}_{\text {air }}, \mathrm{MRT}-$ of the entire indoor space

ii. Local Environment Parameters: $\mathrm{V}_{\text {air }}, \mathrm{RH}, \mathrm{T}_{\text {air }}, \mathrm{MRT}$ - of the PCS-conditioned space

iii. Local Body Parameters: Heat Flux, $\mathrm{T}_{\text {skin }}, \mathrm{T}_{\text {core }}$ - of the subject's body

iv. Clothing Insulation (clo) and clothing area fraction - of the subject's clothing

v. Metabolic Rate (MET) - of the subject

vi. Sensible Energy Consumption and Latent Energy Consumption - of the PCS device

In addition, the studies should also include transient measurements along with the steady-state measurements as well as the stabilisation time for each experiment. If the study involves human subjects, it should include votes for Overall and Local Thermal Sensation, Thermal Comfort, Thermal Acceptability, Air Movement Acceptability and Air Movement Preference at the steady state - the scales for the same should be as per the internationally accepted ASHRAE scales of comfort, acceptability, preference, and sensation. The studies often include a small sample size of a rather limited subset of the population; for instance - some studies include only university students. This population subset differs from the general population in terms of age, education level, health, etc., and might introduce to a bias. The studies should, therefore make sure to induct diverse samples.

The studies should necessarily mention the dimensions of the experimental/field facility, the PCS setup, along with the distance between the subject and the PCS device. It should also inform us if the subjects were in control of the temperature, direction, and air velocity of the PCS (if applicable), and if the PCS operation led to any instances of discomfort such as dry eyes or runny nose. The description of the study should account for its temporal and spatial resolution, along with the detailed experimental methodology. The various examples of data types and collection methods for cases involving PCS can be referred from Kim et al. and Liu et al. [176], [177].

When considering the aspect of efficiency, energy consumption, and associated cost of PCS, the studies should necessarily measure the Corrective Power for a standardized comparison; a systematic full-scale cost analysis methodology for the energy and financial cost is yet to be devised and standardised and reserves the scope of future research. The studies should ensure the reporting of 'effect sizes' and prioritize presenting statistical results over descriptive comparisons for a more reasoned understanding.

\subsection{PCS and Alliesthesia}

PCS are mentioned to support the notion of adaptive thermal comfort by enabling the occupants to control their individual comfort perception. While this has a positive effect on the behavioural adaptive opportunities and the notion of perceived control, it is not quantified yet that to what extent does the application of PCS reduce the psychological adaptive mechanisms so the subjects always remain comfortable. 
One of the primary focusses in any approach towards attaining thermal comfort is idealising the neutral thermal sensation as the ideal. However, non-neutral thermal conditions have been deliberated to have positive effect on the health [178]. Multiple studies have shown that maintaining slightly uncomfortable thermal conditions can lead to several health benefits, specifically for the diabetics [179], [180]. Studies have also questioned the meaningfulness of the paradigm of thermal neutrality [181]-[184]. Although PCS offer a large potential to contribute towards alliesthesia due to their ability of dynamically changing the thermal perception, there have been nearly no studies documenting the topic of PCS vis-à-vis alliesthesia. This also reserves the scope for further enquiry and research.

\subsection{The Future of PCS}

This study reviewed the abilities of PCS to provide a degree of thermal comfort in varied ambient conditions and discussed the comfort, sensation and air quality delivered. It also reviewed their energy use, energy savings, and provided a possible way forward to assess the layers of economic costs associated with PCS operation, such as capital cost, operational cost, and maintenance cost. Despite numerous existent studies on the topic, there still exist multiple possible avenues involving associated sub-themes of PCS which should be studied in the future to make the technology more widespread and relevant. The following is the probable list of avenues which could be researched upon.

1. Studies with increased emphasis on PCS devices which utilise radiative and conductive modes and their combination as the mode of heat transfer.

2. Studies assessing the thermal comfort and energy savings of PCS devices simultaneously - this could be studied in air conditioned spaces, mixed mode spaces, and naturally ventilated spaces.

3. Studies focussing on PCS operation in field conditions involving occupants and facility managers.

4. Studies focussing on PCS which provide comfort conditions in extreme indoor air temperature and/or RH conditions for both heating and cooling dominated environments.

5. Studies to understand the simultaneous effect of thermal alliesthesia and PCS on occupants.

The list is non-exhaustive and reserves the possibility of multiple inter-disciplinary coalitions in order to devise more energy-efficient and comfort-inducing PCS devices. Given the drastic rise in the space cooling demand of a large part of the planet, 'cooling' is gradually being established as a fundamental need. With the eventual climatic extremes and energy production challenges, optimised utilisation of PCS will be of crucial importance to provide affordable and sustainable thermal comfort to the masses.

\section{Acknowledgement}

The project was performed within the framework of the International Energy Agency - Energy in Buildings and Communities Program (IEA-EBC) Annex69 "Strategy and Practice of Adaptive Thermal Comfort in Low Energy Buildings".

\section{Author Agreement/Declaration of Conflicts of Interest}

We wish to confirm that there are no known conflicts of interest associated with this publication and there has been no significant financial support for this work that could have influenced its outcome.

We confirm that the revised manuscript has been read and approved by all named authors and that there are no other persons who satisfied the criteria for authorship but are not listed. We further confirm that the order of authors listed in the revised manuscript has been approved by all of us.

We confirm that we have given due consideration to the protection of intellectual property associated with this work and that there are no impediments to publication, including the timing of publication, with respect to intellectual property. In so doing we confirm that we have followed the regulations of our institutions concerning intellectual property. 


\section{References}

[1] M. A. Ortiz, S. R. Kurvers, and P. M. Bluyssen, “A review of comfort, health, and energy use: Understanding daily energy use and wellbeing for the development of a new approach to study comfort," Energy Build., vol. 152, pp. 323-335, 2017.

[2] R. de Dear et al., "Progress in thermal comfort research over the last twenty years," Indoor Air, vol. 23, no. 6, pp. 442-461, 2013.

[3] Y. Kobayashi and S. I. Tanabe, "Development of JOS-2 human thermoregulation model with detailed vascular system,” Build. Environ., vol. 66, pp. 1-10, 2013.

[4] J. W. Ring and R. de Dear, "Temperature Transients: A Model for Heat Diffusion through the Skin, Thermoreceptor Response and Thermal Sensation,” Indoor Air, vol. 1, no. 4, pp. 448-456, 1991.

[5] T. L. Madsen and B. Saxhof, "An unconventional method for reduction of the energy consumption for heating of buildings combined," in Second International CIB Symposium on Energy Conservation in the Built Environment, Copenhagen, 1979.

[6] R. Kalaimani, M. Jain, S. Keshav, and C. Rosenberg, "On the interaction between personal comfort systems and centralized hvac systems in office buildings," Adv. Build. Energy Res., pp. 1-29, 2018.

[7] S. B. Godithi, E. Sachdeva, V. Garg, R. Brown, C. Kohler, and R. Rawal, “A review of advances for thermal and visual comfort controls in personal environmental control (PEC) systems.," Intell. Build. Int., vol. 11, no. 2, pp. 75-104, 2019.

[8] H. Zhang et al., "Using footwarmers in offices for thermal comfort and energy savings," Energy Build., vol. 104, pp. 233-243, 2015.

[9] D. B. Greenberger, S. Strasser, L. L. Cummings, and R. B. Dunham, "The impact of personal control on performance and satisfaction,” Organ. Behav. Hum. Decis. Process., vol. 43, no. 1, pp. 29-51, 1989.

[10] J. Kim et al., "Occupant comfort and behavior: High-resolution data from a 6-month field study of personal comfort systems with 37 real office workers," Build. Environ., vol. 148, no. November, pp. 348-360, 2018.

[11] S. A. Samani, S. Z. A. Rasid, and S. B. Sofian, "Perceived level of personal control over the work environment and employee satisfaction and work performance," Perform. Improv., vol. 54, no. 9, pp. 28-35, 2015.

[12] J. Toftum, "Central automatic control or distributed occupant control for better indoor environment quality in the future," Build. Environ., vol. 45, no. 1, pp. 23-28, 2010.

[13] Y. Zhao, H. Zhang, E. Arens, and Q. Zhao, "Thermal sensation and comfort models for non-uniform and transient environments, part IV: Adaptive neutral setpoints and smoothed whole-body sensation model," Building and Environment, vol. 72. pp. 300-308, 2014.

[14] A. K. Melikov, "Personalized ventilation," Indoor Air, Suppl., vol. 14, no. SUPPL. 7, pp. 157-167, 2004.

[15] A. K. Melikov, “Advanced air distribution,” ASHRAE J., vol. 53, no. 11, pp. 73-77, 2011.

[16] Y. Ren, L. Duanmu, and Q. Jin, "Equivalent temperature based comfort zone study under task / ambient conditioning system," Indoor Air 2016, no. 2007, pp. 1-9, 2016.

[17] M. Veselý and W. Zeiler, "Personalized conditioning and its impact on thermal comfort and energy performance - A review," Renew. Sustain. Energy Rev., vol. 34, pp. 401-408, 2014.

[18] A. Warthmann, D. Wölki, H. Metzmacher, and C. van Treeck, "Personal Climatization Systems-A Review on Existing and Upcoming Concepts," Appl. Sci., vol. 9, no. 1, p. 35, 2018.

[19] Y. He, N. Li, M. He, and D. He, "Using radiant cooling desk for maintaining comfort in hot environment," Energy Build., vol. 145, pp. 144-154, 2017.

[20] F. Bauman, G. Carter, A. Baughman, and E. Arens, "A Field Study of PEM (Personal Environmental Module) Performance in Bank of America's San Francisco Office Buildings," Univ. California, Berkeley, vol. CEDR-01-97, 1998. 
[21] W. M. Kroner and J. A. Stark-Martin, "Environmentally Responsive Workstations and Office Worker Productivity,” ASHRAE Trans., vol. 8, no. 3, pp. 750-755, 1994.

[22] H. Zhang, E. Arens, and Y. Zhai, "A review of the corrective power of personal comfort systems in nonneutral ambient environments," Build. Environ., vol. 91, pp. 15-41, 2015.

[23] R. de Dear, "Revisiting an old hypothesis of human thermal perception: Alliesthesia," Build. Res. Inf., vol. 39, no. 2, pp. 108-117, 2011.

[24] T. Parkinson and R. de Dear, "Thermal pleasure in built environments: Physiology of alliesthesia," Build. Res. Inf., vol. 43, no. 3, pp. 288-301, 2015.

[25] M. Indraganti, R. Ooka, and H. B. Rijal, "Thermal comfort in offices in India: Behavioral adaptation and the effect of age and gender," Energy Build., vol. 103, pp. 284-295, 2015.

[26] S. Karjalainen, "Thermal comfort and gender: A literature review," Indoor Air, vol. 22, no. 2, pp. 96109, 2012.

[27] J. Kim, R. de Dear, C. Cândido, H. Zhang, and E. Arens, "Gender differences in office occupant perception of indoor environmental quality (IEQ),” Build. Environ., vol. 70, pp. 245-256, 2013.

[28] M. Schweiker, G. M. Huebner, B. R. M. Kingma, R. Kramer, and H. Pallubinsky, "Drivers of diversity in human thermal perception - A review for holistic comfort models," Temperature, vol. 5, no. 4, pp. 308-342, 2018.

[29] Y. Zhang and R. Zhao, "Relationship between thermal sensation and comfort in non-uniform and dynamic environments," Build. Environ., vol. 44, no. 7, pp. 1386-1391, 2009.

[30] Y. Zhang, H., Arens, E., \& Zhai, “A review of the corrective power of personal comfort systems in nonneutral ambient environments,” Build. Environ., vol.91, pp. 15-41, 2015.

[31] H. Heberle, G. V. Meirelles, F. R. da Silva, G. P. Telles, and R. Minghim, "InteractiVenn: a web-based tool for the analysis of sets through Venn diagrams," BMC Bioinformatics, vol. 16, no. 169, 2015.

[32] V. Eck, N. Jan, and L. Waltman, "Software Survey: VOSviewer, a Computer Program for Bibliometric Mapping," Scientometrics, vol. 84, no. 2, pp. 523-538, 2010.

[33] J. Verhaart, M. Veselý, and W. Zeiler, "Personal heating: Effectiveness and energy use," Build. Res. Inf., vol. 43, no. 3, pp. 346-354, 2015.

[34] J. E. Brooks and K. C. Parsons, "An ergonomics investigation into human thermal comfort using an automobile seat heated with encapsulated carbonized fabric (ECF)," Ergonomics, vol. 42, no. 5, pp. 661-673, 1999.

[35] Y. He, N. Li, L. Zhou, K. Wang, and W. Zhang, "Thermal comfort and energy consumption in cold environment with retrofitted Huotong (warm-barrel)," Build. Environ., vol. 112, pp. 285-295, 2017.

[36] Y. He, N. Li, W. Zhang, and L. Zhou, "Thermal comfort of sellers with a kind of traditional personal heating device (Huotong) in marketplace in winter," Build. Environ., vol. 106, pp. 219-228, 2016.

[37] H. Oi, K. Yanagi, K. Tabat, and Y. Tochihar, "Effects of heated seat and foot heater on thermal comfort and heater energy consumption in vehicle," Ergonomics, vol. 54, no. 8, pp. 690-699, 2011.

[38] Y. F. Zhang, D. P. Wyon, L. Fang, and A. K. Melikov, "The influence of heated or cooled seats on the acceptable ambient temperature range,” Ergonomics, vol. 50, no. 4, pp. 586-600, 2007.

[39] H. Zhang, E. Arens, D. E. Kim, E. Buchberger, F. Bauman, and C. Huizenga, "Comfort, perceived air quality, and work performance in a low-power task-ambient conditioning system," Build. Environ., vol. 45, no. 1, pp. 29-39, 2010.

[40] S. Carmichael et al., "Annual Energy Savings and Thermal Comfort of Autonomously Heated and Cooled Office Chairs,” National Renewable Energy Laboratory (NREL), NREL/TP-6A80-66431, July. 2016.

[41] E. Arens, H. Zhang, and C. Huizenga, "Partial- and whole-body thermal sensation and comfort - Part II: Non-uniform environmental conditions," J. Therm. Biol., vol. 31, no. 1-2 SPEC. ISS., pp. 53-59, 2006. 
[42] W. Pasut, H. Zhang, E. Arens, S. Kaam, and Y. Zhai, "Effect of a heated and cooled office chair on thermal comfort," HVAC R Res., vol. 19, no. 5, pp. 574-583, 2013.

[43] W. Pasut, H. Zhang, E. Arens, and Y. Zhai, "Energy-efficient comfort with a heated/cooled chair: Results from human subject tests,” Build. Environ., vol. 84, pp. 10-21, 2015.

[44] M. Luo, E. Arens, H. Zhang, A. Ghahramani, and Z. Wang, "Heating and cooling the human body with energy-efficient personal thermal comfort systems," in The 15th Conference of the International Society of Indoor Air Quality \& Climate (ISIAQ), Philadelphia, USA, 2018.

[45] M. Vesely, W. Zeiler, G. Boxem, and D. R. Vissers, "The human body as sensor for thermal comfort control," in Proceedings of the International Conference on Cleantech for Smart Cities and Buildings (CISBAT 2013), 2013, no. September, pp. 379-384.

[46] M. Alain, G. Kamel, and G. Nesreen, "A simplified combined displacement and personalized ventilation model," HVAC R Res., vol. 18, no. 4, pp. 737-749, 2012.

[47] Q. Jin, L. Duanmu, H. Zhang, X. Li, and H. Xu, “Thermal sensations of the whole body and head under local cooling and heating conditions during step-changes between workstation and ambient environment," Build. Environ., vol. 46, no. 11, pp. 2342-2350, 2011.

[48] A. K. Melikov and G. L. Knudsen, "Human Response to an Individually Controlled Microenvironment," HVAC\&R Res., vol. 13, no. 4, pp. 645-660, 2007.

[49] S. Watanabe, A. K. Melikov, and G. L. Knudsen, "Design of an individually controlled system for an optimal thermal microenvironment,” Build. Environ., vol. 45, no. 3, pp. 549-558, 2010.

[50] J. Kaczmarczyk, A. Melikov, and D. Sliva, "Effect of warm air supplied facially on occupants' comfort," Build. Environ., vol. 45, no. 4, pp. 848-855, 2010.

[51] K. Tsuzuki, E. Arens, F. Bauman, and D. Wyon, "Individual thermal comfort control with deskmounted and floor-mounted task/ambient conditioning (TAC) systems," in Indoor Air, August 8-13, Edinburgh, 1999, pp. 7-12.

[52] L. Lan et al., "Pilot study on the application of bedside personalized ventilation tosleeping people," Build. Environ., vol. 67, pp. 160-166, 2013.

[53] H. Amai, S. ichi Tanabe, T. Akimoto, and T. Genma, "Thermal sensation and comfort with different task conditioning systems," Build. Environ., vol. 42, no. 12, pp. 3955-3964, 2007.

[54] F. Bauman, T. Carter, and A. Baughman, "Field study of the impact of a desktop task/ambient conditioning system in office buildings," ASHRAE Trans., vol. 104, no. 1, 1998.

[55] A. K. Melikov, B. Krejciríková, J. Kaczmarczyk, M. Duszyk, and T. Sakoi, "Human response to local convective and radiant cooling in a warm environment," HVAC R Res., vol. 19, no. 8, pp. 1023-1032, 2013.

[56] M. J. Barwood, S. Davey, J. R. House, and M. J. Tipton, "Post-exercise cooling techniques in hot, humid conditions,” Eur. J. Appl. Physiol., vol. 107, no. 4, pp. 385-396, 2009.

[57] C. Gao, K. Kuklane, F. Wang, and I. Holmér, "Personal cooling with phase change materials to improve thermal comfort from a heat wave perspective," Indoor Air, vol. 22, no. 6, pp. 523-530, 2012.

[58] D. Faulkner, W. J. Fisk, and D. P. Sullivan, "Indoor airflow and pollutant removal in a room with desktop ventilation," ASHRAE Trans., vol. 99, no. pt 2, pp. 750-758, 1993.

[59] D. Pan, M. Chan, L. Xia, X. Xu, and S. Deng, "Performance evaluation of a novel bed-based task/ambient conditioning (TAC) system," Energy Build., vol. 44, no. 1, pp. 54-62, 2012.

[60] F. Bauman, H. Zhang, E. A. Arens, and C. Benton, "Localized comfort control with a desktop task conditioning system: laboratory and field measurements," ASHRAE Trans., vol. 99, no. 2, pp. 733-749, 1993.

[61] M. Dalewski, A. K. Melikov, and M. Vesely, "Performance of ductless personalized ventilation in conjunction with displacement ventilation: Physical environment and human response," Build. Environ., vol. 81, pp. 354-364, 2014. 
[62] N. Gong et al., "The Acceptable Air Velocity Range for Local Air Movement in The Tropics," vol. 12, no. 4, pp. 1065-1076, 2011.

[63] J. Kaczmarczyk, A. Melikov, Z. Bolashikov, L. Nikolaev, and P. O. Fanger, "Human response to five designs of personalized ventilation," HVAC R Res., vol. 12, no. 2, pp. 367-384, 2006.

[64] Y. Chen, B. Raphael, and S. C. Sekhar, "Individual control of a personalized ventilation system integrated with an ambient mixing ventilation system," HVAC R Res., vol. 18, no. 6, pp. 1136-1152, 2012.

[65] S. C. Sekhar et al., "Findings of Personalized Ventilation Studies in a Hot and Humid Climate Findings of Personalized Ventilation Studies in a," vol. 11, no. 4, pp. 603-620, 2005.

[66] W. Sun, K. W. Tham, W. Zhou, and N. Gong, "Thermal performance of a personalized ventilation air terminal device at two different turbulence intensities,” Build. Environ., vol. 42, pp. 3974-3983, 2007.

[67] J. Niu, N. Gao, M. Phoebe, and Z. Huigang, "Experimental study on a chair-based personalized ventilation system,” Build. Environ., vol. 42, pp. 913-925, 2007.

[68] F. Bauman et al., "Localized thermal distribution for office buildings; Final Report - Phase III," Cent. Environ. Des. Res. Univ. California, Berkeley, 1994.

[69] B. Yang, S. C. Sekhar, and A. K. Melikov, "Ceiling-mounted personalized ventilation system integrated with a secondary air distribution system - a human response study in hot and humid climate," Indoor Air, vol. 20, no. 4, pp. 309-319, 2010.

[70] B. Yang, A. Melikov, and C. Sekhar, "Performance evaluation of ceiling mounted personalized ventilation system," in ASHRAE Transactions, 2009, vol. 115 PART 2, pp. 395-406.

[71] L. J. Lo and A. Novoselac, "Localized air-conditioning with occupancy control in an open office," Energy Build., vol. 42, no. 7, pp. 1120-1128, 2010.

[72] S. Atthajariyakul and C. Lertsatittanakorn, "Small fan assisted air conditioner for thermal comfort and energy saving in Thailand," Energy Convers. Manag., vol. 49, no. 10, pp. 2499-2504, 2008.

[73] E. A. Arens, E. S. Bauman, L. E. Johnston, and H. Zhang, "Testing of Localized Thermal Distribution Systems in a New Controlled Environment Chamber," Indoor Air, vol. 1, no. 3, pp. 263-281, 1991.

[74] F. S. Bauman, L. P. Johnston, H. Zhang, and E. A. Arens, "Performance testing of a floor-based, occupant-controlled office ventilation system," ASHRAE Trans., no. pt 1, pp. 553-565, 1991.

[75] F. S. Bauman, E. A. Arens, S. Tanabe, H. Zhang, and A. Baharlo, "Testing and optimizing the performance of a floor-based task conditioning system,” Energy Build., vol. 22, no. 3, pp. 173-186, 1995.

[76] T. Zhang, P. Li, Y. Zhao, and S. Wang, "Various air distribution modes on commercial airplanes. Part 1: Experimental measurement," HVAC and R Research, vol. 19, no. 3. pp. 268-282, 2013.

[77] T. T. Zhang, P. Li, and S. Wang, "A personal air distribution system with air terminals embedded in chair armrests on commercial airplanes,” Build. Environ., vol. 47, no. 1, pp. 89-99, 2012.

[78] T. Akimoto, F. Bauman, C. Benton, and E. Arens, "Field Study of a Desktop-Based Task Conditioning System,” J. Archit. Plan. (Transactions AIJ), vol. 61, no. 490, pp. 35-46, 1996.

[79] K. W. Tham and J. Pantelic, "Performance evaluation of the coupling of a desktop personalized ventilation air terminal device and desk mounted fans," Build. Environ., vol. 45, pp. 1941-1950, 2010.

[80] R. Li, S. C. Sekhar, and A. K. Melikov, "Thermal comfort and IAQ assessment of under-floor air distribution system integrated with personalized ventilation in hot and humid climate," Build. Environ., vol. 45, no. 9, pp. 1906-1913, 2010.

[81] J. Verhaart, R. Li, and W. Zeiler, "User interaction patterns of a personal cooling system: A measurement study," Sci. Technol. Built Environ., vol. 24, no. 1, pp. 57-72, 2018.

[82] J. H. Yang, S. Kato, and H. T. Seok, "Measurement of airflow around the human body with wide-cover type personal air-conditioning with PIV," Indoor Built Environ., vol. 18, no. 4, pp. 301-312, 2009. 
[83] Q. Jin and L. Duanmu, "Experimental study of thermal sensation and physiological response during step changes in non-uniform indoor environment.," Sci. Technol. Built Environ., vol. 22, no. 2, pp. 237-247, 2016.

[84] S. H. Cho, W. T. Kim, and M. Zaheer-uddin, "Thermal characteristics of a personal environment module task air conditioning system: An experimental study,” Energy Convers. Manag., vol. 42, no. 8, pp. 1023-1031, 2001.

[85] A. K. Melikov, M. A. Skwarczynski, J. Kaczmarczyk, and J. Zabecky, "Use of personalized ventilation for improving health, comfort, and performance at high room temperature and humidity," Indoor Air, vol. 23 , no. 3 , pp. 250-263, 2013.

[86] A. K. Melikov, R. Cermak, and M. Majer, "Personalized ventilation: Evaluation of different air terminal devices," Energy Build., vol. 34, no. 8, pp. 829-836, 2002.

[87] Y. He, N. Li, X. Wang, M. He, and D. He, "Comfort, energy efficiency and adoption of personal cooling systems in warm environments: A field experimental study," Int. J. Environ. Res. Public Health, vol. 14, no. 11, 2017.

[88] C. Habchi, W. Chakroun, S. Alotaibi, K. Ghali, and N. Ghaddar, "Effect of shifts from occupant design position on performance of ceiling personalized ventilation assisted with desk fan or chair fans," Energy Build., vol. 117, pp. 20-32, 2016.

[89] C. Shen, N. Gao, and T. Wang, "CFD study on the transmission of indoor pollutants under personalized ventilation,” Build. Environ., vol. 63, pp. 69-78, 2013.

[90] N. P. Gao, H. Zhang, and J. L. Niu, "Investigating indoor air quality and thermal comfort using a numerical thermal manikin," Indoor Built Environ., vol. 16, no. 1, pp. 7-17, 2007.

[91] B. Halvoňová and A. K. Melikov, "Performance of ductless' personalized ventilation in conjunction with displacement ventilation: Impact of intake height," Build. Environ., vol. 45, no. 4, pp. 996-1005, 2010 .

[92] M. Kanaan, N. Ghaddar, and K. Ghali, "Quality of inhaled air in displacement ventilation systems assisted by personalized ventilation," HVAC R Res., vol. 18, no. 3, pp. 500-514, 2012.

[93] N. P. Gao and J. L. Niu, "Personalized Ventilation for Commercial Aircraft Cabins," J. Aircr., vol. 45, no. 2, pp. 508-512, 2008.

[94] X. Li, J. Niu, and N. Gao, "Co-occupant's exposure to exhaled pollutants with two types of personalized ventilation strategies under mixing and displacement ventilation systems," Indoor Air, vol. 23, no. 2, pp. 162-171, 2013.

[95] G. Naíping and N. Jianlei, "Improvement of Facial Humidity and Reduction of Pollutant Inhalation in Commercial Aircraft Cabins via Application of Personalized Ventilation," ASHRAE Trans., vol. 114, no. 2, pp. 37-44, 2008.

[96] N. Gao, J. Niu, and H. Zhang, "Coupling CFD and Human Body Thermoregulation Model for the Assessment of Personalized Ventilation Coupling CFD and Human Body Thermoregulation Model for the Assessment of Personalized Ventilation,” HVAC R Res., vol. 9669, no. April, pp. 37-41, 2017.

[97] A. Makhoul, K. Ghali, and N. Ghaddar, "The energy saving potential and the associated thermal comfort of displacement ventilation systems assisted by personalized ventilation," Indoor Built Environ., vol. 22, pp. 508-519, 2013.

[98] Z. D. Bolashikov, A. Melikov, and M. Krenek, "Improved performance of personalized ventilation by control of the convection flow around occupant body," ASHRAE Trans., vol. 115 PART 2, pp. 421-431, 2009.

[99] R. Cermak and A. K. Melikov, "Protection of occupants from exhaled infectious agents and floor material emissions in rooms with personalized and underfloor ventilation," HVAC R Res., vol. 13, no. 1, pp. 23-38, 2007.

[100] R. Cermak, A. Melikov, L. Forejt, and O. Kovar, "Performance of Personalized Ventilation in Conjunction with Mixing and Displacement Ventilation," HVAC\&R Res., vol. 12, no. 2, pp. 295-311, 
2006.

[101] Q. He, J. Niu, N. Gao, T. Zhu, and J. Wu, "CFD study of exhaled droplet transmission between occupants under different ventilation strategies in a typical office room," Build. Environ., vol. 46, no. 2, pp. 397-408, 2011.

[102] a. Melikov, T. Ivanova, and G. Stefanova, "Seat headrest-incorporated personalized ventilation: Thermal comfort and inhaled air quality," Build. Environ., vol. 47, pp. 100-108, 2012.

[103] Z. Bolashikov, A. Melikov, and M. Krenek, "Control of the Free Convective Flow around the Human Body for Enhanced Inhaled Air Quality: Application to a Seat-Incorporated Personalized Ventilation Unit," vol. 16, no. 2, pp. 161-188, 2011.

[104] Z. Bolashikov, A. Melikov, and M. Spilak, "Experimental investigation on reduced exposure to pollutants indoors by applying wearable personalized ventilation," HVAC R Res., vol. 19, no. 4, pp. 385-399, 2013.

[105] T. L. Madsen, “Thermal effects of ventilated car seats,” Int. J. Ind. Ergon., vol. 13, no. 3, pp. 253-258, 1994.

[106] P. Zítek, T. Vyhlídal, G. Simeunović, L. Nováková, and J. Č́žžek, "Novel personalized and humidified air supply for airliner passengers,” Build. Environ., vol. 45, no. 11, pp. 2345-2353, 2010.

[107] J. Kaczmarczyk, A. Melikov, and P. O. Fanger, "Human response to personalized ventilation and mixing ventilation," Indoor Air, vol. 14, no. s8, pp. 17-29, 2004.

[108] R. K. Dygert and T. Q. Dang, "Experimental validation of local exhaust strategies for improved IAQ in aircraft cabins," Build. Environ., vol. 47, no. 1, pp. 76-88, 2012.

[109] S. H. Ho, L. Rosario, and M. M. Rahman, "Thermal comfort enhancement by using a ceiling fan," Appl. Therm. Eng., vol. 29, no. 8-9, pp. 1648-1656, 2009.

[110] W. Sun, K. W. D. Cheong, and A. Melikov, "Subjective study of thermal acceptability of novel enhanced displacement ventilation system and implication of occupants' personal control," Build. Environ., vol. 57, pp. 49-57, 2012.

[111] P. Jacobs and W. F. De Gids, "Individual and collective climate control in aircraft cabins," Int. J. Veh. Des., vol. 42, no. 1, p. 57, 2006

[112] D. Faulkner, W. J. Fisk, D. P. Sullivan, and S. M. Lee, "Ventilation efficiencies and thermal comfort results of a desk-edge-mounted task ventilation system," Indoor Air, vol. 14, no. s8, pp. 92-97, 2004.

[113] S. Kato and J. H. Yang, "Study on inhaled air quality in a personal air-conditioning environment using new scales of ventilation efficiency," Build. Environ., vol. 43, no. 4, pp. 494-507, 2008.

[114] H. E. Khalifa, M. I. Janos, and J. F. Dannenhoffer, "Experimental investigation of reduced-mixing personal ventilation jets,” Build. Environ., vol. 44, no. 8, pp. 1551-1558, 2009.

[115] J. S. Russo, T. Q. Dang, and H. E. Khalifa, "Computational analysis of reduced-mixing personal ventilation jets,” Build. Environ., vol. 44, no. 8, pp. 1559-1567, 2009.

[116] N. Gao and J. Niu, "CFD study on micro-environment around human body and personalized ventilation," Build. Environ., vol. 39, pp. 795-805, 2004.

[117] N. Gao and J. Niu, "Modeling the performance of personalized ventilation under different room airflows," Ninth Int. IBPSA Conf. Build. Simul. Gr. 2005., vol. 11, no. 4, pp. 587-602, 2005.

[118] E. Arens, T. Xu, K. Miura, Z. Hui, M. Fountain, and F. Bauman, “A study of occupant cooling by personally controlled air movement,” Energy Build., vol. 27, no. 1, pp. 45-59, 1998.

[119] F. H. Rohles, "Ceiling fans as extenders of the summer comfort envelope.," 1983.

[120] B. Yang, S. Schiavon, C. Sekhar, D. Cheong, K. W. Tham, and W. W. Nazaroff, "Cooling efficiency of a brushless direct current stand fan," Build. Environ., vol. 85, pp. 196-204, 2015.

[121] J. Hua, Q. Ouyang, Y. Wang, H. Li, and Y. Zhu, "A dynamic air supply device used to produce simulated natural wind in an indoor environment," Build. Environ., vol. 47, no. 1, pp. 349-356, 2012. 
[122] B. Zhao and P. Guan, "Modeling particle dispersion in personalized ventilated room," Build. Environ., vol. 42, no. 3, pp. 1099-1109, 2007.

[123] M. A. Skwarczynski, A. K. Melikov, J. Kaczmarczyk, and V. Lyubenova, "Impact of individually controlled facially applied air movement on perceived air quality at high humidity," Build. Environ., vol. 45, no. 10, pp. 2170-2176, 2010.

[124] Z. Adamu, M. Cook, and A. Price, "Natural Personalised Ventilation-A Novel Approach," Int. J. Vent., vol. 10, no. 3, pp. 263-275, 2011.

[125] H. Kubo, N. Isoda, and H. Enomoto-Koshimizu, "Cooling effects of preferred air velocity in muggy conditions," Build. Environ., vol. 32, no. 3, pp. 211-218, 1997.

[126] Y. Zhai, H. Zhang, Y. Zhang, W. Pasut, E. Arens, and Q. Meng, "Comfort under personally controlled air movement in warm and humid environments," Build. Environ., vol. 65, pp. 109-117, 2013.

[127] Y. Zhai, Y. Zhang, H. Zhang, W. Pasut, E. Arens, and Q. Meng, "Human comfort and perceived air quality in warm and humid environments with ceiling fans," Build. Environ., vol. 90, pp. 178-185, 2015.

[128] X. Zhou, Q. Ouyang, G. Lin, and Y. Zhu, "Impact of dynamic airflow on human thermal response," Indoor Air, vol. 16, no. 5, pp. 348-355, 2006.

[129] S. Watanabe, T. Shimomura, and H. Miyazaki, "Thermal evaluation of a chair with fans as an individually controlled system,” Build. Environ., vol. 44, no. 7, pp. 1392-1398, 2009.

[130] L. Huang, Q. Ouyang, Y. Zhu, and L. Jiang, "A study about the demand for air movement in warm environment," Build. Environ., vol. 61, pp. 27-33, 2013.

[131] A. C. Boerstra, M. te Kulve, J. Toftum, M. G. L. C. Loomans, B. W. Olesen, and J. L. M. Hensen, "Comfort and performance impact of personal control over thermal environment in summer: Results from a laboratory study," Build. Environ., vol. 87, pp. 315-326, 2015.

[132] A. Lipczynska, J. Kaczmarczyk, and A. K. Melikov, "Thermal environment and air quality in office with personalized ventilation combined with chilled ceiling," Build. Environ., vol. 92, pp. 603-614, 2015.

[133] E. Arens, H. Zhang, and W. Pasut, "Thermal comfort and perceived air quality of a PEC system," Indoor Air 2011, June 5-10, pp. 0=6, 2011.

[134] L. Huang, Q. Ouyang, and Y. Zhu, "Perceptible airflow fluctuation frequency and human thermal response," Build. Environ., vol. 54, pp. 14-19, 2012.

[135] W. Pasut, E. Arens, H, Zhang, and Y. Zhai, "Enabling energy-efficient approaches to thermal comfort using room air motion,” Build. Environ., vol. 79, pp. 13-19, 2014.

[136] W. Yi, Y. Zhao, and A. P. C. Chan, "Evaluation of the ventilation unit for personal cooling system (PCS),"Int. J. Ind. Ergon., vol. 58, pp. 62-68, 2017.

[137] A. Makhoul, K. Ghali, and N. Ghaddar, "Desk fans for the control of the convection flow around occupants using ceiling mounted personalized ventilation," Build. Environ., vol. 59, no. 2013, pp. 336$348,2013$.

[138] A. Makhoul, K. Ghali, N. Ghaddar, and W. Chakroun, "Investigation of particle transport in offices equipped with ceiling-mounted personalized ventilators," Build. Environ., vol. 63, no. 2013, pp. 97-107, 2013.

[139] B. Halvonova and A. K. Melikov, "Performance of 'ductless' personalized ventilation in conjunction with displacement ventilation: Impact of disturbances due to walking person(s)," Build. Environ., vol. 45, no. 2, pp. 427-436, 2010.

[140] B. Halvonova and A. K. Melikov, "Performance of Ductless Personalized Ventilation in Conjunction with Displacement Ventilation: Impact of Workstations Layout and Partitions," Indoor Environ., vol. 16, no. August, pp. 17-22, 2008.

[141] R. K. Dygert and T. Q. Dang, "Mitigation of cross-contamination in an aircraft cabin via localized 
exhaust," Build. Environ., vol. 45, no. 9, pp. 2015-2026, 2010.

[142] B. Yang and S. C. Sekhar, "The influence of evenly distributed ceiling mounted personalized ventilation devices on the indoor environment," Int. J. Vent., vol. 7, no. 2, pp. 99-112, 2008.

[143] Y. Bin and S. C. Sekhar, "Three-dimensional numerical simulation of a hybrid fresh air and recirculated air diffuser for decoupled ventilation strategy," Build. Environ., vol. 42, no. 5, pp. 1975-1982, 2007.

[144] L. Pang, J. Xu, L. Fang, M. Gong, H. Zhang, and Y. Zhang, "Evaluation of an improved air distribution system for aircraft cabin," Build. Environ., vol. 59, pp. 145-152, 2013.

[145] B. Yang and C. Sekhar, "Interaction of dynamic indoor environment with moving person and performance of ceiling mounted personalized ventilation system," Indoor Built Environ., vol. 23, no. 7, pp. 920-932, 2013.

[146] S. Schiavon and A. K. Melikov, "Energy saving and improved comfort by increased air movement," Energy Build., vol. 40, no. 10, pp. 1954-1960, 2008.

[147] Y. He, W. Chen, Z. Wang, and H. Zhang, "Review of fan-use rates in field studies and their effects on thermal comfort, energy conservation , and human productivity," Energy Build., vol. 194, pp. 140-162, 2019.

[148] T. Sakoi, A. K. Melikov, Z. D. Bolashikov, H. Morikawa, and K. Iwaki, "Use of clothing for body cooling by evaporation," 12th Int. Conf. Indoor Air Qual. Clim. 2011, vol. 2, pp. 1106-1111, 2011.

[149] "EN 15251: Indoor environmental input parameters for design and assessment of energy performance of buildings addressing indoor air quality, thermal environment, lighting and acoustics," Eur. Comm. Stand. Brussels, 2007.

[150] S. Schiavon and A. K. Melikov, "Energy-saving strategies with personalized ventilation in cold climates," Energy Build., vol. 41, no. 5, pp. 543-550, 2009.

[151] S. Schiavon, A. K. Melikov, and C. Sekhar, "Energy analysis of the personalized ventilation system in hot and humid climates," Energy Build., vol. 42, no. 5, pp. 699-707, 2010.

[152] J. E. Seem and J. E. Braun, "The impact of personal environmental control on building energy use," ASHRAE Trans., pp. 903-909, 1992.

[153] M. Heidarinejad, D. A. Dalgo, N. W. Mattise, and J. Srebric, "Personalized cooling as an energy efficiency technology for city energy footprint reduction,” J. Clean. Prod., vol. 171, pp. 491-505, 2018.

[154] L. R. Glicksman and S. Taub, "Thermal and behavioral modeling of occupant-controlled heating, ventilating and air conditioning systems," Energy Build., vol. 25, no. 3, pp. 243-249, 1997.

[155] W. Chakroun, N. Ghaddar, and K. Ghali, "Chilled ceiling and displacement ventilation aided with personalized evaporative cooler,” Energy Build., vol. 43, pp. 3250-3257, 2011.

[156] Y. He, X. Wang, N. Li, M. He, and D. He, "Heating chair assisted by leg-warmer: A potential way to achieve better thermal comfort and greater energy conservation in winter," vol. 158, pp. 1106-1116, 2018.

[157] E. Foda and K. Sirén, "Design strategy for maximizing the energy-efficiency of a localized floor-heating system using a thermal manikin with human thermoregulatory control," Energy Build., vol. 51, pp. 111$121,2012$.

[158] R. Dhumane, J. Ling, V. Aute, and R. Radermacher, "Portable personal conditioning systems: Transient modeling and system analysis," Appl. Energy, vol. 208, pp. 390-401, 2017.

[159] S. Shahzad, J. K. Calautit, K. Calautit, B. Hughes, and A. I. Aquino, “Advanced Personal Comfort System (APCS) for the workplace: A review and case study,” Energy Build., 2018.

[160] A. Rabbani and S. Keshav, "The SPOT* Personal Thermal Comfort System," in Proceedings of the 3rd ACM International Conference on Systems for Energy-Efficient Built Environments, 2016, pp. 75-84.

[161] I. Suzuki, K. Washinosu, and T. Nobe, "Adaptive Effect to Thermal Comfort of Cool Chair in ZEB Office," 7th Wind. Conf. Chang. Context Comf. an unpredictable world, no. April, pp. 12-15, 2010. 
[162] F. Bauman, H. Zhang, E. A. Arens, and C. Benton, "Localized comfort control with a desktop task conditioning system: laboratory and field measurements." 1993.

[163] M. Veselý, P. Molenaar, M. Vos, R. Li, and W. Zeiler, "Personalized heating - Comparison of heaters and control modes," Build. Environ., vol. 112, pp. 223-232, 2017.

[164] A. K. Melikov, “Advanced air distribution: Improving health and comfort while reducing energy use," Indoor Air, vol. 26, Mar. 2015.

[165] S. D. Hamilton, K. W. Roth, and J. Brodrick, "Using microenvironments to provide individual comfort," ASHRAE J., vol. 45, no. 9, p. 65, 2003.

[166] P. X. Gao and S. Keshav, "SPOT: A Smart Personalized Office Thermal Control System," in Proceedings of the Fourth International Conference on Future Energy Systems, 2013, pp. 237-246.

[167] F. S. Bauman and E. Arens, Task/Ambient Conditioning Systems: Engineering and Application Guidelines. 1996.

[168] W. Abou Hweij, N. Ghaddar, K. Ghali, and C. Habchi, "Optimized performance of displacement ventilation aided with chair fans for comfort and indoor air quality,” Energy Build., vol. 127, pp. $907-$ 919, 2016.

[169] F. Bauman et al., "Advanced Integrated Systems Technology Development: Personal Comfort Systems and Radiant Slab Systems. Final report to CEC.," 2015.

[170] P. Ole Fanger, "Human requirements in future air-conditioned environments," Int. J. Refrig., vol. 24, no. 2, pp. 148-153, 2001.

[171] F. H. Rohles, S. A. Konz, and B. W. Jones, "Ceiling fan as extenders of the summer comfort envelope," ASHRAE Trans., vol. 89, no. 1A, pp. 245-263, 1983.

[172] Z. Bolashikov, A. Melikov, and M. Krenek, "Control of the Free Convective Flow around the Human Body for Enhanced Inhaled Air Quality: Application to a Seat-Incorporated Personalized Ventilation Unit," HVAC\&R Res., vol. 16, no. 2, pp. 161-188, Mar. 2010.

[173] M. Taub et al., "The use of footwarmers in offices for thermal comfort and energy savings in winter." 2015.

[174] B. W. Olesen, F. R. d'Ambrosio Alfano, K. Parsons, and B. I. Palella, "The history of international standardization for the ergonomics of the thermal environment," in Proceedings of 9th Windsor Conference: Making Comfort Relevant, 2016, no. April, pp. 15-38.

[175] C. Lomonaco and D. Miller, "Environmental satisfaction, personal control and the positive correlation to increased productivity," Johnson Control., 1997.

[176] J. Kim, S. Schiavon, and G. Brager, "Personal comfort models - new paradigm in thermal comfort for occupant-centric environmental control," in Windsor Conference: Rethinking Comfort, 2018, pp. 419430.

[177] S. Liu, M. Jin, H. P. Das, C. J. Spanos, and S. Schiavon, "Personal thermal comfort models based on physiological parameters measured by wearable sensors.," in Windsor Conference: Rethinking Comfort, 2018, pp. 431-441.

[178] W. van Marken Lichtenbelt, M. Hanssen, H. Pallubinsky, B. R. Kingma, and L. Schellen, "Healthy excursions outside the thermal comfort zone," Build. Res. Inf., vol. 45, no. 7, pp. 819-827, 2017.

[179] M. J. W. Hanssen et al., "Short-term cold acclimation recruits brown adipose tissue in obese humans," Diabetes, vol. 65, no. 5, pp. 1179-1797, 2016.

[180] B. R. Kingma, A. J. H. Frijns, W. H. M. Saris, and W. D. van M. van Steenhoven, A.A. Lichtenbelt, "Increased systolic blood pressure after mild cold and rewarming: relation to cold-induced thermogenesis and age," Acta Physiol., vol. 203, no. 4, pp. 419-427, 2011.

[181] M. A. Humphreys and M. Hancock, "Do people like to feel 'neutral'?: Exploring the variation of the desired thermal sensation on the ASHRAE scale.," Energy Build., vol. 39, no. 7, pp. 867-874, 2007. 
[182] M. Fountain, G. S. Brager, and R. J. de Dear, "Expectations of indoor climate control," Energy Build., vol. 24, no. 3, pp. 179-182, 1996.

[183] S. Shahzad, J. Brennan, D. Theodossopoulos, J. K. Calautit, and B. R. Hughes, "Does a neutral thermal sensation determine thermal comfort?," Build. Serv. Eng. Res. Technol., vol. 39, no. 2, pp. 183-195, 2018.

[184] M. Schweiker et al., "Challenging the assumptions for thermal sensation scales," Build. Res. Inf., vol. 45, no. 5, pp. 572-589, 2017. 